OAK RIDGE
NATIONAL LABORATORY

MANAGED BY UT-BATTELLE

FOR THE DEPARTMENT OF ENERGY
ORNL/TM-2009/041

\author{
John D. Hunn, Robert N. Morris, \\ James H. Miller, and Rodney D. Hunt
}

May 2009

\section{Revision 1} assumes any legal liability or responsibility for any third party's use, or the results of such use, of any information, apparatus, product or process disclosed in this report, or represents that its use by such third party would not infringe privately owned rights. 


\section{DOCUMENT AVAILABILITY}

Reports produced after January 1, 1996, are generally available free via the U.S. Department of Energy (DOE) Information Bridge.

Web site http://www.osti.gov/bridge

Reports produced before January 1, 1996, may be purchased by members of the public from the following source.

National Technical Information Service

5285 Port Royal Road

Springfield, VA 22161

Telephone 703-605-6000 (1-800-553-6847)

TDD 703-487-4639

Fax 703-605-6900

E-mail info@ntis.fedworld.gov

Web site http://www.ntis.gov/support/ordernowabout.htm

Reports are available to DOE employees, DOE contractors, Energy Technology Data Exchange (ETDE) representatives, and International Nuclear Information System (INIS)

representatives from the following source.

Office of Scientific and Technical Information

P.O. Box 62

Oak Ridge, TN 37831

Telephone 865-576-8401

Fax 865-576-5728

E-mail reports@adonis.osti.gov

Web site http://www.osti.gov/contact.html

This report was prepared as an account of work sponsored by an agency of the United States Government. Neither the United States Government nor any agency thereof, nor any of their employees, makes any warranty, express or implied, or assumes any legal liability or responsibility for the accuracy, completeness, or usefulness of any information, apparatus, product, or process disclosed, or represents that its use would not infringe privately owned rights. Reference herein to any specific commercial product, process, or service by trade name, trademark, manufacturer, or otherwise, does not necessarily constitute or imply its endorsement, recommendation, or favoring by the United States Government or any agency thereof. The views and opinions of authors expressed herein do not necessarily state or reflect those of the United States Government or any agency thereof. 


\title{
Overview of Key Issues and Guidelines for Regulatory Oversight and Inspection of High Temperature Gas Reactor Fuel Fabrication and Quality Control Activities
}

\author{
prepared by \\ John D. Hunn, Robert N. Morris, \\ James H. Miller and Rodney D. Hunt \\ Oak Ridge National Laboratory \\ Oak Ridge, Tennessee 37831-6093 \\ managed by UT-Battelle, LLC \\ for the \\ U.S. DEPARTMENT OF ENERGY \\ under contract DE-AC05-00OR22725
prepared for
U.S. Nuclear Regulatory Commission
under

DOE Interagency Agreement 1886-T378-07

NRC JCN Number N6471

ORNL/TM-2009/041

May 2009 


\section{FOREWORD}

This document presents information about inspection of critical fuel attributes that are used as part of specifications in the fabrication of TRISO coated particle fuel. In some cases, the values and techniques that are discussed represent those used in the early part of the R\&D associated with fuel qualification and may not represent those used in actual future production of fuel for high temperature gas reactors. As the fuel fabrication process matures from the laboratory scale through engineering scale to full production scale, it is anticipated that the specification and the associated techniques used to demonstrate compliance with the specification will evolve to meet the needs and requirements of a fuel fabrication facility and the specific high temperature gas reactor application. 


\section{TABLE OF CONTENTS}

1 Introduction and Objectives ................................................................................................... 7

2 Critical Product Parameters for Fuel Quality and Performance.......................................... 11

2.1 Identification of Important Fuel Product Parameters ............................................................... 11

2.2 Relative Priority of Fuel Product Parameters........................................................................... 21

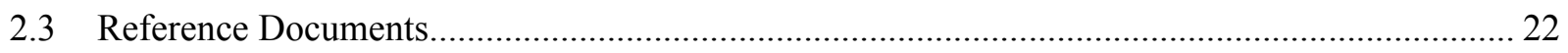

3 Fuel Product Inspection and Testing Equipment and Procedures ..................................... 24

3.1 Analysis Methods for Important Fuel Product Parameters …................................................... 24

3.2 Description of HTGR Fuel Characterization Equipment and Operation ................................... 29

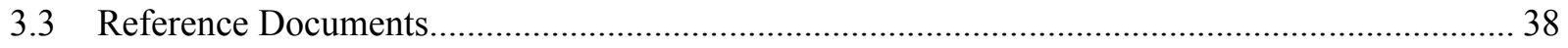

4 Critical Process Equipment and Process Parameters ...................................................... 41

4.1 Description of Fuel Process Equipment and Operation ............................................................ 41

4.2 Identification of Important Fuel Processing Parameters ............................................................ 54

4.3 Kinds and Periodicity of Process Parameter Data Collected …….............................................. 57

4.4 Relative Priority of Fuel Process Parameters .............................................................................. 58

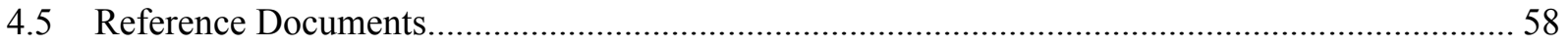

5 Calibration Testing Equipment and Calibration Inspection Procedures........................ 60

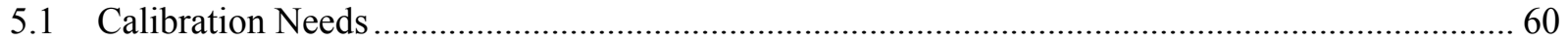

5.2 Relative Priority of Calibration Procedures …................................................................................ 66

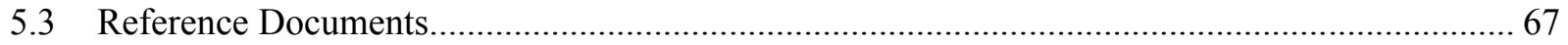

6 Maintenance Procedures for Fuel Fabrication Process Equipment ................................. 68

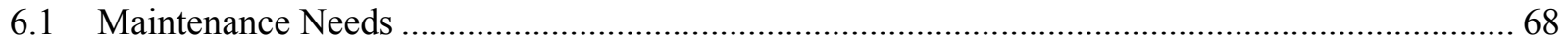

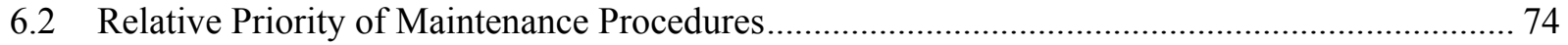

7 Sampling Methods, Statistical Analysis Methods and Acceptance Criteria ................... 75

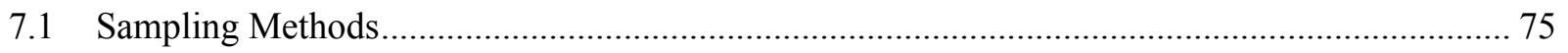

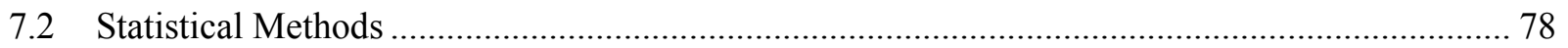

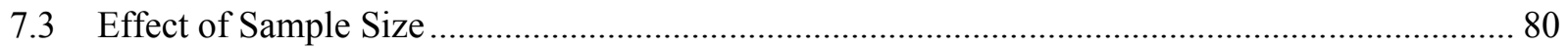

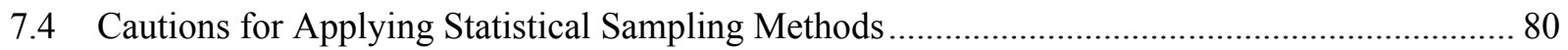

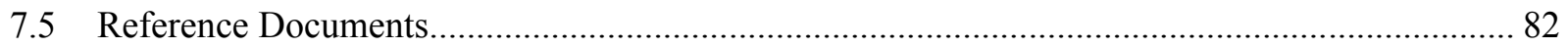

8 Training and Qualification of Fuel Fabrication Facility Staff............................................ 83

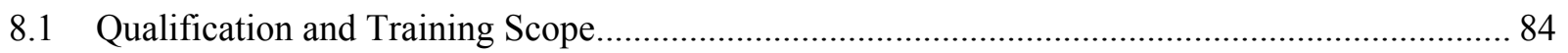

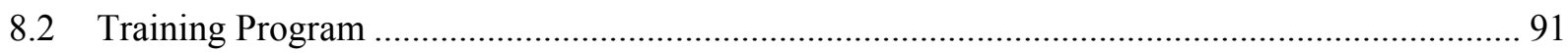

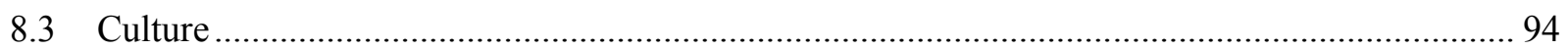

8.4 Personnel Positions at an HTGR Fuel Fabrication Facility ..................................................... 95 


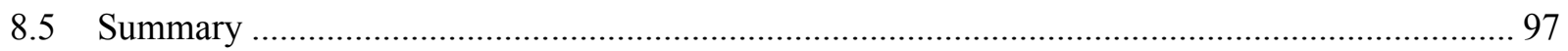

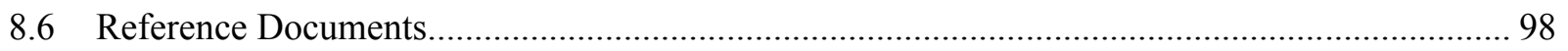

9 Draft NRC Fuel Fabrication Inspection Protocol............................................................... 99

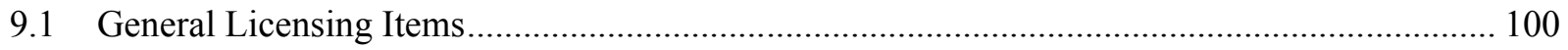

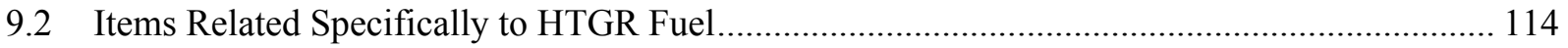

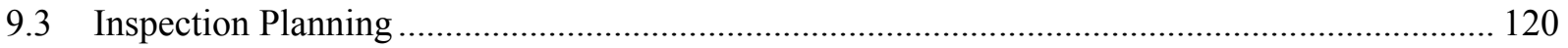

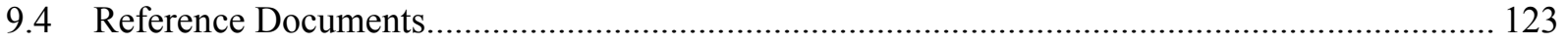




\section{ACRONYMS}

$\begin{array}{ll}\text { 2-MGEM } & \text { Two-Modulator Generalized Ellipsometry Microscope } \\ \text { ADAMS } & \text { Agency-wide Documents Access Management System } \\ \text { ADUN } & \text { Acid Deficient Uranyl Nitrate } \\ \text { AGR } & \text { Advanced Gas (Cooled) Reactor } \\ \text { ALARA } & \text { As Low As Reasonably Achievable } \\ \text { AO } & \text { Anticipated Operational Event } \\ \text { ASTM } & \text { American Society for Testing and Materials } \\ \text { BAF } & \text { Bacon Anisotropy Factor } \\ \text { BAF } & \text { Optical Bacon Anisotropy Factor } \\ \text { BDBA } & \text { Beyond Design Basis Accident } \\ \text { CFP } & \text { Coated Fuel Particle } \\ \text { CVD } & \text { Chemical Vapor Deposition } \\ \text { DAM } & \text { Data Acquisition Method } \\ \text { DBA } & \text { Design Basis Accident } \\ \text { DOE } & \text { United States Department of Energy } \\ \text { FB } & \text { Fluidized Bed } \\ \text { FB-CVD } & \text { Fluidized Bed Chemical Vapor Deposition } \\ \text { HEPA } & \text { High Efficiency Particulate Air } \\ \text { HMTA } & \text { Hexamethylene } \\ \text { HTGR } & \text { High Temperature Gas (Cooled) Reactor } \\ \text { ICP-AES } & \text { Inductively Coupled Plasma Atomic Emission Spectroscopy } \\ \text { ICP-MS } & \text { Inductively Coupled Plasma Mass Spectrometer } \\ \text { IPyC } & \text { Inner Pyrocarbon (layer) } \\ \text { IROFS } & \text { Items Relied On for Safety } \\ \text { ISA } & \text { Integrated Safety Assessment } \\ \text { LWR } & \text { Light Water Reactor } \\ \text { MFC } & \text { Mass Flow Controller } \\ \text { MTS } & \text { Methyltrichlorosilane } \\ \text { NFPA } & \text { National Fire Prevention Association } \\ \text { NIST } & \text { National Institute of Standards and Technology } \\ \text { NMC\&A } & \text { Nuclear Materials Control and Accountability } \\ \text { NRC } & \text { United States Nuclear Regulatory Commission } \\ \text { OAF } & \text { Optical Anisotropy Factor } \\ \text { OPTAF } & \text { Optical Anisotropy Factor } \\ \text { OPyC } & \text { Outer Pyrocarbon (layer) } \\ \text { PVC } & \text { Polyvinyl Chloride } \\ \text { QA } & \text { Quality Assurance } \\ \text { QC } & \text { Quality Control } \\ \text { RDX } & \text { Cyclotrimethylenetrinitramine } \\ \text { SEM } & \text { Scanning Electron Microscope } \\ \text { SiC } & \text { Silicon Carbide (layer) } \\ \text { SNM } & \text { Special Nuclear Material } \\ \text { Sol-gel } & \text { Solution Gelation } \\ \text { TRISO } & \text { Tristructural-Isotropic } \\ \text { UCO } & \text { Uranium Oxycarbide } \\ \text { UHP } & \text { Ultra High Purity } \\ & \end{array}$




\section{FIGURES}

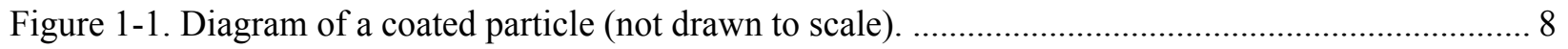

Figure 1-2. Fuel form for a pebble bed HTGR $\left(\mathrm{UO}_{2}\right.$ kernel) ............................................................ 9

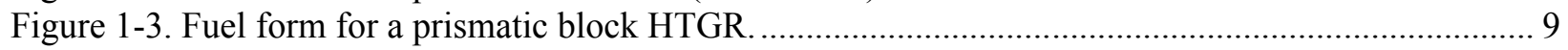

Figure 3-1. Shadowgraph of a kernel showing its deviation from a perfect circle................................. 32

Figure 3-2. Mounted and polished compact cross-section showing a broken particle. ............................ 33

Figure 3-3. ORNL Two-Modulator Generalized Ellipsometry Microscope (2-MGEM)......................... 34

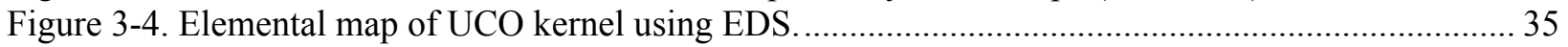

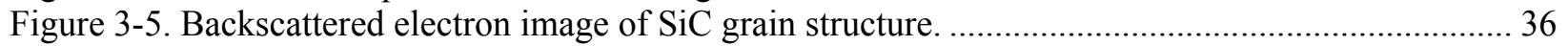

Figure 3-6. Deconsolidation apparatus for compacts and pebbles........................................................ 38

Figure 4-1. Laboratory-scale equipment for converting chilled broth into uniform gel spheres............... 42

Figure 4-2. Flow diagram of external gelation kernel fabrication process. ............................................. 43

Figure 4-3. Detailed drawing of a 50-mm laboratory-scale FB-CVD furnace. ........................................ 46

Figure 4-4. Illustration of the overcoated particle fuel element forming process.................................... 50

Figure 4-5. Illustration of the injection method, generally used only for compacts............................... 50

Figure 4-6. Green fuel element bakeout process. The $\mathrm{HCl}$ purge is optional........................................ 52

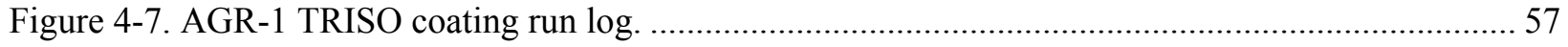

Figure 6-1. Laboratory-scale equipment for converting chilled broth into uniform gel spheres............... 69

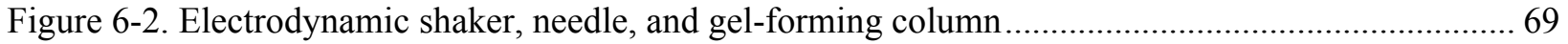

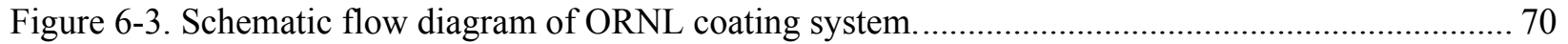

Figure 6-4. Detailed drawing of a 50-mm laboratory-scale FB-CVD furnace. ......................................... 71

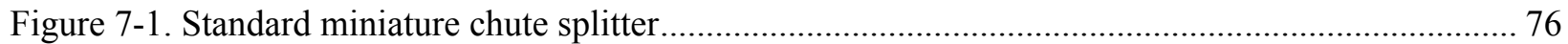

Figure 7-2. Rotary riffler for coated particle fuel QC designed by ORNL............................................ 77

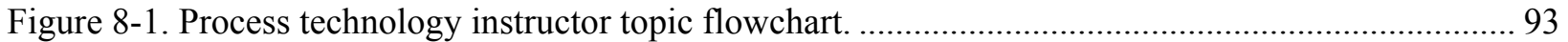

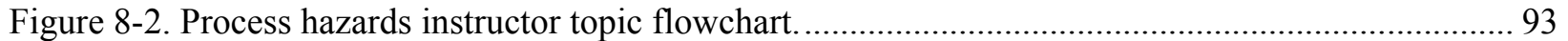

Figure 8-3. Operating, safety procedures, and practices instructor topic flowchart. ............................... 93

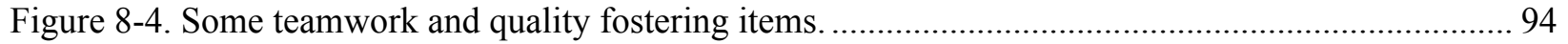

Figure 8-5. Basic Conceptual Fuel Fabrication Organization Chart..................................................... 96

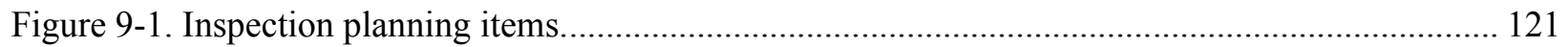




\section{INTRODUCTION AND OBJECTIVES}

The purpose of this document is to give the reader a general overview of the coated fuel particle (CFP) fuel fabrication and inspection techniques and methods so that he or she can begin a review of a proposed or existing CFP fuel fabrication facility. In particular, the following is of major interest:

1. The important fuel manufacturing process parameters and fuel product parameters and their associated specifications and the relationship of these parameters to fuel performance during operational fuel irradiation and accidents;

2. The methods used to characterize and measure fabricated fuel properties, including those associated with the kernels and coatings, matrix and fuel elements;

3. The manufacturing process controls and product controls that keep variation of the fuel characteristics within allowable tolerances, including the chemical vapor deposition coater characteristics (e.g., size, fluidization gas, coating gas distribution, etc.);

4. The statistical methods, product sampling analysis methods, and statistical acceptance calculations.

Unlike light water reactor (LWR) fuel, high temperature gas cooled reactor (HTGR) fuel is expected to perform without significant failure during anticipated operational (AO) events, design basis accidents (DBA), and even some beyond design basis accidents (BDBA). In this regard, the quality and constancy of fuel fabrication within the established manufacturing specifications and procedures is known to play a decisive role in determining the in-reactor requirements and the strong relation between fabrication and performance require that the NRC understand its unique manufacturing process and quality control methods. A knowledge infrastructure for HTGR fuel fabrication is needed to ensure appropriate regulatory oversight of HTGR fuel fabrication facilities, including input to potential technical specifications for fuel manufacture, inspection programs for HTGR fuel manufacturing facilities, and HTGR safety reviews.

The basis of the HTGR safety case and safety analysis is the expectation and the requirement that CFPs will have a very low failure rate within the licensing-basis envelope. Accordingly, an HTGR applicant must assure with high confidence that only a very small fraction (i.e., roughly $10^{-5}$ to $10^{-4}$, depending on the specific design) of the CFPs within the core will fail as a result of the combined effects of manufacturing defects, operational service conditions, and any accident conditions. The applicant must demonstrate in the review of HTGR fuel design, fabrication, irradiation testing, and safety that the fuel containing the CFPs which will be loaded into the HTGR core will meet this expectation and requirement with a high confidence level.

Since CFPs provide the main barrier to fission product release in an HTGR and because fuel fabrication determines fuel performance in-reactor and during accidents, the NRC staff must have sufficient knowledge and information of HTGR fuel fabrication process and quality controls to ensure adequate regulatory oversight and controls of HTGR fuel fabrication facilities. Also, compared to the manufacture of LWR fuel, HTGR fuel manufacture requires enhanced regulatory oversight (because of the complex fuel design and difficult to measure material properties) and controls to ensure the requisite fuel characteristics and quality over the life of the fuel supply. This may involve fuel fabrication technical specifications and will involve fuel manufacture inspections by the NRC. The need for enhanced regulatory oversight and controls is 
a significant HTGR safety issue. Alternative measures might involve reactor coolant activity monitoring and periodic end-of-life fuel accident simulation testing. However, these alternatives have technical, safety, and regulatory advantages and disadvantages.

The objective of this report is to provide NRC staff with the insights, information, and in-depth knowledge of contemporary HTGR fuel fabrication, including the critical process parameters, critical product parameters, and quality control measures that are vital to achieving the required fuel quality and fuel performance over the life of the fuel supply for the plant. This objective supports the major objective of developing draft guidance (i.e. a protocol) on the conduct of inspections at contemporary HTGR fuel fabrication facilities to provide regulatory assurance that the fuel is being fabricated within the critical process parameters and the critical product parameters, and that the required quality control measures are being adequately implemented to ensure the fuel is being produced in a manner which consistently meets the required level of fuel quality.

Briefly, a coated fuel particle is composed of a kernel which contains the fissile material, a buffer layer which provides expansion space for released gases and attenuates fission recoils, an inner pyrocarbon layer (IPyC) which provides support and compressive stress for the $\mathrm{SiC}$ layer, a $\mathrm{SiC}$ layer which is the fission product barrier, and an outer pyrocarbon layer which also provides a compressive stress on the $\mathrm{SiC}$ as well a measure of physical protection and a binding surface for integrating the particle into a fuel form. These layers are formed under a special coating process and have a unique microstructure. A diagram of a coated particle is shown in Figure 1-1.

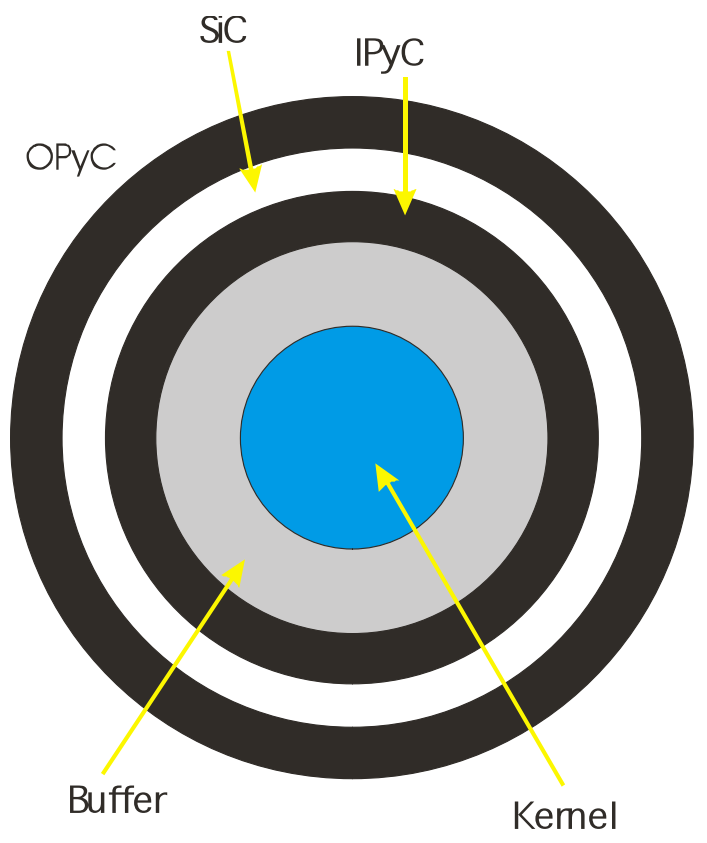

Figure 1-1. Diagram of a coated particle (not drawn to scale).

Thousands of coated fuel particles are contained within a fuel compact in a carbon matrix. The two commonly used fuel forms are a cylindrical compact and spherical fuel element. The compact is inserted into a structural graphite block fuel element for prismatic block core HTGRs while the fuel sphere is the element for pebble bed "core" HTGRs. Generally, the spherical fuel element is designed for considerable physical handling, while the compact has a higher fuel particle density and is physically protected from external loads by the structural graphite block. 
A pebble and its cross section are shown in Figure 1-2. Figure 1-3 shows a fuel compact and a prismatic block

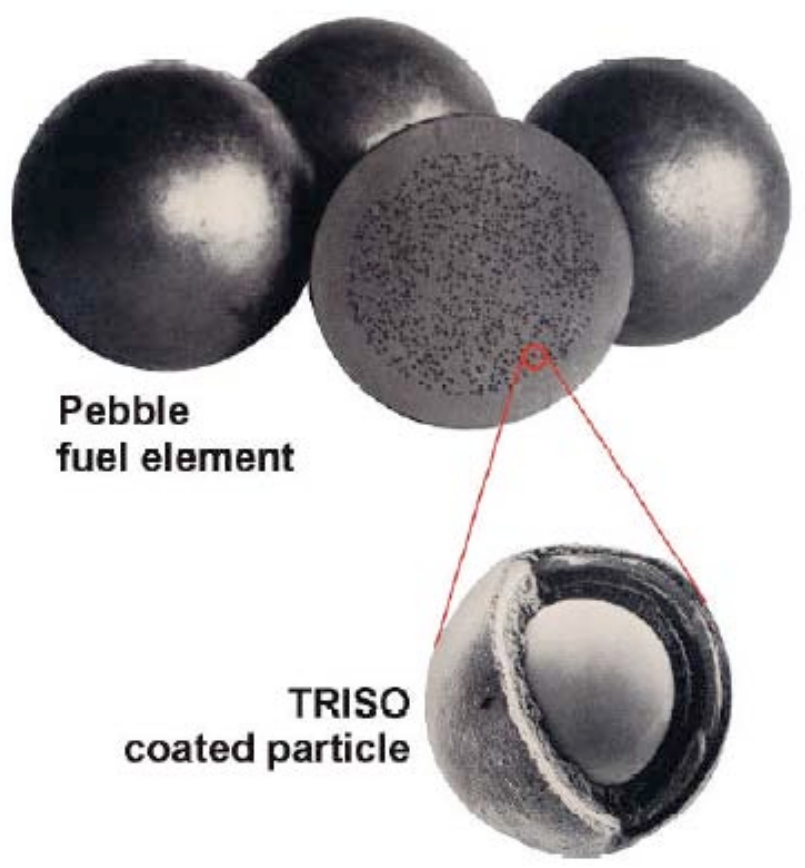

Figure 1-2. Fuel form for a pebble bed HTGR (UO $\mathrm{O}_{2}$ kernel).

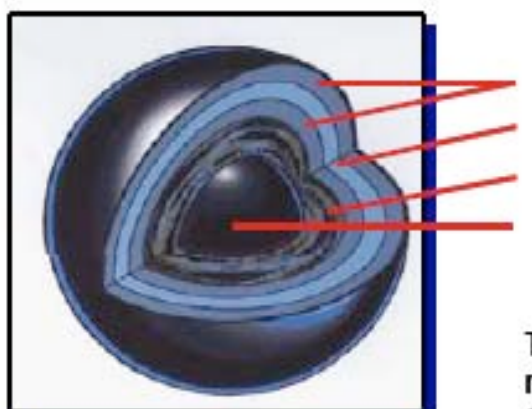

Pyrolytic Carbon

Silicon Carbide

Porous Carbon Buffer

Uranium Oxycarbide

TRISO Coated fuel particles (left) are formed into fuel rods (center) and inserted into graphite fuel elements

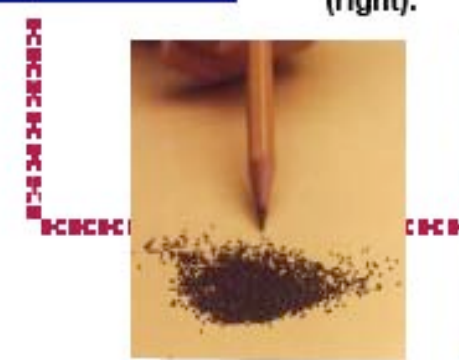

PARTICLES

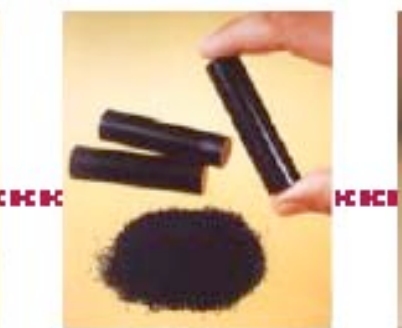

COMPACTS

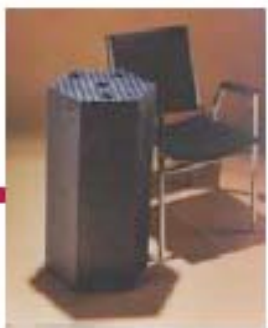

FUEL ELEMENTS

Figure 1-3. Fuel form for a prismatic block HTGR. 
The following sections detail the issues identified in the introduction and how one may go about inspecting them. The subject matter has been broken down into 8 topical areas associated with an HTGR fuel fabrication facility inspection:

1. Critical Product Parameters for Fuel Quality and Performance

2. Fuel Product Inspection and Testing Equipment and Procedures

3. Critical Process Equipment and Process Parameters for Fuel Quality and Performance

4. Calibration Testing Equipment and Calibration Inspection Procedures for Critical Product and Process Parameters

5. Maintenance Procedures for Fuel Fabrication Process Equipment

6. Sampling Methods, Statistical Analysis Methods and Acceptance Criteria

7. Training and Qualification of Fuel fabrication Facility Staff

8. Draft NRC Fuel fabrication Inspection Protocol

While each of these areas encompasses a broad range of important information and techniques, only those areas of critical importance to fuel quality and fuel performance are described. The inspector is assumed to have had some technical background or training and general knowledge of HTGR fuel. The major purpose of this document is to give the inspector a more focused and detailed understanding of the issues associated with the specialized methods required for the fabrication and inspection of HTGR fuel so as to achieve and maintain the required fuel quality. References are listed at the end of each topic as a source of more detail and are also available through ADAMS (Agency-wide Documents Access Management System, the NRC document database). One issue of note is that a significant amount of process knowledge as well as product knowledge may be required to conduct an effective inspection to assure that the fuel quality meets all of the requirements to be loaded into an HTGR reactor core.

A final issue is that US researchers have had little experience with spherical element fuel and most of the detailed procedures for fabricating this fuel are not openly available to them because of language and proprietary issues. While compact and spherical fuel have very similar needs and fabrication methods, the inspector should be aware of the differences between the two types (different particle loadings, perhaps different kernel designs, and impact requirements) and should inquire about specific licensing details only touched upon in this report if an ambiguous situation should arise.

The evolution of the fuel product specification is beyond the scope of this report and is a lengthy subject covering aspects of irradiation testing, inspection tools, fabrication aspects, and materials properties. Much work was conducted in the areas of internal versus external gelation for kernel fabrication, thermoplastic versus thermosetting resins for compact/sphere fabrication, and slug injection versus overcoating for compact production. Lengthy discussions were conducted on these and other topics; the final fabrication process was based on practical issues as well as in and out of pile testing. The connection between measured parameters and irradiation performance remains elusive for some material properties despite much testing and analysis. Should the particulars of a specific requirement be required, it is recommended that the inspector seek out experts in the field. 


\section{CRITICAL PRODUCT PARAMETERS FOR FUEL QUALITY AND PERFORMANCE}

The purpose of this section is to briefly outline the physical parameters that have an important effect on the performance of coated fuel particles. This section focuses on a reference TRISO coated particle comprised of a kernel, buffer layer, inner pyrocarbon (IPyC) layer, silicon carbide $(\mathrm{SiC})$ layer, and outer pyrocarbon $(\mathrm{OPyC})$ layer. Other more recent innovations such as kernel additives and getter layers will only be briefly discussed. These additions to the reference TRISO coated particle design do not change the basic performance of the coatings and their addition to fuel fabrication can be handled on a case-by-case basis.

The critical fuel product parameters are those physical parameters or properties that need to be controlled in order to obtain the desired performance of the TRISO coated particle fuel. Performance aspects include meeting reactor operational design criteria (e.g., fuel loading, criticality and control, and thermal performance) and minimizing fission product release under normal and accident conditions. The acceptable range for each critical product parameter is typically documented in a fuel product specification. The criteria used to establish the acceptable range of each product parameter varies. It may be based on engineering design-analysis calculations, historical operating performance, controlled performance test data, fuel performance modeling, or expected process results. The acceptable range is developed through fuel design and development programs and the results are documented and provided to the fuel production facility. The inspector should refer to the current Fuel Specification Document for detailed particle design and material information.

\subsection{Identification of Important Fuel Product Parameters}

The following subsections contain tables of critical product parameters for the fuel kernel, each coating layer, the finished TRISO coated particle, and the final fuel form (i.e., a spherical fuel element or a cylindrical compact). These parameters are typically included in a TRISO coated particle fuel manufacturing specification. Fuel quality specifications usually involve two types of properties - variable and attribute. A variable property is a parameter that varies in a continuous manner about the mean value, preferably with a normal (Gaussian) distribution. Variable properties are related to normal and expected variation in a well-controlled process. Specifications for variable properties involve limits on the mean and/or limits on the tails of the distribution. An attribute property involves a pass/fail condition (binary test). Attribute properties are related to abnormal or undesirable events that occur during processing. Specifications for attribute properties involve the maximum allowable percentage of defects in a population. This is discussed in more detail in Section 7.

\subsubsection{Kernel}

The kernel of the coated particle contains the fissionable material. This may be in the form of uranium dioxide $\left(\mathrm{UO}_{2}\right)$, or a combination of uranium carbide and uranium dioxide (referred to as uranium oxycarbide or UCO). The kernel is where the fission process and any subsequent chemical reactions occur. The kernel is the active element of the coated particle. During reactor operation, heat is generated in the kernel as well as internal pressure from evolved fission products. Because of this, the kernel chemistry is very important and many of the critical product 
parameters relate to this aspect. The U-235 enrichment must always be specified because it is critical to the reactor core nuclear design and heat generated in the kernel. For HTGR designs, the enrichment is typically less than $20 \%$ to reduce proliferation issues. The kernel stoichiometry (metal to oxygen ratio and/or carbon to oxygen ratio) is also determined by the engineering design. Oxygen freed from the oxide during fission serves an important role in immobilizing metallic fission products. However, excess oxygen can result in kernel migration (known as the "amoeba effect") or react with carbon in the buffer to form $\mathrm{CO}$ and increase internal pressure. Uranium carbide or other oxygen getters (e.g., $\mathrm{ZrC}$ ) may be added to control $\mathrm{CO}$ production and/or reduce kernel migration in an oxide kernel. The atomic ratios for the heavy metal versus oxygen, carbon, or added getters are specified. A minimum acceptable value for total uranium is also often specified to ensure proper fuel loading. Upper critical limits for various impurities are also specified because impurities can have detrimental effects on TRISO coated particle fuel operation and performance via chemical reactions of the impurities with the coatings.

The geometry and structure of the fuel kernels are important for both the reactor operation and fission product retention. In addition, the kernel properties can affect the coating process or the quality of the TRISO coated particle coatings. A minimum mean kernel envelope density is typically specified. It is defined as the mass of a sample of kernels divided by the sum of the volumes enclosed by a snuggly fitting envelope around each kernel. The envelope volume of a kernel includes the open and closed pore volume. Kernel density affects the resistance of the kernels to fracture during handling and coating, as well as possibly limiting kernel reactions with coating gas byproducts during coating. It may also limit low burn-up fission product release. The kernel density, together with its diameter, also ensures proper fuel loading per particle.

Kernel diameter is specified in terms of the average diameter of each kernel, which assumes a spherical geometry. An average kernel diameter is specified in order to insure adequate fuel loading. In addition, large kernels with thin buffer layers could have inadequate void volume in the buffer, which is needed to prevent over-pressurization of the coatings due to fission gas and $\mathrm{CO}$ release from the kernel. The deviation from a perfect spherical geometry can be reported in various ways. The typical method for TRISO coated particle fuel kernels is to determine an aspect ratio of the maximum length divided by the minimum length of a chord passing through the geometric center of the circumferential projection for a single orientation of the kernel (using a shadowgraph, see Section 3). This may also be defined as the ellipticity if the chords are perpendicular as in the case of an ellipse. This approach is limited in both its ability to define the actual shape of the kernel and to detect the maximum aspect ratio of each kernel. However, if the kernels do not deviate too dramatically from a spherical geometry and a sufficient number of kernels are analyzed, it is acceptable to use the single aspect ratio analysis to statistically determine the fraction of kernels in a batch or composite with asphericities above a critical limit.

An acceptance criterion for the kernel microstructure is not typically specified. However, microstructure should still be considered as it can impact assumptions made when measuring other critical parameters and thus affect the performance of the fuel. In multiphase particles (e.g., UCO), the stoichiometry specification assumes a certain degree of intermingling of the phases (i.e., $\mathrm{UC}, \mathrm{UC}_{2}$, and $\mathrm{UO}_{2}$ ). Cross-sectioned images of the internal kernel structure should be examined to verify that the kernel manufacturing process results in a sufficiently uniform distribution of the phases. In addition, the properties of each individual kernel directly affect the performance of each individual TRISO coated particle. However, with the exception of diameter and shape, the critical kernel parameters are not measured on individual kernels, but rather on large numbers of kernels to produce a combined result equivalent to the mean value. Hence, 
there is no measurement sensitivity to individual deviations from the mean. This is why typical fuel specifications do not include acceptance criteria for the distribution of many critical parameters. Sufficient process knowledge or demonstration that the kernel production process produces a uniform product is necessary for the validation of the use of inspection methods that measure mean sample values as opposed to individual kernel properties (see Section 7). Generally, a dense, spherical kernel with a homogeneous microstructure free from cracks, pores, or other flaws or asymmetries is desired. See Table 2-1 for a representative listing of requirements.

Table 2-1. Critical kernel parameters and typical acceptance criteria

\begin{tabular}{|c|c|c|}
\hline Critical Parameter & Typically Specified Criteria & Example - AGR-1 \\
\hline$U-235$ enrichment & $\begin{array}{l}\text { Range on mean value } \\
\text { Limits on distribution not specified but } \\
\text { uniform feedstock assumed }\end{array}$ & $19.80 \pm 0.01 \%$-wt U-235 \\
\hline Kernel stoichiometry & $\begin{array}{l}\text { Lower limit on total } U \\
\text { Range on mean value of atomic ratios } \\
\text { Upper and lower limits on atomic ratios }\end{array}$ & $\begin{array}{l}\geq 87 \% \text {-wt } \mathrm{U} \\
1.50 \pm 0.20 \text { mean } \mathrm{O} / \mathrm{U} \\
0.50 \pm 0.20 \text { mean } \mathrm{C} / \mathrm{U} \\
\leq 1 \% \text { kernels } \leq 0.2 \mathrm{C} / \mathrm{U} \\
\leq 1 \% \text { kernels } \geq 0.8 \mathrm{C} / \mathrm{U}\end{array}$ \\
\hline Impurity content & Upper limit & $\begin{array}{l}\leq 100 \text { ppm-wt Li, } \mathrm{Na}, \mathrm{Ca}, \mathrm{V}, \mathrm{Cr}, \mathrm{Mn}, \mathrm{Fe}, \\
\mathrm{Co}, \mathrm{Ni}, \mathrm{Cu}, \mathrm{Zn}, \mathrm{Al}, \mathrm{Ca} \\
\leq 1500 \text { ppm-wt } \mathrm{P} \text { or } \mathrm{S}\end{array}$ \\
\hline $\begin{array}{l}\text { Kernel envelope } \\
\text { density }\end{array}$ & $\begin{array}{l}\text { Lower limit of } 90-95 \% \text { theoretical } \\
\text { density }\end{array}$ & $\geq 10.4 \mathrm{Mg} / \mathrm{m}^{3}$ \\
\hline Kernel shape & Upper limit on asphericity & $\leq 10 \%$ kernels $\geq 1.05$ aspect ratio \\
\hline Kernel diameter & $\begin{array}{l}\text { Range on mean value } \\
\text { Lower limit on distribution } \\
\text { Upper limit on distribution }\end{array}$ & $\begin{array}{l}350 \pm 10 \mu \mathrm{m} \\
\leq 1 \% \text { kernels }<300 \mu \mathrm{m} \\
\leq 1 \% \text { kernels }>400 \mu \mathrm{m}\end{array}$ \\
\hline Kernel microstructure & Not specified & Not specified \\
\hline
\end{tabular}

\subsubsection{Buffer layer}

The first coating layer is a coating of the fuel kernel and is a $\sim 50 \%$ dense pyrolytic carbon that "buffers" the next layer (inner pyrolytic carbon, IPyC) from the fission recoils (range of about 30 microns) and provides an expansion volume for the released fission gases and any generated CO. Density is determined by measuring the envelope density with a mercury porosimeter. Envelope density is the mass of the buffer material divided by the envelope volume of the buffer. The envelope volume is the volume within a surface that closely follows the contours of the buffer surface without penetrating into surface pores smaller than a certain size. Preferably, this envelope surface is close to the surface expected to be enclosed by the next layer, (IPyC).

The free volume in the buffer determines its ability to limit the maximum internal pressure on the particle layers by providing free space to accommodate kernel swelling and any released fission gases. A specified density of around 50\% along with a sufficient envelope volume ensures adequate free volume while also providing enough carbon to attenuate the potential damage to the layer coatings due to fission product recoils and provides good heat transfer characteristics. The geometry of the buffer is that of a hollow sphere. The inner radius of the buffer is a function of and controlled by the specification on the kernel diameter. Assuming a well defined inner radius and spherical shape, analysis of buffer thickness is sufficient to monitor the buffer volume. A lower critical limit on buffer thickness, in conjunction with the specified density, 
ensures sufficient void volume to limit internal pressurization and attenuate fission product recoil.

Missing buffer, or particles with abnormally thin buffer, may be listed in a fuel specification as an attribute defect. The absence of the buffer layer will result in a fully TRISO-coated particle diameter significantly smaller than the average particle diameter. These particles may be removed during post-fabrication sorting through sieving or through the use of a roller micrometer. The roller micrometer performs the same function as a sieve stack to separate spherical particles as a function of diameter.

The buffer layer is deposited relatively rapidly, making it the most variable of the particle coatings in terms of thickness, shape, and microstructure. It also experiences the largest change in surface area during deposition. This can result in non-uniform coatings if the gas flows are held constant, which is the standard practice. The increase in surface area may decrease the deposition rate, which may result in an increase in the average density as a function of increasing coating layer radius. The increased surface area may also result in local depletion of the coating gases which could also adversely affect coating uniformity. Although not normally specified, the buffer microstructure should be relatively uniform. Some variation in porosity as a function of radius is expected, but the layer should be fairly homogeneous without clear indications of segregation between porous and non-porous material.

The buffer deposition can improve the sphericity of the particle by filling in and smoothing out slight asphericities in the kernel surface. However, because it is a relatively soft and rapidly deposited layer, the buffer is easily distorted by physical contact and is often the source of large dents or flats in the final TRISO coated particle caused by particle to particle contact during deposition of the buffer. The control of the buffer shape is therefore covered in the specification by an analysis of the final TRISO coated particle shape. Table 2-2 is a listing of typical buffer specifications.

Table 2-2. Critical buffer Layer parameters and typical acceptance criteria

\begin{tabular}{|l|l|l|}
\hline Critical Parameter & Typically Specified Criteria & Example - AGR-1 \\
\hline Buffer envelope density & Range on mean value & $1.03 \pm 0.15 \mathrm{Mg} / \mathrm{m}^{3}$ \\
\hline Buffer shape & Not specified & $\begin{array}{l}\text { Controlled by final TRISO coated } \\
\text { particle shape }\end{array}$ \\
\hline Buffer thickness & $\begin{array}{l}\text { Range on mean value } \\
\text { Lower limit on distribution }\end{array}$ & $\begin{array}{l}100 \pm 15 \mu \mathrm{m} \\
\leq 1 \% \text { kernels } \leq 55 \mu \mathrm{m}\end{array}$ \\
\hline Buffer microstructure & Not specified & Not specified \\
\hline $\begin{array}{l}\text { Missing buffer defect } \\
\text { fraction }\end{array}$ & Upper limit & $\begin{array}{l}\text { Controlled by size separation (sieving or } \\
\text { roller-miking) }\end{array}$ \\
\hline
\end{tabular}

\subsubsection{IPyC Layer}

The second coating layer is a dense pyrolytic carbon layer called the inner pyrocarbon (IPyC) layer. The IPyC layer helps retain fission products during irradiation by providing good fission gas retention (but poor fission metal retention). Its integrity during reactor operation is therefore important.

During TRISO coated particle manufacture, the IPyC provides a suitable surface and structural support for the $\mathrm{SiC}$ layer deposition. It also reduces the tensional loading on the $\mathrm{SiC}$ layer during operation by putting the $\mathrm{SiC}$ layer into compression due to irradiation-induced shrinkage of the IPyC layer. In order for $\mathrm{SiC}$ compression to occur, the open porosity of the IPyC surface is 
designed to allow moderate $\mathrm{SiC}$ infiltration to produce a strong interface bond between the IPyC layer and the $\mathrm{SiC}$ layer. This allows shrinkage of the IPyC to result in a compressive force on the $\mathrm{SiC}$ layer, increasing the $\mathrm{SiC}$ layer's resistance to failure due to internal pressurization of the particle.

The graphitic nanoparticles in the pyrocarbon layer exhibit a different magnitude and rate of irradiation induced shrinkage along directions parallel to and perpendicular to the carbon basal planes. For this reason, it is important that these nanoparticles be isotropically distributed in the layer. Certain deposition process conditions can result in a preferred orientation of the basal planes. A microstructure which is significantly anisotropic must be avoided because it leads to significant anisotropic dimensional changes. This can cause the IPyC layer to crack or delaminate at the $\mathrm{SiC}$ interface. This condition can then cause the $\mathrm{SiC}$ layer to radially crack (i.e., fail) due to increased local stress. Pyrocarbon anisotropy is typically measured optically and an upper limit is specified.

$\mathrm{HCl}$ is formed as a byproduct of the $\mathrm{SiC}$ layer deposition process. The IPyC layer protects the kernel from $\mathrm{HCl}$ intrusion during initial $\mathrm{SiC}$ deposition. Resistance to $\mathrm{HCl}$ intrusion is important because this could result in the formation of chloride compounds and uranium migration out of the kernel. A high density IPyC layer ensures a minimum permeability to $\mathrm{HCl}$ during $\mathrm{SiC}$ deposition and to fission product gases during irradiation. However, high IPyC layer density is accompanied by high IPyC layer anisotropy. High IPyC layer density can also limit creep, which is important because high creep rates can moderate high stress concentrations from forming in the layers. IPyC layer density is therefore specified with upper and lower limits in order to balance the requirement for low permeability with that for low anisotropy and adequate creep characteristics.

IPyC layer thickness is also specified with upper and lower critical limits. The lower critical limit (in conjunction with a lower limit on the density) is to ensure limited permeability and the upper limit (in conjunction with an upper limit on the anisotropy) is to minimize irradiation induced stress. Representative specifications for the IPyC are listed in Table 2-3.

Table 2-3. Critical IPyC Layer parameters and typical acceptance criteria

\begin{tabular}{|l|l|l|}
\hline Critical Parameter & Typically Specified Criteria & Example - AGR-1 \\
\hline IPyC density & Range on mean value & $1.90 \pm 0.05 \mathrm{Mg} / \mathrm{m}^{3}($ note 1$)$ \\
& Lower limit on distribution & $\leq 1 \% \leq 1.80 \mathrm{Mg} / \mathrm{m}^{3}$ \\
& Upper limit on distribution & $\leq 1 \% \geq 2.00 \mathrm{Mg} / \mathrm{m}^{3}$ \\
\hline IPyC anisotropy & Upper limit on mean & $\leq 1.035 \mathrm{BAF}$ \\
& Upper limit on distribution & $<1 \% \geq 1.06 \mathrm{BAF}$ \\
\hline IPyC thickness & Range on mean value & $40 \pm 4 \mu \mathrm{m}$ \\
& Lower limit on distribution & $\leq 1 \% \leq 30 \mu \mathrm{m}$ \\
& Upper limit on distribution & $\leq 1 \% \geq 56 \mu \mathrm{m}$ \\
\hline IPyC microstructure & Range on mean crystallite size & Not specified \\
\hline IPyC permeability & Not specified & Not specified \\
\hline IPyC open porosity & Range on mean value & Not specified, $1.3 \mathrm{ml} / \mathrm{m}^{2}$ desired \\
\hline
\end{tabular}

Note 1: The IPyC layer density is typically specified in terms of the sink-float density. This is the density of a liquid medium, that when surrounding the material to be measured, results in zero buoyancy.

\subsubsection{SiC Layer}

The third coating layer is a silicon carbide ( $\mathrm{SiC}$ ) layer. The SiC layer is the primary barrier for fission product retention within the particle and provides structural integrity in the TRISO coated 
particle. A lower limit on the thickness is specified to ensure sufficient strength in this layer to withstand internal pressurization due to fission product gases built up during irradiation. A fine grain microstructure is desirable both for increased layer toughness and for minimum permeability. SiC layers deposited under certain conditions can exhibit large columnar grains that result in a weaker material and possibly excessive diffusion along the grain boundaries. The $\mathrm{SiC}$ density is also a good indicator of the strength and the quality of the SiC layer. Low density may be an indicator of a porous or off-stoichiometric $\mathrm{SiC}$ layer (small deposits of free $\mathrm{Si}$ in the layer).

Because the $\mathrm{SiC}$ layer is the primary barrier for fission product retention, any breach in this barrier layer is considered a particle failure. Such a failure during manufacture is referred to as a particle defect. The burn-leach (BL) test is designed to identify through-layer defects in the SiC layer. This test removes the outer pyrocarbon (OPyC) and any exposed inner carbon layers and leaches out any subsequently exposed uranium in the kernel. In this way the number of exposed kernels (i.e. the number of particles with through-wall cracked SiC layers) can be quantified. Intact pyrocarbon layers can only be relied on to slow the eventual release of fission products; gases may be held well, but metals are poorly retained. The specified maximum particle defect fraction is therefore directly related to the allowable fission product release limit.

During SiC deposition, some particles may be ejected out of the central fluidized bed region within the coater and contact the upper walls of the coating chamber. In some instances, these excursions may result in the inclusion of a lenticular-shaped layer of low density soot (carbon or $\mathrm{SiC}$ ) overlaid with normal $\mathrm{SiC}$. This is an undesirable condition which can affect the performance of the $\mathrm{SiC}$ layer during reactor operation. In some fuel manufacturing programs, this condition has been detected by the optical manifestation of light scattering from the soot inclusion and has thus been called a "goldspot" defect. However, for fine grained SiC, this optical effect does not occur and other tests for soot inclusions are required (see Section 3). Table 2-4 is a listing of typical SiC layer requirements.

\section{Table 2-4. Critical SiC Layer parameters and typical acceptance criteria}

\begin{tabular}{|l|l|l|}
\hline Critical Parameter & Typically Specified Criteria & Example - AGR-1 \\
\hline SiC density & $\begin{array}{l}\text { Lower limit on mean value } \\
\text { Lower limit on distribution }\end{array}$ & $\begin{array}{l}\geq 3.19 \mathrm{Mg} / \mathrm{m}^{3} \\
\leq 1 \% \leq 3.17 \mathrm{Mg} / \mathrm{m}^{3} \text { (note 1) }\end{array}$ \\
\hline SiC thickness & $\begin{array}{l}\text { Range on mean value } \\
\text { Lower limit on distribution }\end{array}$ & $\begin{array}{l}35 \pm 3 \mu \mathrm{m} \\
\leq 1 \% \leq 25 \mu \mathrm{m}\end{array}$ \\
\hline SiC microstructure & Upper limit on mean crystallite size & $\begin{array}{l}\text { Visual standard, no columnar grains }> \\
\text { half layer thickness }\end{array}$ \\
\hline SiC BL defect fraction & Upper limit & $\leq 1 \cdot 10^{-4}$ \\
\hline $\begin{array}{l}\text { Soot inclusion defect } \\
\text { fraction }\end{array}$ & Upper limit & $\leq 1 \cdot 10^{-3}$ goldspots \\
\hline
\end{tabular}

Note 1: The SiC density is typically specified in terms of the sink-float density. This is the density of a liquid medium, that when surrounding the material to be measured, results in zero buoyancy.

\subsubsection{OPyC Layer}

The fourth coating layer is a dense pyrolytic carbon layer called the outer pyrocarbon (OPyC) layer. This layer provides a protective outer coating for the $\mathrm{SiC}$ as well as a bonding layer for the next layer which is the compacting matrix material. The OPyC layer also provides additional strength to the particle by putting the $\mathrm{SiC}$ into compression due to irradiation shrinkage of the OPyC layer. The performance requirements for the OPyC layer are similar to the IPyC layer, 
particularly in regards to low anisotropy for irradiation stability. Although the OPyC layer is not primarily designed to serve as a fission product barrier, a minimum thickness is specified to ensure some level of gas retention in the case of failed SiC and IPyC layers and to provide at least a moderate level of compressive force on the SiC layer. Density range is controlled as for the IPyC layer to ensure low permeability to fission products without excessive density that may be accompanied by high anisotropy or an inadequate rate of irradiation induced creep, which helps relieve local stress and prevent cracking.

Outer surface porosity of the OPyC layer enhances matrix material bonding; however, excessive bond strength may cause the OPyC to fracture and pull away from the $\mathrm{SiC}$ as the matrix material shrinks during heat treatment and irradiation. For this reason, missing OPyC in particles deconsolidated from representative sample compacts are considered defects and a maximum allowable fraction is specified (see Sections 2.1.6 and 2.1.7). In addition, missing OPyC could occur due to fluidization anomalies. Therefore, an upper limit on the fraction of coated fuel particles with missing OPyC may also be specified for the as-coated particles. Deconsolidation tests are implemented prior to compacting. See Table 2-5 for a listing of typical OPyC layer requirements.

Although actually an attribute of the entire coated particle, particle shape is included in Table 2-5 because the measurement is performed after OPyC layer deposition. Excessive faceting is considered a defect because regions of high curvature may result in unacceptable stress concentration in the various layers.

Table 2-5. Critical OPyC Layer parameters and typical acceptance criteria

\begin{tabular}{|l|l|l|}
\hline Critical Parameter & Typically Specified Criteria & Example - AGR-1?? \\
\hline OPyC density & Range on mean value & $1.90 \pm 0.05 \mathrm{Mg} / \mathrm{m}^{3}$ (note 1) \\
& Lower limit on distribution & $\leq 1 \% \leq 1.80 \mathrm{Mg} / \mathrm{m}^{3}$ \\
& Upper limit on distribution & $\leq 1 \% \geq 2.00 \mathrm{Mg} / \mathrm{m}^{3}$ \\
\hline OPyC anisotropy & Upper limit on mean & $\leq 1.035 \mathrm{BAF}$ \\
& Upper limit on distribution & $<1 \% \geq 1.06 \mathrm{BAF}_{\mathrm{o}}$ \\
\hline OPyC thickness & Range on mean value & $40 \pm 4 \mu \mathrm{m}$ \\
& Lower limit on distribution & $\leq 1 \% \leq 20 \mu \mathrm{m}$ \\
\hline Particle shape & Upper limit on asphericity & $\leq 1 \%$ particles $\geq 1.14$ aspect ratio \\
\hline $\begin{array}{l}\text { Missing } \text { OPyC defect } \\
\text { fraction }\end{array}$ & Upper limit & $\leq 3 \cdot 10^{-4}$ \\
\hline OPyC microstructure & Range on mean crystallite size & Not specified \\
\hline OPyC open porosity & Range on mean value & Not specified, $1.3 \mathrm{ml} / \mathrm{m}^{2}$ desired \\
\hline
\end{tabular}

Note 1: The OPyC density is typically specified in terms of the sink-float density. This is the density of a liquid medium, that when surrounding the material to be measured, results in zero buoyancy.

\subsubsection{Cylindrical Fuel Compact}

The prismatic block gas cooled reactor designs utilize columns of cylindrical fuel compacts embedded in hexagonal-shaped graphite fuel blocks. Thousands of particles are uniformly and randomly embedded in cylindrically shaped compacts. The process to embed the particles involves either a thermoplastic resin injection molding process or a thermosetting resin overcoating and molding process (this process will be described in later sections). Graphite material is mixed with carbonaceous resin to form a conductive carbonaceous matrix after heat treatment. The initial matrix impurity content and the compact heat treatment process, which can drive off some impurities, are important. In addition to process controls on the heat treatment and starting 
materials, upper critical limits are established for final compact impurities. Impurities are controlled to limit chemical attack on the $\mathrm{SiC}$ or reactor components and to meet reactor core neutronics requirements. Uranium impurities in the matrix are especially important in that they contribute to the fission product release from the fuel. Because the most likely source of significant uranium impurity is from exposed kernels in broken or defective particles, the uranium impurity content is quantified by the average uranium content in each kernel and treated as a particle defect property.

Compact dimensions are critical to insertion of the compacts in the prismatic fuel block and heat transfer in the prismatic block. For this reason, compact diameter and length are likely to be measured for product acceptance on every compact. This is a design specific detail and depends on the overall tolerance control and heat transfer requirements.

As mentioned in Section 2.1.5, missing $\mathrm{OPyC}$ in particles deconsolidated from representative sample compacts are considered defects and a maximum allowable fraction is specified. Burnleach $\mathrm{SiC}$ defect fraction is also re-evaluated after compacting, to show that the compacting process did not result in particles being fractured by compressive stresses. Section 2.1.3 stated that $\mathrm{IPyC}$ permeability is controlled in order to limit $\mathrm{HCl}$ intrusion during $\mathrm{SiC}$ deposition, which may leach uranium from the kernel into the buffer and IPyC layers. Fission recoils in or near the $\mathrm{IPyC}$ or $\mathrm{SiC}$ can result in much greater irradiation damage to those layers than fast neutrons, which can lead to particle failure. After compacting, uranium dispersion in the buffer and IPyC layers is looked for using $\mathrm{x}$-ray techniques, with an unacceptable level being used to identify a particle as having defective IPyC. Uranium dispersion in the buffer is difficult to quantify and the $\mathrm{x}$-ray analysis sensitivity is usually limited to a fraction of a percent of the kernel's total uranium content. At the present time the uranium dispersion requirements are not rigorously defined; the current Fuel Specification Document should be consulted for guidance.

Typical compact requirements are listed in Table 2-6. 
Table 2-6. Critical cylindrical compact parameters and typical acceptance criteria. Note: critical parameters marked as "not specified" may assume greater importance in production fuel. The current Fuel Specification Document should be consulted for these items.

\begin{tabular}{|c|c|c|}
\hline Critical Parameter & Typically Specified Criteria & Example - AGR-1 \\
\hline Compact diameter & Absolute range on value & $12.22-12.46 \mathrm{~mm}$ \\
\hline Compact length & Absolute range on value & $25.02-25.40 \mathrm{~mm}$ \\
\hline Uranium loading & Range on mean value & $0.905 \pm 0.040 \mathrm{~g} \mathrm{U}$ \\
\hline Impurity content & $\begin{array}{l}\text { Upper limit on mean value outside } \mathrm{SiC} \\
\text { Upper limit on distribution }\end{array}$ & $\begin{array}{l}\leq 25 \mu \mathrm{g} / \text { compact } \mathrm{Fe} \\
\leq 1 \% \geq 100 \mu \mathrm{g} / \text { compact } \mathrm{Fe} \\
\leq 75 \mu \mathrm{g} / \text { compact } \mathrm{Cr}, \mathrm{Mn}, \mathrm{Co}, \mathrm{Ni} \\
\leq 1 \% \geq 300 \mu \mathrm{g} / \text { compact } \mathrm{Cr}+\mathrm{Mn}+\mathrm{Co}+\mathrm{Ni} \\
\leq 90 \mu \mathrm{g} / \text { compact } \mathrm{Ca} \\
\leq 45 \mu \mathrm{g} / \text { compact } \mathrm{Al} \\
\leq 30 \mu \mathrm{g} / \text { compact } \mathrm{Cl} \\
\leq 400 \mu \mathrm{g} / \text { compact } \mathrm{T}+\mathrm{V}\end{array}$ \\
\hline Exposed Uranium & $\begin{array}{l}\text { Upper limit on the fraction of exposed } \\
\text { kernels }\end{array}$ & $\leq 10^{-4}$ \\
\hline Defective $\mathrm{SiC}$ & $\begin{array}{l}\text { Upper limit on the fraction particle } \\
\text { with defective } \mathrm{SiC}\end{array}$ & $\leq 2 \cdot 10^{-4}$ \\
\hline Defective IPyC & $\begin{array}{l}\text { Upper limit on the fraction particle } \\
\text { with defective IPyC }\end{array}$ & $\leq 2 \cdot 10^{-4}$ \\
\hline Defective OPyC & $\begin{array}{l}\text { Upper limit on the fraction particle } \\
\text { with defective OPyC }\end{array}$ & $\leq 10^{-2}$ \\
\hline Matrix density & Lower limit on mean value & Not specified \\
\hline Thermal conductivity & Lower limit on mean value & Not specified \\
\hline Crush strength & Lower limit on load to breaking & Not specified \\
\hline Particle distribution & Uniform distribution & Not specified \\
\hline
\end{tabular}

\subsubsection{Spherical Fuel Element}

Pebble bed reactor designs utilize spherical fuel elements often referred to as fuel "pebbles". The basic concept of embedding particles in a graphite matrix is the same as for cylindrical compacts. The spheres consist of a spherical fuel region with the embedded fuel particles surrounded by a thin unfueled layer (no fuel particles). The unfueled layer protects the fuel particles and allows for machining of the outer surface to ensure a nearly perfect sphere of accurate diameter. The fueled region is fabricated by first uniformly mixing overcoated particles in the graphite matrix material. Compacting is usually done by compressing the mix of overcoated particles and matrix material. The fuel free zone is then added around the fueled region by adding an additional layer of matrix material in a second molding operation. Pebbles generally have a lower particle to matrix fraction (i.e., packing fraction) with a premium on a dense, low shrinkage matrix.

Many of the critical parameters for cylindrical compacts also apply to spherical fuel elements. However, a fuel pebble must be a more mechanically rugged fuel form than a fuel compact. This is because, in a pebble bed reactor, each spherical fuel element is dropped multiple times from a considerable height into the pebble bed core during a continuous in-line fuel loading and removal process. For this reason, some additional parameters such as drop strength and abrasion resistance are also specified. Graphite dust generation in a pebble bed reactor is also a potentially significant mechanism for radionuclide transport from the fuel pebble surface during reactor operation as well as the release of the accumulated fission product laden dust in the reactor system during a potential accident. Therefore, abrasion resistance (i.e. resistance to pebble 
graphite dust generation during pebble movement trough the reactor core) is also important. Corrosion resistance to the pebble bed reactor helium impurities is also an important parameter. These additional requirements are due to the fact that the pebbles move during operation and are not shielded by a graphite block and are exposed directly to the helium coolant. Some typical requirements are listed in Table 2-7.

Table 2-7. Critical Pebble fuel element parameters and typical acceptance criteria

\begin{tabular}{|c|c|c|}
\hline Critical Parameter & Typically Specified Criteria & Example - HTR-10 \\
\hline Outer diameter & Absolute range on value & $59.6-60.2 \mathrm{~mm}$ \\
\hline Mass & Absolute range on value & Not listed \\
\hline $\begin{array}{l}\text { Free fuel shell } \\
\text { thickness }\end{array}$ & Absolute range on value & $4.0-6.0 \mathrm{~mm}$ \\
\hline $\begin{array}{l}\text { Coated particles in } \\
\text { shell region }\end{array}$ & Not listed & Not listed \\
\hline Surface Defects & Not listed & Not listed \\
\hline Uranium loading & Range on mean value & $5.0 \pm 0.2 \mathrm{~g} \mathrm{U}$ \\
\hline Impurity content & $\begin{array}{l}\text { Upper limit on mean value outside } \mathrm{SiC} \\
\text { Upper limit on equivalent boron } \\
\text { content for all impurities }\end{array}$ & $\begin{array}{l}\leq 300 \mathrm{ppm} \text { ash } \\
\leq 3.0 \mathrm{ppm} \mathrm{Li} \\
\leq 3.0 \mathrm{ppm} \text { equivalent boron content } \\
\text { Other impurities not listed individually in } \\
\text { reference } \\
\text { Note: although not listed, control of impurity } \\
\text { metals such as Fe is important. }\end{array}$ \\
\hline Exposed uranium & $\begin{array}{l}\text { Upper limit on the fraction of exposed } \\
\text { kernels }\end{array}$ & $\leq 3 \cdot 10^{-4}$ \\
\hline Defective SiC & $\begin{array}{l}\text { Upper limit on the fraction particle with } \\
\text { defective } \mathrm{SiC}\end{array}$ & Not listed \\
\hline Defective IPyC & $\begin{array}{l}\text { Upper limit on the fraction particle with } \\
\text { defective IPyC }\end{array}$ & Not listed \\
\hline Defective $O P y C$ & $\begin{array}{l}\text { Upper limit on the fraction particle with } \\
\text { defective OPyC }\end{array}$ & Not listed \\
\hline Matrix density & Lower limit on mean value & $>1.70$ \\
\hline Thermal conductivity & Lower limit on mean value & $\geq 0.25 \mathrm{~W} / \mathrm{cm} \cdot \mathrm{K}$ at $1000^{\circ} \mathrm{C}$ \\
\hline Crush strength & Lower limit on load to breaking & $\geq 18 \mathrm{kN}$ between parallel plates \\
\hline Particle distribution & Uniform distribution & Not listed \\
\hline Drop test & $\begin{array}{l}\text { Lower limit on number of drops } \\
\text { without breaking }\end{array}$ & $\geq 50$ at $4 \mathrm{~m}$ \\
\hline Erosion rate & Upper limit on material loss & $\begin{array}{l}\leq 6 \mathrm{mg} / \mathrm{h} \text { per fuel element, tumbled } 20 \text { hours } \\
\text { with } 20 \text { spheres }\end{array}$ \\
\hline Corrosion rate & Upper limit on material loss & $\leq 1.3 \mathrm{mg} / \mathrm{cm}^{2} \cdot \mathrm{h}, 1000^{\circ} \mathrm{C}, \mathrm{He}+1 \mathrm{vol} \% \mathrm{H}_{2} \mathrm{O}$ \\
\hline $\begin{array}{l}\text { Anisotropy of thermal } \\
\text { expansion }\end{array}$ & Not listed & Not listed \\
\hline Dynamic E-modulus & Not listed & Not listed \\
\hline $\begin{array}{l}\text { Specific electrical } \\
\text { resistance }\end{array}$ & Not listed & Not listed \\
\hline Bending strength & Not listed & Not listed \\
\hline
\end{tabular}




\subsection{Relative Priority of Fuel Product Parameters}

All the parameters that have been listed in the preceding tables of this section are important and an inspection protocol should categorize them into five areas: geometry (dimensions), density, composition and microstructure, impurities, and damaged or defective fuel fractions. The most important early indicators of fuel quality are fuel defect fraction, dimensional accuracy, pyrocarbon anisotropy, and $\mathrm{SiC}$ grain size. These four items are among the highest priority for inspection.

Geometry is the easiest to understand and demonstrate and a set of micrographs along with the measurement statistics can be easily reviewed to determine if the most basic fuel specifications are being met:

1. Kernel diameter and sphericity

2. Layer thicknesses

3. Cylindrical or spherical fuel element dimensions

Density is a critical parameter by itself because it is, in some cases, difficult to measure, it is linked to many microstructural properties that may be important for the irradiation performance of the layers, and it may have a narrow acceptable range, which would require accurate analysis methods. The method by which the density is defined and measured is also important (see Section 3). The following are all critical:

1. Kernel density

2. Buffer layer density

3. IPyC layer density

4. SiC layer density

5. OPyC layer density

6. Matrix material density

Composition and microstructure determine the fuel loading and the irradiation performance. These parameters may be the most difficult to quantify and interpret because of the specialized nature of the instruments involved:

1. Kernel uranium content, stoichiometry, and U/O or U/C ratios.

2. Uranium dispersion into the buffer layer and IPyC layer

3. IPyC layer anisotropy

4. SiC layer grain structure, voids, inclusions, or pores

5. OPyC layer anisotropy

6. Matrix intrusion into OPyC layer

7. Matrix thermal conductivity

8. Pebble abrasion resistance

9. Pebble breaking strength of final fuel form

10. Pebble corrosion resistance of final fuel form

Impurities are important in the sense of controlling the fabrication process. The important point is to check for raw material composition control and to see that "tramp" uranium (i.e., natural 
uranium impurity content) in the raw feed materials or broken particles is not being spread throughout the fuel form. They may also control corrosion resistance.

The fuel defect fraction as measured by leach-burn-leach (LBL) is an important indicator of fabrication success and overall fuel quality. Two important areas to check when developing the fabrication processes are coated particle defect fraction after fabrication, but prior to compacting and the defect fraction of the final fuel form (i.e., after compacting). The two defect fractions should be similar; a large difference between the two (greater than what one would expect from roughly statistical variation) would indicate that particles are being damaged in the fuel element fabrication process. A mature fabrication process may only require LBL defect fraction analysis of the final fuel form in order to ensure that defects are below specified values.

In summary, an inspector should verify that the particles and fuel forms meet their specified design dimensions and exhibit the proper microstructure, that the fuel forms meet the fuel failure fraction specification, and that abrupt increases in particle defects do not occur as one proceeds through the fabrication process.

\subsection{Reference Documents}

Information in Section 2 has been summarized from the documents listed in Table 2-8. For more detailed information, the inspector should consult those documents. The fuel specifications associated with the Advanced Gas Reactor (AGR) Fuel Development and Qualification Program are based on an accumulation of the knowledge gained by previous coated particle fuel programs and represent the most up to date approach (circa 2008).

Certain documents listed below are for official internal NRC use only and their distribution is restricted to NRC unless approved by both NRC and DOE. These documents are labeled with an asterisk $\left(^{*}\right)$. 
Table 2-8. List of reference documents.

\begin{tabular}{|c|c|c|}
\hline Document Title & Reference & Description \\
\hline $\begin{array}{l}\text { *Product Specification for NPR- } \\
\text { MHTGR Performance Test Fuel }\end{array}$ & *NPR ES-51393 & $\begin{array}{l}\text { Provides acceptance criteria for NPR-MHTGR } \\
\text { performance test fuel. Lists product parameter } \\
\text { specifications. (1991) }\end{array}$ \\
\hline $\begin{array}{l}\text { *GT-MHR Fuel Product } \\
\text { Specification }\end{array}$ & $\begin{array}{l}\text { *GA DOE-GT- } \\
\text { MHR-100209 }\end{array}$ & $\begin{array}{l}\text { Provides acceptance criteria for GT-MHR fuel. Lists } \\
\text { product parameter specifications. (1994) }\end{array}$ \\
\hline $\begin{array}{l}\text { *TRISO Fuel Particle Coating } \\
\text { Design Basis }\end{array}$ & $\begin{array}{l}\text { *GA DOE-GT- } \\
\text { MHR-100225 }\end{array}$ & $\begin{array}{l}\text { Provides design bases for the product parameters and } \\
\text { specifications in the GT-MHR fuel product specification. } \\
\text { (1994) }\end{array}$ \\
\hline $\begin{array}{l}\text { *Key Differences in the } \\
\text { Fabrication, Irradiation and Safety } \\
\text { Testing of US and German } \\
\text { TRISO-coated Particle Fuel and } \\
\text { Their Implications on Fuel } \\
\text { Performance }\end{array}$ & $\begin{array}{l}\text { *INEEL/EXT- } \\
02-00300 \text { and } \\
\text { Nucl. Eng. and } \\
\text { Design Vol. 222, } \\
\text { pp. 281-297 }\end{array}$ & $\begin{array}{l}\text { A historical look at both German and US fuel in an effort } \\
\text { to explain large differences in behavior. (2002) }\end{array}$ \\
\hline $\begin{array}{l}\text { *Preliminary Fuel Product } \\
\text { Specification for the Baseline } \\
\text { Advanced Gas Reactor fuel design }\end{array}$ & *GA 911034 & $\begin{array}{l}\text { Preliminary list of important product parameters and } \\
\text { specified values. Also lists important product parameters } \\
\text { and specifications. (2002) }\end{array}$ \\
\hline $\begin{array}{l}\text { *AGR-1 Fuel Product } \\
\text { Specification and Characterization } \\
\text { Guidance }\end{array}$ & *INL EDF-4380 & $\begin{array}{l}\text { Provides acceptance criteria for AGR-1 fuel product. Lists } \\
\text { product parameter specifications. Also lists some process } \\
\text { parameter specifications and guidance for additional } \\
\text { characterization. (2004-6) }\end{array}$ \\
\hline *AGR-2 Fuel Specification & *INL SPC-923 & $\begin{array}{l}\text { Provides acceptance criteria for AGR-2 fuel product. Lists } \\
\text { product parameter specifications. Also lists some process } \\
\text { parameter specifications. (2007) }\end{array}$ \\
\hline $\begin{array}{l}\text { *AGR-3 \& } 4 \text { Fuel Product } \\
\text { Specification }\end{array}$ & *INL EDF-6638 & $\begin{array}{l}\text { Provides acceptance criteria for AGR-3 and AGR-4 fuel } \\
\text { product. Lists product parameter specifications. Also lists } \\
\text { some process parameter specifications. (2006) }\end{array}$ \\
\hline $\begin{array}{l}\text { TRISO-Coated Particle Fuel } \\
\text { Phenomenon Identification and } \\
\text { Ranking Tables (PIRTs) for } \\
\text { Fission Product Transport Due to } \\
\text { Manufacturing, Operations, and } \\
\text { Accident }\end{array}$ & $\begin{array}{l}\text { NUREG/CR- } \\
6844\end{array}$ & $\begin{array}{l}\text { Discusses issues affecting fuel performance and lists } \\
\text { critical product parameters and their impact on fuel } \\
\text { performance. (2004) }\end{array}$ \\
\hline $\begin{array}{l}\text { Fabrication of the First-Loading } \\
\text { Fuel of the High Temperature } \\
\text { Engineering Test Reactor }\end{array}$ & $\begin{array}{l}\text { Jour. Nucl. Sci. } \\
\& \text { Tech. Vol. 36, } \\
\text { pp. } 683-690\end{array}$ & $\begin{array}{l}\text { Contains Japanese HTTR specifications for coated } \\
\text { particles and annular fuel compacts (1999) }\end{array}$ \\
\hline $\begin{array}{l}\text { Spherical Fuel Elements for } \\
\text { Advanced HTR Manufacture and } \\
\text { Qualification by Irradiation } \\
\text { Testing }\end{array}$ & $\begin{array}{l}\text { Jour. of Nucl. } \\
\text { Mater. Vol. 171, } \\
\text { pp. } 9-18\end{array}$ & Summary of fuel pebble work (1990) \\
\hline $\begin{array}{l}\text { Research and Development of Fuel } \\
\text { Element for Chinese } 10 \mathrm{MW} \text { High } \\
\text { Temperature Gas-cooled Reactor }\end{array}$ & $\begin{array}{l}\text { Jour. Nucl. Sci. } \\
\& \text { Tech. Vol. } 37 \text {, } \\
\text { pp. } 802-806\end{array}$ & $\begin{array}{l}\text { Contains Chinese HTR-10 specifications for coated } \\
\text { particles and spherical fuel elements. (2000) }\end{array}$ \\
\hline $\begin{array}{l}\text { Design and manufacture of the fuel } \\
\text { element for the } 10 \mathrm{MW} \text { high } \\
\text { temperature gas-cooled reactor }\end{array}$ & $\begin{array}{l}\text { Nucl. Eng. and } \\
\text { Design, } 218 \\
\text { (2002) } 91-102 \text {. }\end{array}$ & \\
\hline $\begin{array}{l}\text { Manufacture and characteristics of } \\
\text { spherical fuel elements for the } \\
\text { HTR-10 }\end{array}$ & $\begin{array}{l}\text { Nucl. Eng. and } \\
\text { Design, 236 } \\
\text { (2006) 643-647. }\end{array}$ & \\
\hline
\end{tabular}




\section{FUEL PRODUCT INSPECTION AND TESTING EQUIPMENT AND PROCEDURES}

A host of specialized inspection techniques, equipment, and procedures are required to evaluate TRISO coated particle fuels. Unlike LWR fuel where the pellets and tubing are inspected prior to assembly and then receive a post assembly inspection, TRISO coated particle fuel coatings are usually applied sequentially, one layer at a time, but in a continuous coating operation. This means the fuel form and coated particles must be taken apart to determine if the individual layers meet the specifications. The process is a complex one requiring the preparation of ceramographic mounts, removal of layers, leaching, burning carbon away, and handling small fragments. A large number of very small particles must be handled in an efficient and nonbiased way to ensure timely and accurate results.

Some of the apparatus used in CFP fuel are quite different than those used in LWR fuel and new techniques must be learned. While statistical methods are used in all fuel manufacturing, they are of particular importance in CFP fuel inspection and evaluation. This places a premium on high volume data collection. In addition, great care must be taken not to create artifacts and to minimize repeat efforts because of the significant amount of time it takes to collect and analyze the data.

\subsection{Analysis Methods for Important Fuel Product Parameters}

The following subsections contain tables of the critical product parameters as described in Section 2 for the fuel kernels, each coating layer, the final TRISO particles, and the final fuel form (pebble bed reactor spherical fuel elements "pebbles" or prismatic block reactor cylindrical fuel compacts). For each critical parameter, the common inspection method and equipment are listed. References to examples of written procedures from Table 3-10 are cited where available. Section 3.2 contains a description of the test equipment and analysis methods. 


\subsubsection{Kernel}

Table 3-1 lists the typical critical kernel parameters found in a TRISO coated particle fuel specification along with the corresponding analysis method(s) and equipment used to obtain the values for that parameter. References to examples of written procedures from Table 3-10 are cited where available.

\section{Table 3-1. Analysis Methods for critical kernel parameters}

\begin{tabular}{|l|l|l|}
\hline Critical Parameter & Typically Analysis Method and Equipment & Example Procedure - AGR-1 \\
\hline U-235 enrichment & $\begin{array}{l}\text { Acid dissolution and chemical analysis by } \\
\text { ICP-MS or equivalent }\end{array}$ & Standard chemical methods \\
\hline Kernel stoichiometry & $\begin{array}{l}\text { Combustion analysis using oxygen and } \\
\text { carbon analyzers combined with acid } \\
\text { dissolution analysis of uranium content }\end{array}$ & Standard chemical methods \\
\hline Impurity content & $\begin{array}{l}\text { Acid dissolution and analysis by ICP-MS or } \\
\text { equivalent }\end{array}$ & Standard chemical methods \\
\hline Kernel envelope density & $\begin{array}{l}\text { Measure weight/volume ratio using mercury } \\
\text { porosimeter }\end{array}$ & AGR-CHAR-DAM-15 \\
\hline Kernel shape & Shadowscopy using optical microscope & AGR-CHAR-DAM-06, DAM-09 \\
\hline Kernel diameter & Shadowscopy using optical microscope & AGR-CHAR-DAM-06, DAM-09 \\
\hline Kernel microstructure & $\begin{array}{l}\text { Examine cross-sections using optical } \\
\text { microscope or SEM }\end{array}$ & AGR-CHAR-DAM-13, DAM-14 \\
\hline
\end{tabular}

\subsubsection{Buffer Layer}

Table 3-2 lists the typical critical buffer parameters found in a TRISO coated particle fuel specification along with the corresponding analysis method(s) and equipment used to obtain the values for that parameter. References to examples of written procedures from Table 3-10 are cited where available.

Table 3-2. Analysis Methods for critical buffer parameters

\begin{tabular}{|l|l|l|}
\hline Critical Parameter & Typically Analysis Method and Equipment & Example Procedure - AGR-1 \\
\hline Buffer envelope density & $\begin{array}{l}\text { Measure weight/volume ratio using mercury } \\
\text { porosimeter }\end{array}$ & AGR-CHAR-DAM-15 \\
\hline Buffer shape & Not measured directly, see OPyC particle shape & \\
\hline Buffer thickness & Measure in cross-section using optical microscope & $\begin{array}{l}\text { AGR-CHAR-DAM-08, DAM- } \\
11, \text { DAM-14 }\end{array}$ \\
\hline Buffer microstructure & $\begin{array}{l}\text { Examine cross-sections using optical microscope } \\
\text { or SEM }\end{array}$ & AGR-CHAR-DAM-13, DAM-14 \\
\hline $\begin{array}{l}\text { Missing buffer defect } \\
\text { fraction }\end{array}$ & $\begin{array}{l}\text { Image whole particles with x-ray radiograph or } \\
\text { measure TRISO particle diameter }\end{array}$ & AGR-CHAR-DAM-07, DAM-10 \\
\hline
\end{tabular}




\subsubsection{IPyC Layer}

Table 3-3 lists the typical critical IPyC parameters found in a TRISO coated particle fuel specification along with the corresponding analysis method(s) and equipment used to obtain the values for that parameter. References to examples of written procedures from Table 3-10 are cited where available.

Table 3-3. Analysis Methods for critical IPyC parameters

\begin{tabular}{|l|l|l|}
\hline Critical Parameter & Typically Analysis Method and Equipment & Example Procedure - AGR-1 \\
\hline$I P y C$ density & Measure buoyancy using gradient density column & AGR-CHAR-DAM-03, DAM-05 \\
\hline IPyC anisotropy & $\begin{array}{l}\text { Measure optical diattenuation using ellipsometry } \\
\text { or measure by optical polarimetry }\end{array}$ & AGR-CHAR-DAM-12, DAM-18 \\
\hline IPyC thickness & $\begin{array}{l}\text { Measure in cross-section using optical } \\
\text { microscope }\end{array}$ & $\begin{array}{l}\text { AGR-CHAR-DAM-08, DAM-11, } \\
\text { DAM-14 }\end{array}$ \\
\hline$I P y C$ microstructure & $\begin{array}{l}\text { Examine cross-sections using optical microscope } \\
\text { or SEM }\end{array}$ & AGR-CHAR-DAM-13, DAM-14 \\
\hline$I P y C$ permeability & $\begin{array}{l}\text { Examine for uranium dispersion using x-ray } \\
\text { radiograph }\end{array}$ & AGR-CHAR-DAM-28 \\
\hline$I P y C$ open porosity & $\begin{array}{l}\text { Measure intrusion volume using mercury } \\
\text { porosimetry }\end{array}$ & AGR-CHAR-DAM-31 \\
\hline
\end{tabular}

Note 1: The IPyC density is typically specified in terms of the sink-float density. This is the density of a liquid medium, that when surrounding the material to be measured, results in zero buoyancy.

\subsubsection{SiC Layer}

Table 3-4 lists the typical critical SiC parameters found in a TRISO coated particle fuel specification along with the corresponding analysis method(s) and equipment used to obtain the values for that parameter. References to examples of written procedures from Table 3-10 are cited where available.

Table 3-4. Analysis Methods for critical SiC parameters

\begin{tabular}{|l|l|l|}
\hline Critical Parameter & Typically Analysis Method and Equipment & Example Procedure - AGR-1 \\
\hline SiC density & $\begin{array}{l}\text { Measure buoyancy using gradient density } \\
\text { column }\end{array}$ & AGR-CHAR-DAM-02, DAM-04 \\
\hline SiC thickness & $\begin{array}{l}\text { Measure in cross-section using optical } \\
\text { microscope }\end{array}$ & $\begin{array}{l}\text { AGR-CHAR-DAM-08, DAM-11, } \\
\text { DAM-14 }\end{array}$ \\
\hline SiC microstructure & $\begin{array}{l}\text { Examine cross-sections using optical microscope } \\
\text { or SEM }\end{array}$ & $\begin{array}{l}\text { AGR-CHAR-DAM-13, DAM-14, } \\
\text { DAM-23 }\end{array}$ \\
\hline SiC BL defect fraction & $\begin{array}{l}\text { Burn off exposed carbon and leach out uranium } \\
\text { from particles with SiC defects using nitric acid } \\
\text { reflux vessel }\end{array}$ & AGR-CHAR-DAM-21 \\
\hline $\begin{array}{l}\text { Soot inclusion defect } \\
\text { fraction }\end{array}$ & $\begin{array}{l}\text { Burn off OPyC layer and look for optical } \\
\text { evidence of inclusion or cross-section and } \\
\text { observe with optical microscope }\end{array}$ & AGR-CHAR-DAM-20 \\
\hline
\end{tabular}




\subsubsection{OPyC Layer}

Table 3-5 lists the typical critical OPyC parameters found in a TRISO coated particle fuel specification along with the corresponding analysis method(s) and equipment used to obtain the values for that parameter. References to examples of written procedures from Table 3-10 are cited where available.

\section{Table 3-5. Analysis Methods for critical OPyC parameters}

\begin{tabular}{|l|l|l|}
\hline Critical Parameter & Typically Analysis Method and Equipment & Example Procedure - AGR-1 \\
\hline OPyC density & $\begin{array}{l}\text { Measure buoyancy using gradient density } \\
\text { column }\end{array}$ & AGR-CHAR-DAM-03, DAM-05 \\
\hline OPyC anisotropy & $\begin{array}{l}\text { Measure optical diattenuation using } \\
\text { ellipsometry or measure by optical polarimetry }\end{array}$ & AGR-CHAR-DAM-12, DAM-18 \\
\hline OPyC thickness & $\begin{array}{l}\text { Measure in cross-section using optical } \\
\text { microscope }\end{array}$ & $\begin{array}{l}\text { AGR-CHAR-DAM-08, DAM-11, } \\
\text { DAM-14 }\end{array}$ \\
\hline Particle shape & Shadowscopy using optical microscope & AGR-CHAR-DAM-07, DAM-10 \\
\hline $\begin{array}{l}\text { Missing OPyC defect } \\
\text { fraction }\end{array}$ & Manual inspection using optical microscope & AGR-CHAR-DAM-19 \\
\hline OPyC microstructure & $\begin{array}{l}\text { Examine cross-sections using optical } \\
\text { microscope or SEM }\end{array}$ & AGR-CHAR-DAM-13, DAM-14 \\
\hline OPyC open porosity & $\begin{array}{l}\text { Measure intrusion volume using mercury } \\
\text { porosimetry }\end{array}$ & AGR-CHAR-DAM-31 \\
\hline
\end{tabular}

\subsubsection{Cylindrical Fuel Compact}

Table 3-6 lists the typical critical cylindrical compact parameters found in a TRISO coated particle fuel specification along with the corresponding analysis method(s) and equipment used to obtain the values for that parameter. References to examples of written procedures from Table 3-10 are cited where available.

Table 3-6. Analysis Methods for critical cylindrical compact parameters

\begin{tabular}{|l|l|l|}
\hline Critical Parameter & Typically Analysis Method and Equipment & $\begin{array}{l}\text { Example Procedure - } \\
\text { AGR-1 }\end{array}$ \\
\hline Compact diameter & Manually measure diameter using digital caliper & AGR-CHAR-DAM-24 \\
\hline Compact length & Manually measure using digital height gauge & AGR-CHAR-DAM-24 \\
\hline Uranium loading & $\begin{array}{l}\text { Expose kernels, acid leach and measure U by Davies- } \\
\text { Gray titration }\end{array}$ & AGR-CHAR-DAM-25 \\
\hline Impurity content & Acid leach and analyze by mass spectrometry & AGR-CHAR-DAM-26 \\
\hline Exposed Uranium & Acid leach and analyze by mass spectrometry & AGR-CHAR-DAM-26 \\
\hline Defective SiC & $\begin{array}{l}\text { Burn off exposed carbon and leach out uranium from } \\
\text { particles with SiC defects using nitric acid reflux vessel }\end{array}$ & AGR-CHAR-DAM-26 \\
\hline Defective IPyC & Examine for uranium dispersion using x-ray radiograph & AGR-CHAR-DAM-28 \\
\hline Defective OPyC & Deconsolidate compacts to recover particle and inspect & AGR-CHAR-DAM-27 \\
\hline Matrix density & Measure mass and volume of compact and particles & AGR-CHAR-DAM-24 \\
\hline Thermal conductivity & To be determined & Not formalized \\
\hline Crush strength & Determine load to failure & Not formalized \\
\hline Particle distribution & X-ray compact & Not formalized \\
\hline
\end{tabular}




\subsubsection{Spherical Fuel Element}

Table 3-7 lists the typical critical pebble fuel element parameters found in a TRISO coated particle fuel specification along with the corresponding analysis method(s) and equipment used to obtain the values for that parameter. In general, compact and spherical fuel elements have similar analysis methods, but mechanical integrity concerns are much more important for spheres because of the physical environment that this fuel form sees.

Table 3-7. Analysis Methods for critical pebble fuel element parameters

\begin{tabular}{|c|c|c|}
\hline Critical Parameter & Typically Analysis Method and Equipment & Example Procedure \\
\hline Outer diameter & Manually measure diameter & \multirow{15}{*}{$\begin{array}{l}\text { Detailed English language public } \\
\text { versions of these procedures are not } \\
\text { available. }\end{array}$} \\
\hline $\begin{array}{l}\text { Free fuel shell } \\
\text { thickness }\end{array}$ & $\mathrm{X}$ ray compact & \\
\hline Uranium loading & $\begin{array}{l}\text { Expose kernels, acid leach and measure U by } \\
\text { Davies-Gray titration }\end{array}$ & \\
\hline Impurity content & Acid leach and analyze by mass spectrometry & \\
\hline Exposed Uranium & Acid leach and analyze by mass spectrometry & \\
\hline Defective $\mathrm{SiC}$ & $\begin{array}{l}\text { Burn off exposed carbon and leach out uranium } \\
\text { from particles with SiC defects using nitric acid } \\
\text { reflux vessel }\end{array}$ & \\
\hline Defective IPyC & $\begin{array}{l}\text { Examine for uranium dispersion using x-ray } \\
\text { radiograph }\end{array}$ & \\
\hline Defective OPyC & $\begin{array}{l}\text { Deconsolidate compacts to recover particle and } \\
\text { inspect }\end{array}$ & \\
\hline Matrix density & $\begin{array}{l}\text { Measure mass and volume of compact and } \\
\text { particles }\end{array}$ & \\
\hline Thermal conductivity & TBD & \\
\hline Crush strength & Determine load to failure & \\
\hline Particle distribution & X-ray compact & \\
\hline Drop test & $\begin{array}{l}\text { Drop spherical compact from fixed height and } \\
\text { examine }\end{array}$ & \\
\hline Erosion rate & Tumbled 20 hours with 20 spheres & \\
\hline Corrosion rate & Exposure at $1000^{\circ} \mathrm{C}, \mathrm{He}+1 \mathrm{vol} \% \mathrm{H}_{2} \mathrm{O}$ & \\
\hline
\end{tabular}




\subsection{Description of HTGR Fuel Characterization Equipment and Operation}

Table 3-8 is a list of common analysis equipment used for coated particle fuel characterization and the critical product parameters measured by each device. The actual equipment used will depend on the specific fabrication and quality control methods. In the section following the table a description of the equipment and its use for particle analysis is detailed.

\section{Table 3-8. Fuel characterization equipment}

\begin{tabular}{|l|l|}
\hline Equipment & Critical parameters measured \\
\hline Analytical balances & Average particle weight \\
\hline Mercury porosimeter & Kernel envelope density \\
& Buffer envelope density \\
& IPyC open porosity \\
OPyC open porosity \\
\hline Liquid gradient density column & IPyC density \\
& SiC density \\
& OPyC density \\
\hline Optical microscope & Kernel and particle shape \\
& Kernel and particle diameter \\
& Kernel microstructure \\
& Buffer shape \\
& Layer thickness \\
& Coating microstructure \\
& Missing buffer defect fraction \\
& Missing OPyC defect fraction \\
& SiC soot inclusion defect fraction \\
& SiC grain size \\
\hline Optical ellipsometer & IPyC anisotropy \\
& OPyC anisotropy \\
\hline Scanning electron microscope & Kernel microstructure \\
& Coating microstructure \\
\hline X-ray radiography equipment & SiC grain size \\
\hline Electrolytic deconsolidation equipment & Missing buffer defect fraction \\
Burn-Leach equipment & IPyC permeability \\
Analytical chemistry equipment & Defective IPyC after compacting \\
& SiC BL defect fraction \\
& Uranium loading \\
& Impurity content \\
& Exposed Uranium \\
& Defective SiC after compacting \\
& Defective OPyC after compacting \\
\hline
\end{tabular}

\subsubsection{Analytical Balances and Average Particle Weight}

An analytical balance is a standard piece of equipment in any coated particle fuel characterization laboratory. These balances must be routinely calibrated and validated in order to satisfy Nuclear Control and Accountability requirements, as well as QA requirements for the measurements being performed. Particle and sample weights are needed as input for many of the characterization methods described below. The accuracy of the balance is often important in the determination of total uncertainty of these analyses. Typically, a balance accuracy in the $10^{-4} \mathrm{~g}$ range is required. 
Average particle weight is used to determine the number of particles in a large sample. This information is needed by many of the analysis methods in order to perform statistical calculations. Average particle weight is determined by weighing and counting several samples containing 100-200 particles each. Average particle weight is also needed for envelope density determination as described in Section 3.2.2.

\subsubsection{Mercury Porosimeter}

The mercury porosimeter is used to determine kernel and buffer density, as well as open porosity in the IPyC and OPyC layers. The mercury porosimeter is essentially a volume measurement device. A sample of a few thousand particles is placed in a penetrometer cell with mercury and the air is evacuated. Because mercury does not wet to the sample, the mercury will tend to surround the particles with void space between the particles. The volume not occupied by the mercury is the called the bulk volume. Pressure is applied on the mercury to cause it to surround the individual particles. At some point the majority of void space in between the particles is filled with mercury and under this condition the mercury essentially enshrouds each individual particle in the sample. The volume not occupied by the mercury at this pressure is the called the envelope volume. As pressure is increased beyond this point, the open pores at the particle surface are gradually filled, where the size of the penetrated opening is inversely related to the applied pressure. When all open porosity is filled, the volume not occupied by the mercury is the called the skeletal volume. The difference between the envelope volume and the skeletal volume is therefore the open pore volume. These various types of volume and density are defined in ASTM standard D3766.

The envelope density of a sample of kernels is simply the mass of the kernel sample divided by the envelope volume. Note that this method does not resolve envelope volume of an individual kernel, but rather gives an average value for the measured sample. Buffer envelope density is somewhat more complicated to determine because the buffer cannot be isolated. The porosimeter is used to measure the envelope volume of a sample of buffer-coated particles. The envelope volume of the kernels inside the buffer coated particles is then subtracted by various methods. The difference, being the envelope volume of the buffer, is then divided by the weight of the buffer to calculate the envelope density. The weight of the buffer also cannot be measured directly but has to be determined by the difference between the weight of the buffer-coated particles and the weight of the kernels inside. As for the kernel measurement, this analysis does not resolve the density of an individual buffer layer. In addition, because it is not feasible to separate the buffer from the IPyC layer in a fully coated particle, this analysis is not performed on the actual coated particle batch, but is instead performed on buffer-coated particles either removed during coating by hot sampling or obtained by interrupting the coating process. In some cases, as was done for AGR-1, the buffer density is measured on qualification batches and then process control is used to ensure that the buffer of the fully coated particles possesses the same properties.

Open porosity is calculated from the open pore volume of a sample divided by the surface area of that sample and typically reported in units of $\mathrm{ml} / \mathrm{m}^{2}$. Surface area is estimated from the approximate number of particles in the sample and the average diameter of the particles (with the assumption of a spherical shape). 


\subsubsection{Liquid Density Gradient Column}

A liquid density gradient column is used to determine sink-float density of the IPyC, $\mathrm{SiC}$, and OPyC layers. The sink-float density of a material lies in value between the envelope and skeletal densities discussed above. This is because the liquid in the column, which wets the samples, is able to partially penetrate the open porosity. A liquid density gradient column is created by filling a glass column with two liquids of different density, where the ratio of the two liquids is varied during filling in order to create a linear density as a function of the column height. This linear density gradient is determined by measuring the zero buoyancy position of calibrated floats. Different liquid density gradient columns with different density liquids are used to create columns for measuring pyrocarbon (range $1.8-2.0 \mathrm{~g} / \mathrm{cc}$ ) and $\mathrm{SiC}$ (range 3.19-3.21 g/cc). ASTM standard 1505 contains more information on the construction and operation of a liquid density gradient column.

Samples of the IPyC, $\mathrm{SiC}$, and OPyC layers are obtained by fracturing the coatings on individual coated particles. Pieces of free-standing OPyC layer fragments usually can be easily picked out of the fractured coatings because of the weak bonding between the $\mathrm{SiC}$ and $\mathrm{OPyC}$ layers. Freestanding IPyC layer fragments usually can not be obtained after deposition of the $\mathrm{SiC}$ because of the impregnation of $\mathrm{SiC}$ into the open porosity of the IPyC layer, which results in a strong interface bond. For this reason, IPyC density must be determined using hot sampling or interrupted batches, similar to buffer density analysis discussed above. Free-standing $\mathrm{SiC}$ is obtained by picking out multiple layer fragments and heating in air to about $850^{\circ} \mathrm{C}$ to remove the attached pyrocarbon. Care must be exercised to not excessively oxidize the $\mathrm{SiC}$ by heating at too high a temperature or for too long a time. About 50 layer fragments are placed in the appropriate liquid density gradient column. The sink-float density of the fragments is determined by measuring the zero buoyancy position in the column. The values of the measured set of fragments typically exhibit a near Gaussian distribution from which a mean and standard deviation can be calculated.

\subsubsection{Optical Microscope}

Optical microscopy is used to measure particle size and shape and coating thickness. It also is important as a general tool for microstructural analysis and optical inspection for various defects. A standard analytical optical microscope with objective lenses ranging from $5 \mathrm{x}$ to $50 \mathrm{x}$ is typically sufficient. Availability of lower or higher magnification objective may also be useful for some analyses. Both transmitted and reflected illumination is used with darkfield; diffraction contrast and polarization being useful options. In some cases, a dedicated measurement device using the same principles as a standard analytical microscope may be used for certain analyses, such as size and shape.

Particle size and shape are typically measured using a shadow-graphic technique. Transmitted light is used to produce silhouettes of the particles. Analysis of these images produces information on mean particle diameter and aspect ratio. The definition for both these values implicitly assumes a near spherical particle shape. If this assumption is not valid, erroneous conclusions could be drawn about the particle quality. Aspect ratio is defined as the maximum diameter divided by the minimum diameter. This definition is based on an assumption of an oblate spheroid shape (elliptical silhouette). Most aspherical particles exhibit faceting rather than uniform ellipticity. Minor faceting can be scaled with aspect ratio but erroneous conclusions can 
be drawn in the case of multiple faceting in certain geometries. Figure 3-1 shows a cross-section illustrating the deviation from roundness and some computer drawn metrics.

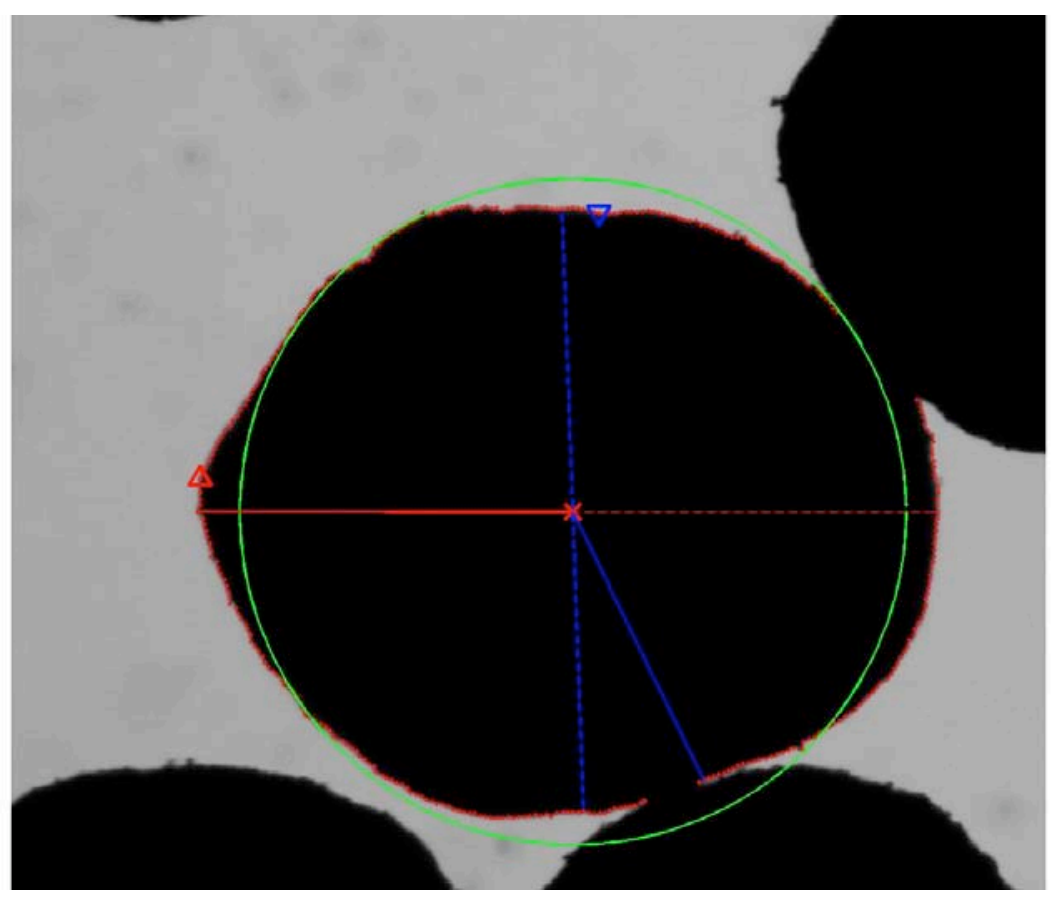

Figure 3-1. Shadowgraph of a kernel showing its deviation from a perfect circle.

Dedicated particle size analyzers have also been used to obtain size and shape information. There are two types that can be applied to coated particle fuel. The first operates on the same principles as the optical microscope to generate shadow images from which size and shape information is extracted. The second uses obscuration of a line laser to determine maximum diameter. This approach is not as accurate as the shadowgraph approach but can be useful if particles are sampled using multiple passes. Throughput for the laser obscuration system is also usually greater. A third commercially available particle size analysis method uses laser diffraction. This method does not generate measurements on individual particles and is not appropriate for this application.

Coating thickness is measured by preparing polished cross-sections and imaging with reflected light. Samples are prepared by arranging a number of particles in a plane and then mounting them in epoxy. The mounted particles are then ground down and polished to expose a mid-plane cross-section. These cross-sections rarely present a planar section that passes exactly through the center of the particle. This results in an imaged layer thickness that is greater than the thickness along the radial direction of the particle. The magnitude of the error can be minimized by polishing the particles as close to the mid-plane as possible. However, care should be taken to correct for imaging off-midplane. Simple geometric corrections are possible by determining the offset of the imaged plane.

Quantified analysis of images obtained for size and shape or coating thickness is best done using modern computerized image analysis techniques. Manual measurements can introduce error from operator bias and tend to be more limited because of the required effort. Automated image analysis allows for both more samples to be analyzed and for more measurements to be made on each imaged sample. 
Optical microscopes are also used for inspection of coated particle fuel for a variety of possible defects. These inspections are often performed with a stereoscope, as opposed to the analytical microscope described above. The stereoscope provides a different viewing angle for each eye, which allows for better depth perception. Stereoscope optics also typically provide a lower range of magnification, which equates to a larger field of view, greater depth of focus, and longer working distance. Missing OPyC layer defect fraction is determined by simple manual inspection of the surface of the coated particles. As many as 100,000 particles may need to be inspected, depending on the specified allowable defect fraction (see Section 7).

Fluidization anomalies during SiC layer deposition sometimes result in particles being ejected from the main coating bed. These particles can collide with the coater walls where they can pick up either carbon or low density $\mathrm{SiC}$ soot. Subsequent coating of this soot results in a lenticular shaped inclusion that weakens the $\mathrm{SiC}$ layer. These inclusions can be imaged by preparing crosssections similar to those used for coating thickness measurements. However, the number of particles that must be analyzed is again in the tens of thousands. Another method that has been used in the past is the "gold spot" analysis method. This method takes advantage of the fact that light scattered from a buried inclusion produces an optical manifestation when viewed at the $\mathrm{SiC}$ surface. Particles are heated in air at $850^{\circ} \mathrm{C}$ to "burn back" the OPyC layer and expose the SiC surface. Oblique illumination of the $\mathrm{SiC}$ layer surface will cause a spot to appear at the surface (sometimes gold in color). One drawback of the gold spot analysis method is that fine grained $\mathrm{SiC}$ produces too much optical scatter to allow soot inclusions to optically manifest unless they are very near the surface. For fine grained $\mathrm{SiC}$, which is the desired microstructure for the $\mathrm{SiC}$ layer, gold spot analysis should not be used to determine soot inclusion defect fraction.

Finally, compacts or pebbles can be cross-sectioned to examine their general structure and search for matrix and compacting defects. An example of a cylindrical compact with a broken particle is shown in Figure 3-2.

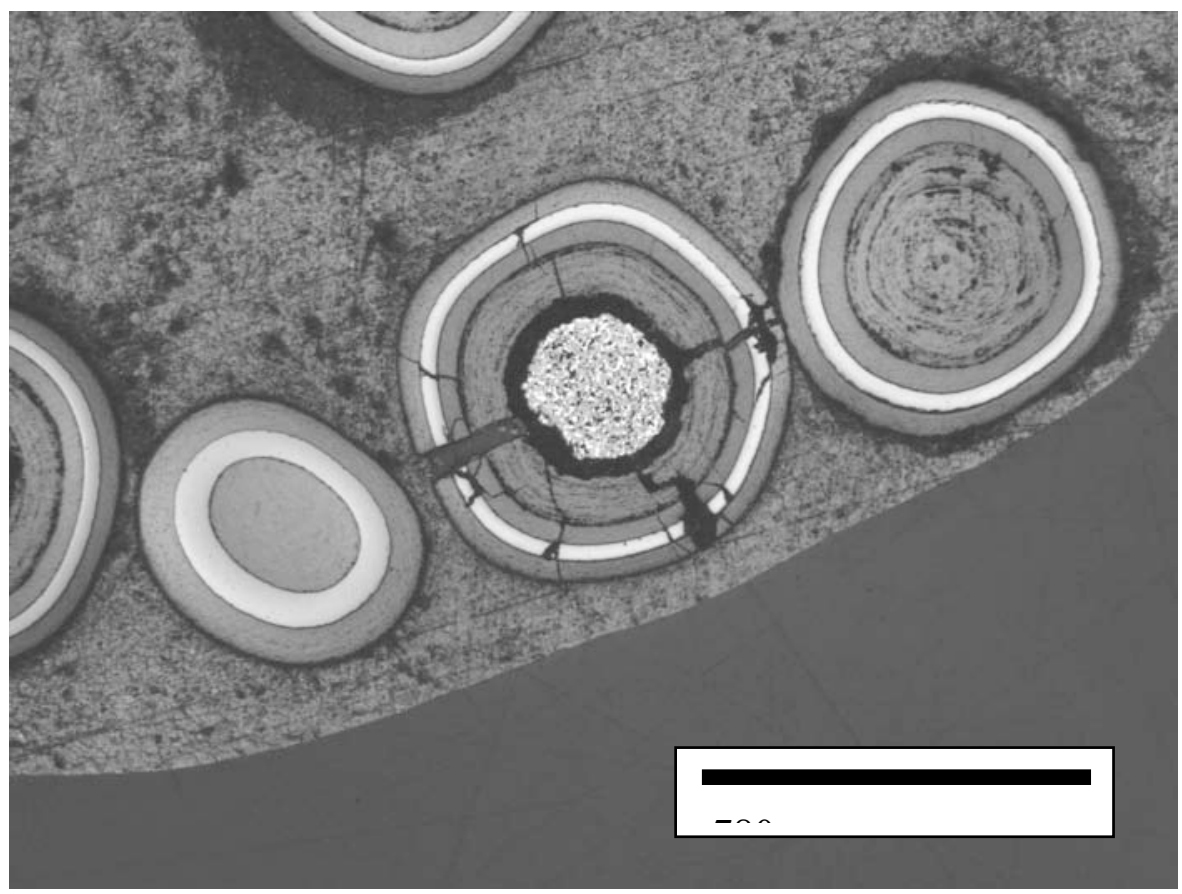

Figure 3-2. Mounted and polished compact cross-section showing a broken particle. 


\subsubsection{Optical Ellipsometer}

Structural stability of pyrolytic carbon under irradiation is sensitive to the degree of preferred orientation of the carbon basal planes. The preferred orientation in pyrolytic carbon can be determined by x-ray diffraction or one of several optical techniques, where the optical anisotropy of the carbon basal planes produces a net macroscopic optical anisotropy in non-isotropic pyrolytic carbon. For measurement on actual TRISO coated fuel particle coatings, the sample geometry does not lend itself to x-ray diffraction and optical methods are preferred. Traditional polarimetry methods originally developed for this purpose had several inherent issues, such as polarization effects in the optical components of the instrument that introduced significant systematic and stochastic errors in the measurement. For this reason, an advanced ellipsometry approach was developed at Oak Ridge National Laboratory. The ORNL Two-Modulator Generalized Ellipsometry Microscope (2-MGEM) was designed to determine pyrocarbon anisotropy at much greater accuracy and sensitivity than can be achieved with an optical polarimeter. This instrument (Figure 3-3) fully determines the change in the elliptical polarization of light when reflected from a pyrocarbon surface by measuring all the elements of the Mueller matrix. From this matrix, the diattenuation, which is directly related to the optical anisotropy, can be determined. Sample preparation is similar to that used for coating thickness to expose a mid-plane cross-section for analysis.

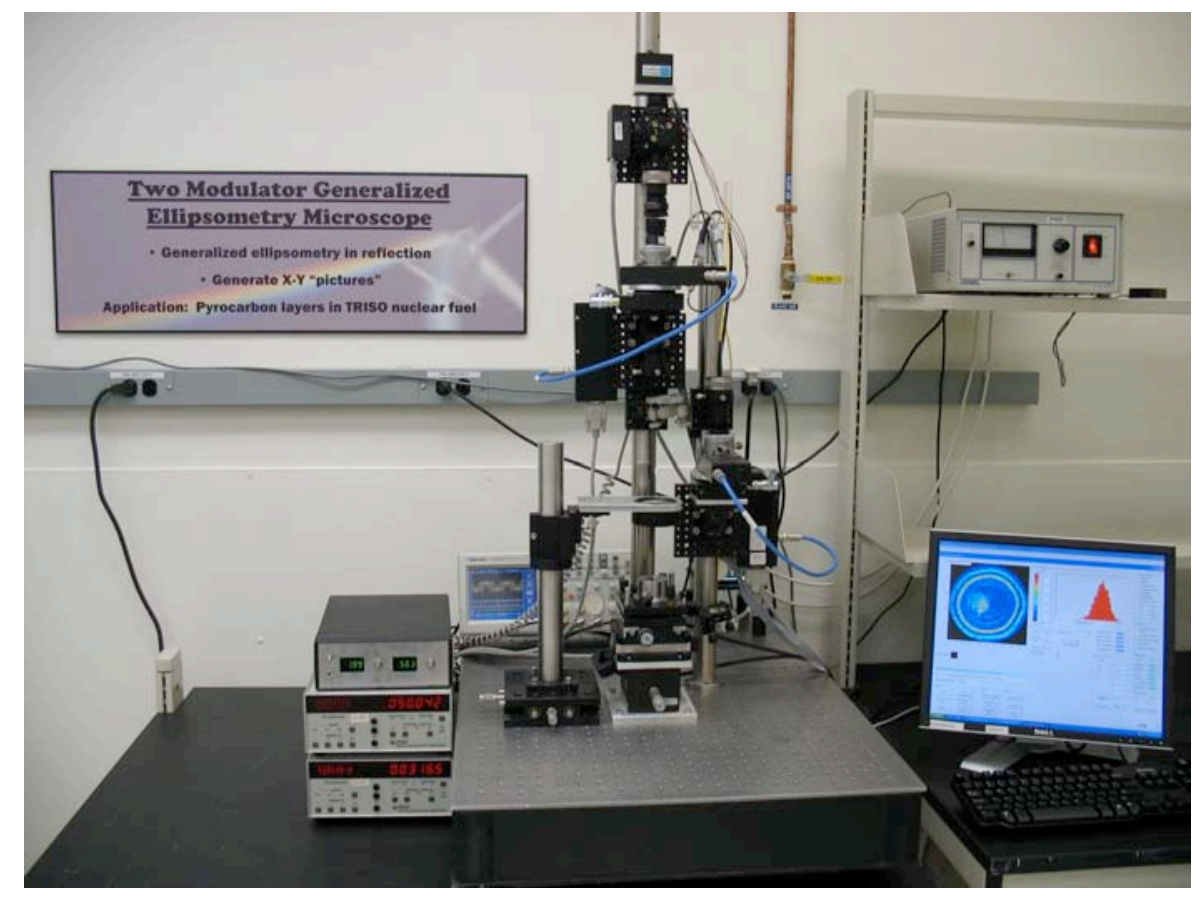

Figure 3-3. ORNL Two-Modulator Generalized Ellipsometry Microscope (2-MGEM).

Several units of anisotropy are in use. The Bacon anisotropy factor (BAF) is defined based on an $\mathrm{x}$-ray measurement technique. BAF is a direct measure of the crystallographic anisotropy. The optical anisotropy factor $\left(\mathrm{OAF}, \mathrm{OPTAF}, \mathrm{or}_{\mathrm{BAF}}\right.$ ) is related to the $\mathrm{BAF}$, but not necessarily a direct equivalence. The basic unit of anisotropy is the diattenuation $(\mathrm{N})$. This is related to the $\mathrm{OAF}$ by the equation, $\mathrm{OAF}=(1+\mathrm{N}) /(1-\mathrm{N})$. 


\subsubsection{Scanning Electron Microscope}

The scanning electron microscope is another standard tool for characterization of coated particles. In many cases, it offers enhanced microstructural analysis beyond the capability of the optical microscope. In addition, elemental analysis is possible by using energy dispersive spectroscopy (EDS). EDS can be useful for distinguishing uranium carbide and uranium dioxide phases in the kernel, detecting uranium dispersion outside of the kernel, or identifying impurities. For example, Figure 3-4 shows elemental maps of a UCO kernel produced by scanning a surface region of a polished cross-section and performing EDS at each spot. Brighter areas in each map correspond to a higher concentration of that element. Backscattered electron imaging can take advantage of the variation in electron stopping power with grain orientation to image the individual $\mathrm{SiC}$ grains for grain size determination (Figure 3-5). This method is preferable over using an optical microscope because acid etching is not required.

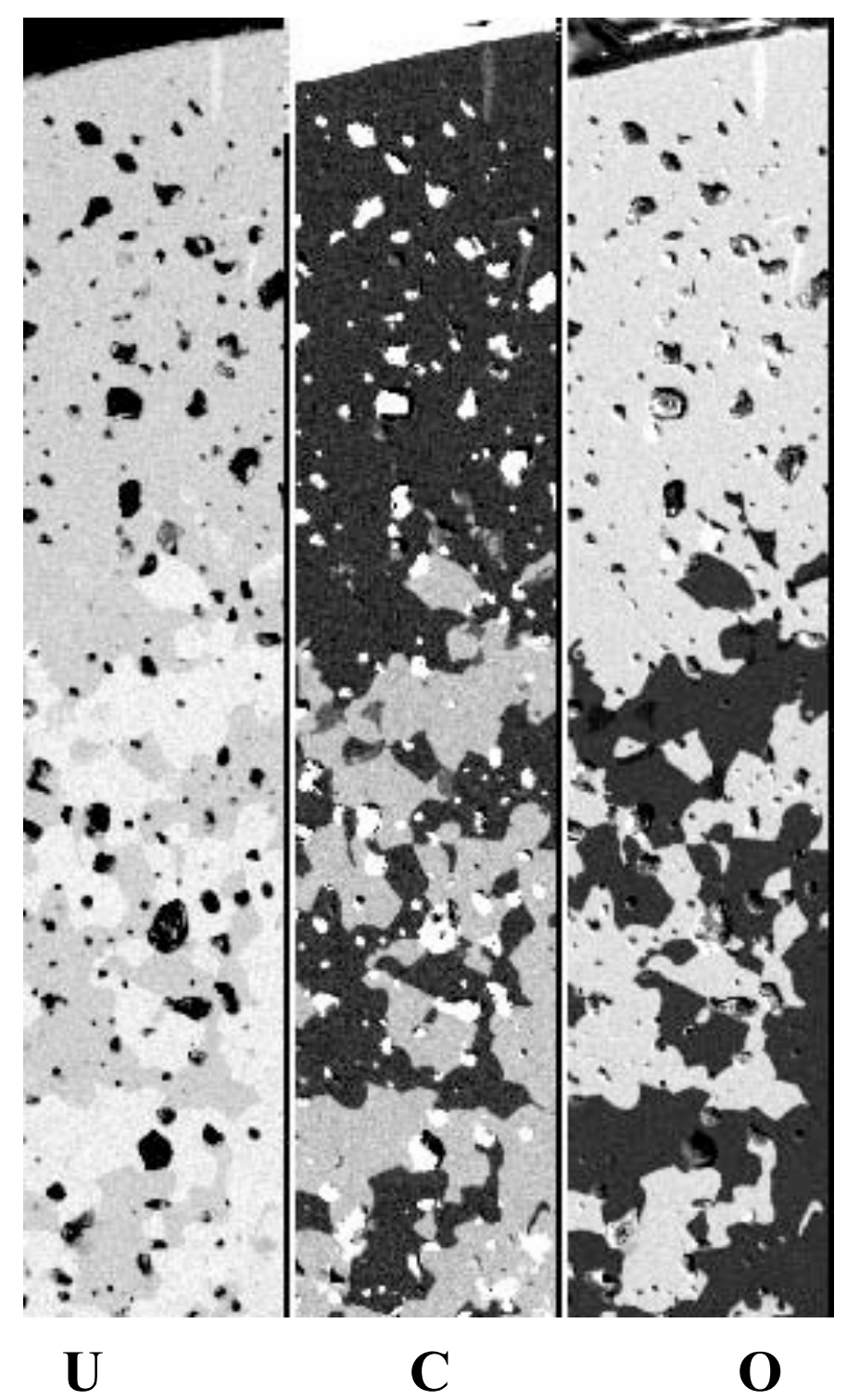

Figure 3-4. Elemental map of UCO kernel using EDS. 


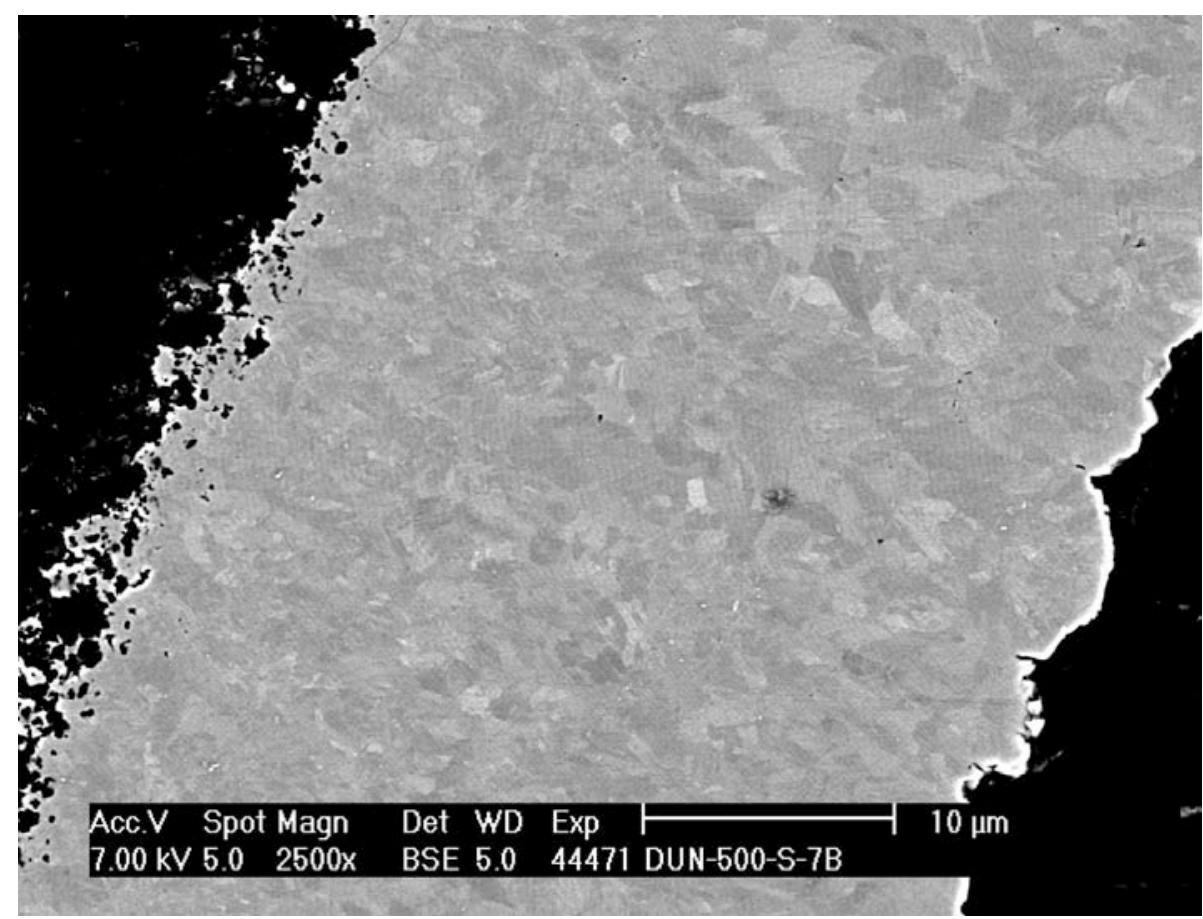

Figure 3-5. Backscattered electron image of SiC grain structure.

\subsubsection{X-ray Radiography Equipment}

X-ray radiography is a powerful non-destructive analysis tool that is often applied to characterize coated particle fuel. X-ray imaging systems vary from inexpensive low resolution film systems to expensive high resolution digital imaging with capabilities for tomographic 3-D reconstruction. X-ray imaging allows the interior microstructure of a coated particle to be viewed without the need for material-o-graphic cross-sectioning. Apart from the obvious advantage in effort, additional advantages are that the defect microstructure is not altered by the grinding and polishing operation and it is possible to image the entire particle (as opposed to just a single cross-section plane). X-ray energy and exposure are chosen so as to optimize the imaging of the layers. X-rays do not penetrate the high density kernel, so no information of kernel microstructure can be obtained by this technique. Resolution of the carbon microstructure is also limited because of the low x-ray density of those layers. However layer interfaces and cracks can be imaged quite well.

X-ray imaging offers a reasonable alternative to optical microscopy for imaging coating thickness. Although x-ray imaging systems of equivalent resolution are expensive when compared to an optical microscope, this cost is somewhat offset by the fact that material-ographic preparation of polished cross-sections is not necessary. X-ray imaging is also useful to perform rapid scanning of particle samples for missing coating layers.

In addition, uranium dispersion out of the kernel and into the buffer/IPyC layers can be detected in X-ray radiographs. Typically, uranium pile-up at the buffer/IPyC interface is looked for as a band of increased X-ray absorption in the area. This uranium dispersion, presumably due to $\mathrm{HCl}$ intrusion through the inner pyrocarbon during SiC coating, is analyzed for after compacting and indicates defective IPyC due to excessive permeability. 


\subsubsection{Acid Dissolution Equipment}

Heavy metal loading in the compacts is determined by burning off the carbon matrix and outer pyrocarbon by heating from $750-950^{\circ} \mathrm{C}$ in air, fracturing the $\mathrm{SiC}$ coating using a Spex mill or equivalent, again burning off exposed carbon and oxidizing the heavy metal in the kernel, and then performing the acid leach.

\subsubsection{Leach-Burn-Leach Equipment}

Many critical compact parameters are determined by a comprehensive analysis process called Leach-Burn-Leach. A nitric acid reflux apparatus is used to leach out and dissolve exposed heavy metals as well as metallic impurities. This equipment usually consists of a heated flask containing nitric acid and a water cooled condenser to condense the acid vapor for return to the heated flask. The material being analyzed can reside in the heated flask or in an intermediate extraction vessel (e.g., Soxhlet Extractor). After sufficient time has been allowed for the nitric acid to dissolve the exposed metals, the liquid is analyzed by various analytical chemistry methods to determine the total amount in solution. Suitable analytical chemistry methods include, but are not limited to, various type of spectroscopy, such as inductively coupled plasma mass spectroscopy (ICP-MS) or ICP-atomic emission spectroscopy (ICP-AES).

This leaching is performed before and after removal of the pyrocarbon layers by burning off the carbon in an oxygen environment above $750^{\circ} \mathrm{C}$. The purpose of the burn is to remove all exposed carbon. If a $\mathrm{SiC}$ layer exhibits a through-layer defect (which could result in fission product release), then the IPyC and buffer layers will be removed during the burn. This allows the acid leach to dissolve the uranium in the kernel. Quantification of the number of kernels indicated by the dissolved uranium in the leachant yields the $\mathrm{SiC}$ layer burn-leach defect fraction.

Prior to the Burn-Leach described above, compacts or pebbles are deconsolidated by electrolytic decomposition in nitric acid. In this process, the compact matrix is preferentially attacked, resulting in the destruction of the compact integrity and recovery of the TRISO coated particles with the OPyC layer still intact. This allows for the manual inspection of the particles to determine $\mathrm{OPyC}$ layer defect fraction as a result of the compacting process. Further leaching of the deconsolidated particle/matrix residue prior to the burn also provides values for the amount of exposed uranium and other impurities.

The deconsolidation apparatus is composed of a container of nitric acid, a means of holding the compact or pebble in the acid so that the released particles can fall free, and a power supply. An illustration is shown in Figure 3-6.

An alternative to this process is to skip the first leach and do only the burn leach steps. Depending on the fuel form and quality control structure, this two step process may provide sufficient data at a saving in time and waste. This process is more typical of the German approach. 

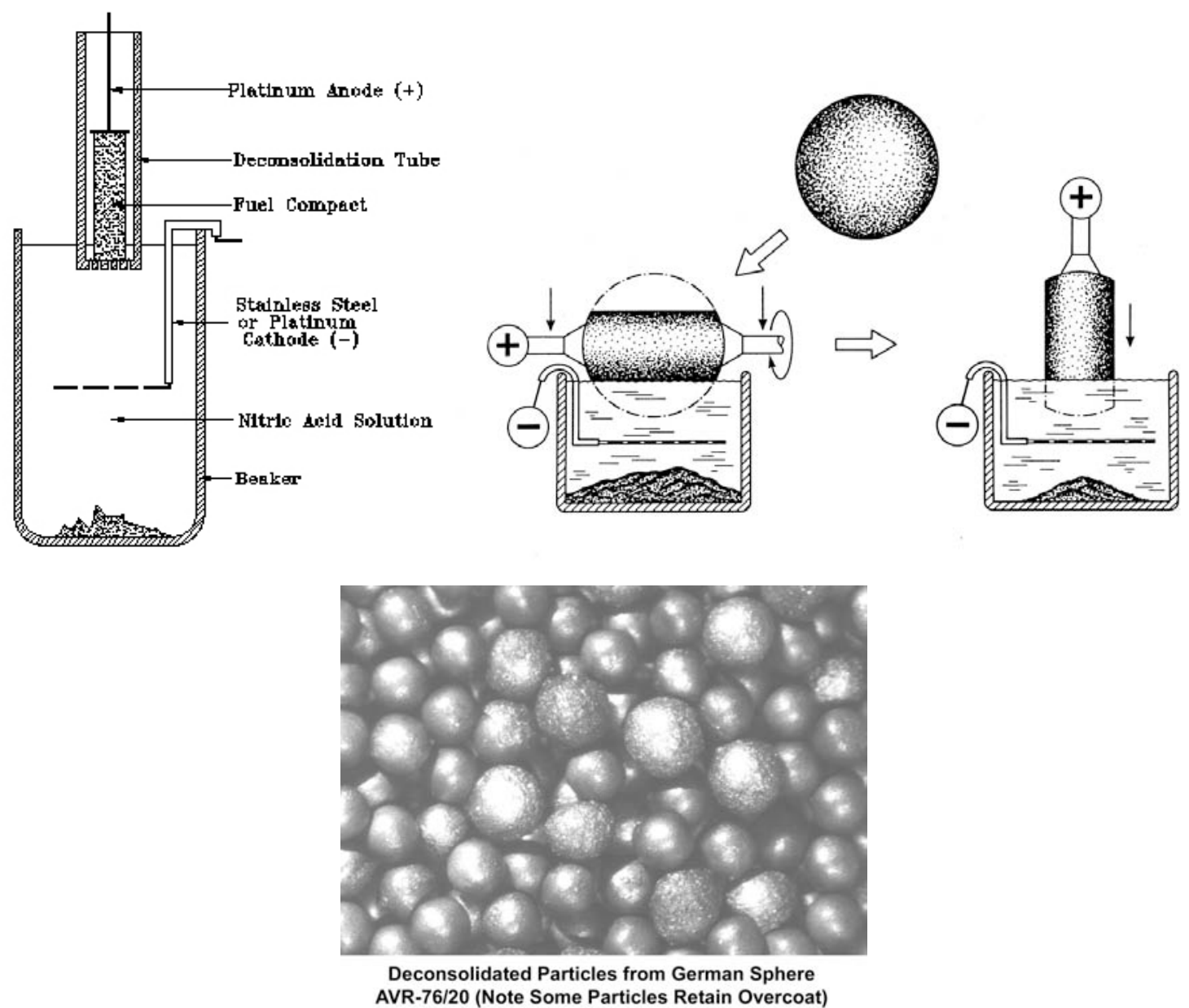

Figure 3-6. Deconsolidation apparatus for compacts and pebbles.

The total uranium loading in a compact can be determined by intentionally destroying the $\mathrm{SiC}$ layer using a Spex mill (similar to a ball mill, but higher energy) and then repeating the burnleach described above. Because of the higher uranium content, analysis is performed using Davies-Grey titration (or equivalent) as opposed to using a mass spectrometry method, which is more suitable for measuring trace impurity concentrations.

Typically, one first deconsolidates a compact or pebble, filters the particles and debris from the solution, and then analyzes the solution for impurities and uranium. The particles are then burned to remove the OPyC and then leached again. This second leachant is then analyzed for impurities and uranium. Finally a portion of the particles are then milled, burned, and leached to determine the uranium loading.

\subsection{Reference Documents}

Information in Section 3 has been summarized from the documents listed in Table 3-9. For more detailed information, the reader should consult those documents. Table 3-10 contains a list of Data Acquisition Methods (DAMs) used as analysis procedures for the inspection of the AGR-1 test fuel. 
Certain documents listed below are for official internal NRC use only and their distribution is restricted to NRC unless approved by both NRC and DOE. These documents are labeled with an asterisk $\left(^{*}\right)$.

Table 3-9. List of reference documents.

\begin{tabular}{|l|l|l|}
\hline Document Title & Reference & Description \\
\hline $\begin{array}{l}\text { Standard Test Method for Density } \\
\text { of Plastics by the Density- } \\
\text { Gradient Technique }\end{array}$ & ASTM D1505-98 & $\begin{array}{l}\text { Example of construction and operation of a liquid } \\
\text { gradient density column }\end{array}$ \\
\hline $\begin{array}{l}\text { Standard Terminology Relating to } \\
\text { Catalysts and Catalysis1 }\end{array}$ & ASTM D3766-86 & ASTM standard definition of density and porosity \\
\hline $\begin{array}{l}\text { Optical anisotropy measurements } \\
\text { of TRISO nuclear fuel particle } \\
\text { cross-sections: the method }\end{array}$ & $\begin{array}{l}\text { J. Nucl. Mater. 372 } \\
(2008) 36-44\end{array}$ & $\begin{array}{l}\text { This paper describes a Two-Modulator Generalized } \\
\text { Ellipsometry Microscope (2-MGEM) which is used } \\
\text { for measuring the pyrocarbon anisotropy }\end{array}$ \\
\hline $\begin{array}{l}\text { EBSD for microstructure and } \\
\text { property characterization of the } \\
\text { SiC coating in TRISO fuel } \\
\text { particles }\end{array}$ & $\begin{array}{l}\text { J. Nucl. Mater. 372 } \\
(2008) \text { 400-404 }\end{array}$ & $\begin{array}{l}\text { This paper describes the use of Electron Backscatter } \\
\text { Diffraction for analysis of SiC }\end{array}$ \\
\hline $\begin{array}{l}\text { Automatic characterization of } \\
\text { cross-sectional coated particle } \\
\text { nuclear fuel using greedy coupled } \\
\text { Bayesian snakes }\end{array}$ & $\begin{array}{l}\text { Proceedings of } \\
\text { Machine Vision } \\
\text { Applications in } \\
\text { Industrial } \\
\text { Inspection XV, Jan. } \\
\text { 28, 2007 }\end{array}$ & $\begin{array}{l}\text { This paper describes the use of computer automated } \\
\text { microscopy and advanced image analysis for } \\
\text { measurement of coating thickness, particle size and } \\
\text { particle shape }\end{array}$ \\
\hline HTGR Fuel Rod Deconsolidation & ORNL/TM-6426 & $\begin{array}{l}\text { This report describes a fuel rod deconsolidation } \\
\text { apparatus and its operation. }\end{array}$ \\
\hline
\end{tabular}


Table 3-10. List of AGR-1 Data Acquisition Methods

\begin{tabular}{|c|c|}
\hline Reference & Document Title \\
\hline *AGR-CHAR-DAM-02 & *Measurement of $\mathrm{SiC}$ Density using a Density Gradient Column \\
\hline *AGR-CHAR-DAM-03 & *Measurement of PyC Density using a Density Gradient Column \\
\hline *AGR-CHAR-DAM-04 & $\begin{array}{l}\text { *Preparation of Liquid Density Gradient Column for Measurement of SiC } \\
\text { Density }\end{array}$ \\
\hline *AGR-CHAR-DAM-05 & $\begin{array}{l}\text { *Preparation of Liquid Density Gradient Column for Measurement of PyC } \\
\text { Density }\end{array}$ \\
\hline *AGR-CHAR-DAM-06 & $\begin{array}{l}\text { *Imaging of Kernel Diameter and Ellipticity Using an Optical Microscope } \\
\text { System }\end{array}$ \\
\hline *AGR-CHAR-DAM-07 & $\begin{array}{l}\text { *Imaging of Coated Particle Diameter and Aspect Ratio Using an Optical } \\
\text { Microscope System }\end{array}$ \\
\hline *AGR-CHAR-DAM-08 & *Imaging of Coating Layer Thickness Using an Optical Microscope System \\
\hline *AGR-CHAR-DAM-09 & *Measurement of Kernel Diameter and Ellipticity Using Image Analysis \\
\hline *AGR-CHAR-DAM-10 & $\begin{array}{l}\text { *Measurement of Coated Particle Diameter and Aspect Ratio Using Image } \\
\text { Analysis }\end{array}$ \\
\hline *AGR-CHAR-DAM-11 & $\begin{array}{l}* \text { Measurement of Coating Layer Thickness Using an Optical Microscope } \\
\text { System }\end{array}$ \\
\hline *AGR-CHAR-DAM-12 & $\begin{array}{l}\text { *Preparation of Polished Coated Particle Cross-sections for Measurement of } \\
\text { Anisotropy }\end{array}$ \\
\hline *AGR-CHAR-DAM-13 & *Preparation of Coated Particle Polished Cross-sections for SEM \\
\hline *AGR-CHAR-DAM-14 & *Preparation of Polished Coated Particle Cross-sections for Optical Imaging \\
\hline *AGR-CHAR-DAM-15 & $\begin{array}{l}\text { *Measurement of Average Kernel Envelope Density using a Mercury } \\
\text { Porosimeter }\end{array}$ \\
\hline *AGR-CHAR-DAM-16 & *Measurement of Buffer Envelope Density using a Mercury Porosimeter \\
\hline *AGR-CHAR-DAM-17 & *Preparation of Random Samples of Particles by Rotary Riffling \\
\hline *AGR-CHAR-DAM-18 & *Measurement of Pyrocarbon Anisotropy \\
\hline *AGR-CHAR-DAM-19 & ${ }^{*}$ Counting of Particles with Missing OPyC Layer by Visual Inspection \\
\hline *AGR-CHAR-DAM-20 & ${ }^{*}$ Counting of Particles with SiC Gold Spot Defects by Visual Inspection \\
\hline *AGR-CHAR-DAM-21 & *Measurement of Number of Particles with SiC Burn-Leach Defects \\
\hline *AGR-CHAR-DAM-22 & *Estimation of Average Particle Weight \\
\hline *AGR-CHAR-DAM-23 & *Imaging of $\mathrm{SiC}$ grain structure \\
\hline *AGR-CHAR-DAM-24 & *Inspection of Compact Diameter and Length \\
\hline *AGR-CHAR-DAM-25 & *Measurement of Fuel Compact Mean Uranium Loading \\
\hline *AGR-CHAR-DAM-26 & $\begin{array}{l}* \text { Measurement of U Contamination, Defective SiC Coating Fraction, and } \\
\text { Impurities in Fuel Compacts by the LBL Method }\end{array}$ \\
\hline *AGR-CHAR-DAM-27 & $\begin{array}{l}\text { *Counting of Particles with Missing or Defective OPyC Layers from } \\
\text { Deconsolidated Compacts by Visual Inspection }\end{array}$ \\
\hline *AGR-CHAR-DAM-28 & ${ }^{*}$ Counting of Particles with Excessive Uranium Dispersion Inside SiC \\
\hline *AGR-CHAR-DAM-29 & $\begin{array}{l}\text { *Imaging of Over-coated Particle Diameter and Aspect Ratio Using an } \\
\text { Optical Microscope System }\end{array}$ \\
\hline *AGR-CHAR-DAM-30 & $\begin{array}{l}\text { *Measurement of Over-coated Particle Diameter and Aspect Ratio Using } \\
\text { Image Analysis }\end{array}$ \\
\hline *AGR-CHAR-DAM-31 & *Measurement of Open Porosity using a Mercury Porosimeter \\
\hline
\end{tabular}




\section{CRITICAL PROCESS EQUIPMENT AND PROCESS PARAMETERS FOR FUEL QUALITY AND PERFORMANCE}

At the present time, the irradiation performance of CFP fuel has not been completely correlated with the measured parameters; knowledge of the fuel fabrication history is also necessary to assure adequate performance. This is not a desirable state of affairs as third party verification of the fuel quality is not possible and the NRC is dependent on the fuel vendor for fabrication history. Thus, the NRC could be forced into a vendor surveillance program. Whether or not fuel performance can ultimately be connected with measurable fuel parameters, the following sections outline important process drivers that affect fuel quality.

\subsection{Description of Fuel Process Equipment and Operation}

TRISO coated particle fuel fabrication is much more complex than LWR fuel fabrication. The fabrication process begins with a solution containing the uranium, which is then gelled into spheres, dried, sintered into hard dense kernels, coated with layers of carbon and $\mathrm{SiC}$, and finally bound into a fuel form. The fuel form is then baked and treated at high temperature. Each step needs to be monitored and held within the specified tolerances. Since fuel performance cannot be predicted solely by final measured fuel product parameters, each step must be documented in a manner that can be reviewed and stored for the long term.

\subsubsection{Kernel Manufacturing Equipment}

The kernel is usually made by an ammonia-based gel-precipitation process, referred to as either "internal" or "external" gelation. In the past, the external gelation method has been used for the pebble fuel kernels and the internal gelation method is favored for the prismatic block fuel kernels. The actual choice of method depends on a variety of factors beyond this discussion such as manufacturing ease and waste handling. The principal issues are solution composition and process control.; the internal gelation process modifies the broth and eliminates the ammonia in the drop columns and replaces it with an immiscible warmed fluid.

Figure 4-1 shows an internal gelation process used to make laboratory-scale quantities of uranium dioxide kernel microspheres. Briefly, for internal gelation, uranium oxide is dissolved in nitric acid and mixed with urea to form acid-deficient uranyl nitrate (ADUN) Carbon powder is added for a UCO kernels. The mixture is then chilled and mixed with hexamethylene (HMTA) to form a broth. This broth is only stable at low temperatures $\left(\sim 0^{\circ} \mathrm{C}\right)$ and is kept chilled in a pot. The broth is then pulsed through needle orifices to form droplets that fall into a heated column of an immiscible liquid (in this case silicone oil at $60^{\circ} \mathrm{C}$ ). The rise in temperature causes internal ammonia production and the droplet to gel. The resulting $\mathrm{UO}_{3} \cdot 2 \mathrm{H}_{2} \mathrm{O}$ spheres sink to the bottom of the column, pass through a serpentine tube to a collector. and are removed after a specified period of time. This aging process impacts the crystal size and slow pour density of the gel spheres. The average diameter of the wet gel spheres is measured with an optical microscope and process knowledge is used to estimate the final diameter of the uranium kernels. Adjustments can be made to the droplet forming process (e.g., orifice size, flow rate, and frequency of needle vibration). The spheres are washed in ammonium hydroxide to remove ammonium nitrate, HMTA, and urea, and then dried. The slow pour density of the air-dried microspheres is measured. If the density is too low, the spheres will like suffer surface erosion and create 
unwanted uranium powder. If the density is too high, then flaking or cracking can be expected during sintering.

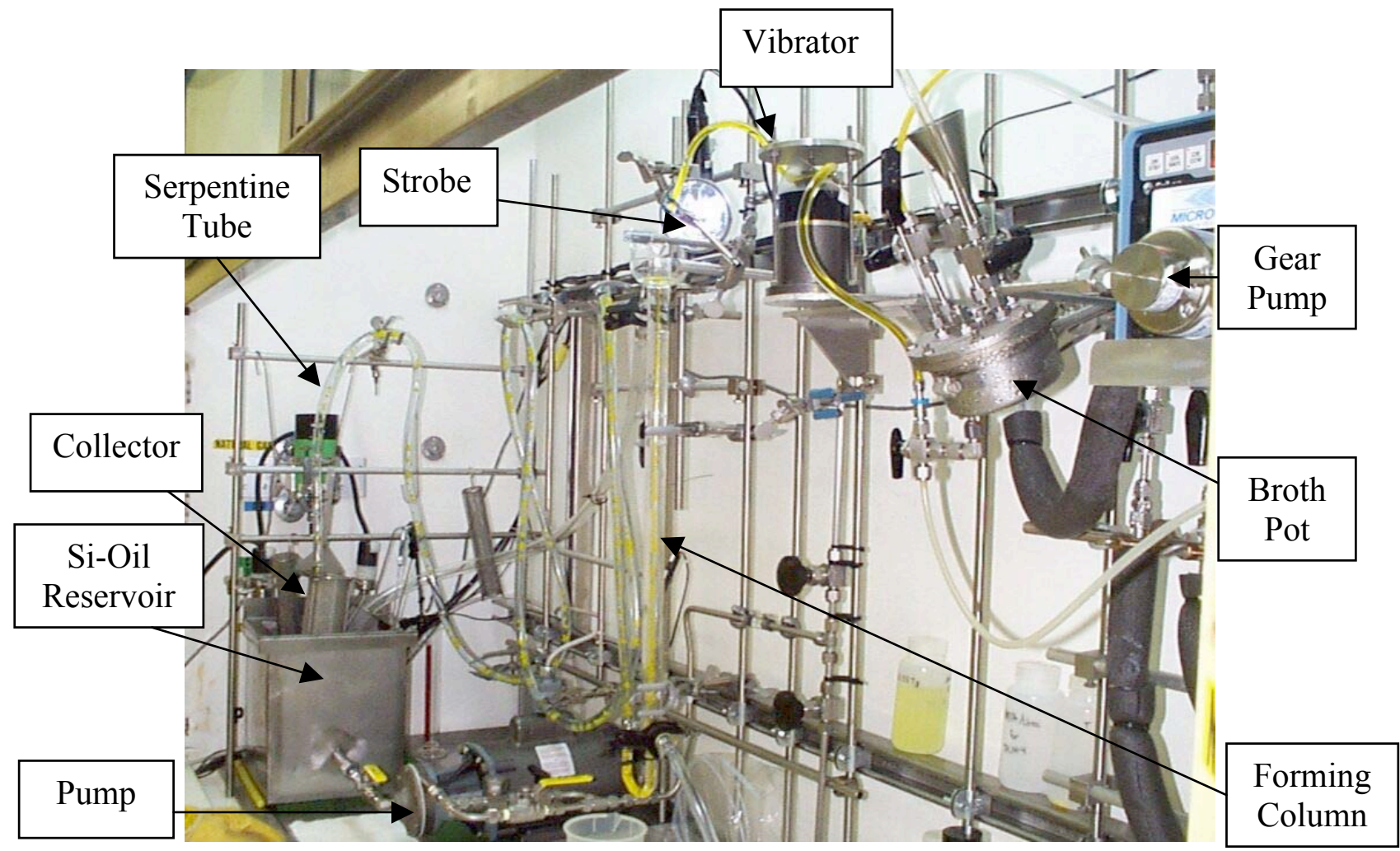

Figure 4-1. Laboratory-scale equipment for converting chilled broth into uniform gel spheres.

An external gelation process can also be used. Figure 4-2 is a flow diagram of the historic external gelation process for $\mathrm{UO}_{2}$. This process also induces gelation with ammonia, but the source of the ammonia is external to the droplet. A somewhat different broth is prepared and pulsed through needle orifices, but this time the droplets fall through an ammonia vapor phase and then into an ammonium hydroxide containing aqueous column to induce the gelling. They are then washed and dried. 


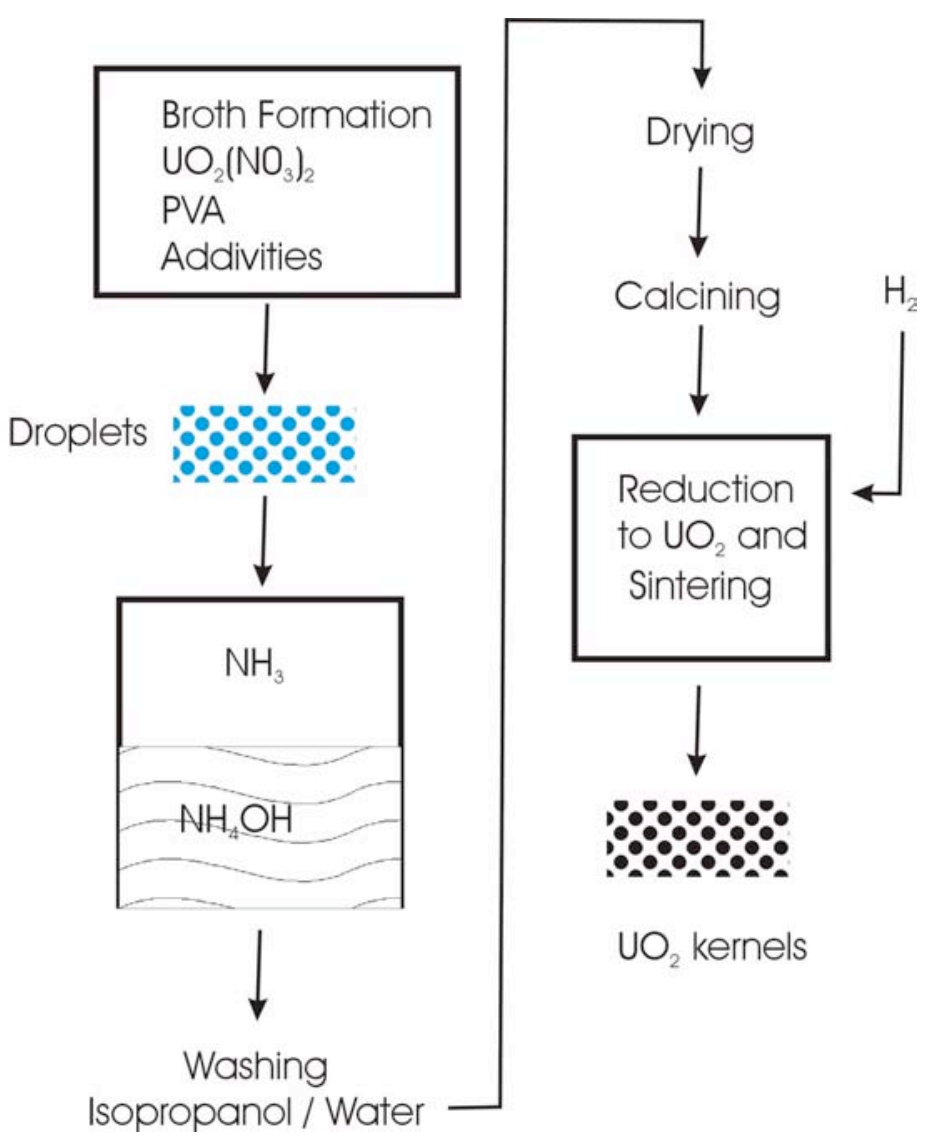

Figure 4-2. Flow diagram of external gelation kernel fabrication process.

The equipment required for kernel formation consists of vats and mixers to store and prepare the solutions (temperature controls may be necessary), metering pumps to supply the forming nozzles, vibrating nozzles to form the droplets, a droplet column that may or may not have an ammonia gas fall zone, and a means to withdraw the gelled droplets from the bottom of the column. A separate vat or column may be used for washing the kernels; additional controls may be required to monitor the rinse solution. During the process the temperatures and solution concentrations are monitored. The vibrating nozzles are driven at a fixed frequency and the metering pumps must deliver a fixed and predictable flow to the nozzles to form consistently sized droplets.

The dried spheres are calcined and sintered in a hydrogen atmosphere to remove the excess oxygen. If they are UCO kernels, they are next sintered in an argon or argon/CO atmosphere to adjust the $\mathrm{O} / \mathrm{C}$ ratio for a UCO kernel. A fluidized bed may be used for the UCO conversion process. The goal at this stage is a hard dense kernel of the proper composition $-\mathrm{UO}_{2}$ or the proper phases for UCO. The drying phase requires a series of furnaces to process the gelled droplets, a means of handling the kernels without damage, and a furnace gas control system to deliver the proper sintering atmosphere. The hot UCO kernels may have to be shielded from air to avoid oxidation.

The kernels are screened for size and tabled to eliminate the non-round and odd shapes. They are inspected for size, size distribution, density, and stoichiometry. This process may involve a set of 
screens to select particles sizes and a vibrating table that has particles introduced on one side and a set of collection bins on the other side. Round particles roll across the table and the non-round particles slide further down the opposite side into another bin. Methods detailed in other Sections of this report detail the inspection process.

Among the many process hazards not discussed in this report, kernel fabrication presents critical safety concerns due to the use of nitric acid combined with the generation of ammonium nitrate. If nitric acid is accidentally combined with ammonium nitrate under certain conditions, cyclotrimethylenetrinitramine, also known as RDX, can be generated. RDX is a very strong explosive compound.

\subsubsection{Coated Particle Manufacturing Equipment}

Coated particle manufacturing equipment varies in size or capacity of the coating chamber and design of components, such as gas delivery system, fluidization nozzle, temperature monitoring and control, etc. The basic concept shared by all these systems is a method to supply reactant and fluidizing gases to the surface of the particle to produce a levitated and cycling bed of particles at a controlled temperature.

The basic coater is usually a vertically-oriented, resistively-heated unit that is comprised of a shell, lid, and base. Internally there is a graphite heating element, coating chamber, and a gas injector. A drawing of a small representative furnace is show in Figure 4-3. The furnace is purged with inert gas (often argon) at all times. The purge gas enters the furnace at the base, the midsection of the shell, and through the port in the lid. The shell, lid, gas injector, and electrodes are water-cooled and the inner wall of the shell and the portion of the injector inserted into the hot zone of the furnace are insulated. Water flow and water temperature for the lid, shell, electrodes, and injector are monitored but not controlled during the coating process. Note that industrial scale coaters may replace water with alternative coolants because of criticality concerns due to large batch sizes.

The inner chamber of the furnace is usually fabricated from graphite and consists of three parts; the lid, the disentrainment chamber, and the coating chamber (Figure 4-3). The coating chamber typically has an inner diameter of $\sim 50$ to $250 \mathrm{~mm}$. Small diameter coaters usually have a one piece coating chamber/gas distributer consisting of a cone at the bottom of the cylindrical chamber with a cone angle of approximately $60^{\circ}$. The larger coaters usually use a special gas distributor with multiple jets and a special shape rather than a simple cone. The diameter of the gas inlet can be varied to control gas velocity in the small designs; a complex gas manifold system may be utilized for the larger coaters. The lid and disentrainment chamber are re-usable and are cleaned thoroughly between runs; for small coaters the one piece coating chamber is often replaced after each run. For larger coaters, only the gas distributor may need to be replaced between runs, due to deposition around the gas inlets, and the separate coating chamber can be cleaned to remove loose carbon deposits.

Process temperature is a critical control parameter and proper monitoring is crucial. Process temperature is often measured using an optical pyrometer to view average particle temperature across the fluidized bed. The top of the fluidized bed may be observed through a viewport (if available and not obscured by soot) in the lid of the furnace employing a $90^{\circ}$ glass prism The pyrometer can be adjusted to measure an "average" temperature across the bed. This approach 
can be used to compensate for the vigorous movement of particles and the variations in temperature within the bed and coater wall. The temperature can be corrected for losses due to the quartz sight glass and glass prism (a nominal $40^{\circ} \mathrm{C}$ for the temperature range of 1200 to $1600^{\circ} \mathrm{C}$ ). In some cases, a thermocouple may be inserted into the bed to measure the process temperature but this can result in process disruption during coating. During operation, external coating chamber temperature is often monitored for furnace control. This can be done using furnace thermocouples or a pyrometer may be sighted on the coating chamber just above the cone or distributor through a window in the furnace. Although the external furnace temperature is not the same as the process temperature, a relationship between the two can often be obtained. The major issue is that a means must be available to obtain a stable representative measurement of the process temperature.

Process gases are often controlled employing mass flow controllers and a series of electricallyoperated pneumatic valves. Methyltrichlorosilane, $\mathrm{CH}_{3} \mathrm{SiCl}_{3}$ or MTS, is a liquid at room temperature. The reactant is introduced to the coating process as a vapor. MTS can be vaporized by bubbling hydrogen carrier gas through the liquid in a temperature-controlled container; other methods may be used as well. Close monitoring of the MTS liquid level and temperature is generally required to maintain an accurate and reproducible flow rate employing this technique. Other more complex designs may be used for specific applications; the major point is that a stable means is required to meter the process gases and reactants into the coater.

The deposition process produces byproducts that must be removed from the exhaust gas stream prior to venting to the environment. Fine particles of carbon (soot) are produced during carbon deposition. Soot is often removed from the gas stream using a bag filter; large coaters may require a rather large filter system to handle the high volume of soot. Back-pressure across the filter is monitored to determine when the filter must be replaced. Exhaust gas temperature can be measured near the entrance of the filter to ensure the temperature limit of the filter is not exceeded.

MTS decomposes to form $\mathrm{SiC}$ and hydrochloric acid. The $\mathrm{HCl}$ is may be removed from the exhaust gas using a dry scrubber, or by other means, depending on the specific design. The scrubber is usually coarse alkali hydroxide pellets (mixtures of calcium, potassium, and sodium hydroxides) that react with the $\mathrm{HCl}$ to form salts and water. The pellets also include a colorchange indicator so that the status of the scrubber is readily observed through a transparent housing.

Kernels or particles to be coated can be introduced to the coating chamber through the port in the furnace lid; other designs may be more suitable for a specific fabrication line. The exact loading method may or may not require gas flow. Coated particles are typically removed from the furnace after cooling to $<40^{\circ} \mathrm{C}$. Gas flows are terminated and the coated particles are drained from the coating chamber through the injector into a collector for the cone designs. They may be vacuumed out for the more complex distributor designs or other provisions made. The important concern is that the process does not introduce foreign objects or impurities into the coater or onto the particles and that the handling does not damage the particles. 


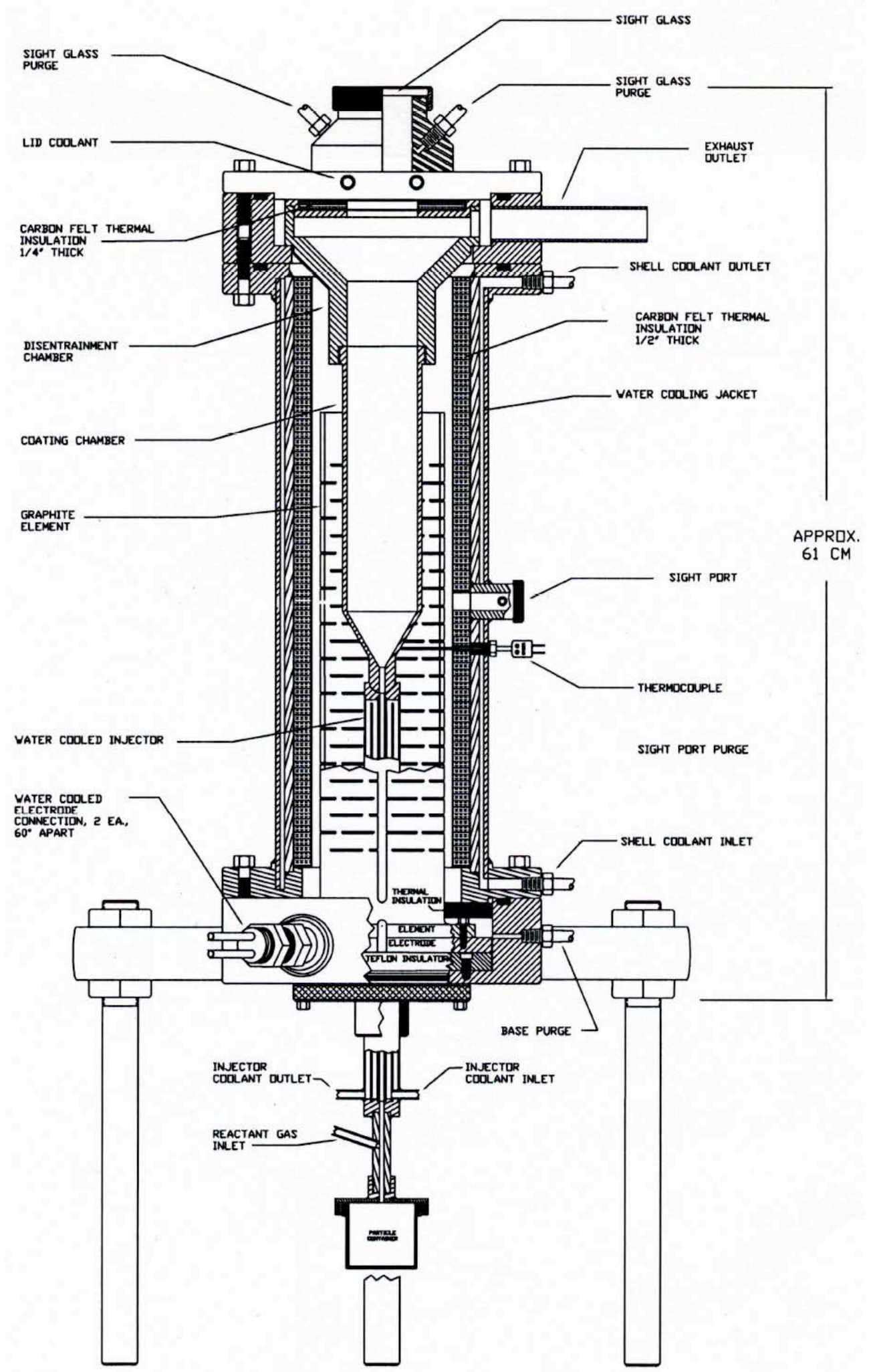

Figure 4-3. Detailed drawing of a 50-mm laboratory-scale FB-CVD furnace. 


\subsubsection{Example of a Laboratory Scale Coating Process}

As an example, the process used for the coating of the AGR-1 TRISO test particles in a laboratory scale coater is outlined (other coaters may have somewhat different process steps). All the layers were coated without removing the particles from the coater. A large production unit will probably have more automation and require less operator interaction. The process proceeds as described below:

1. Startup and Buffer Layer

a. Kernels are loaded into the coating chamber through the port in the furnace lid at room temperature with argon flowing at $11,000 \mathrm{~cm}^{3} / \mathrm{min}$ through the injector into the coating chamber. Exhaust from the furnace flows to the soot filter.

b. By manually controlling furnace power, the furnace is heated at a rate of $100-$ $150^{\circ} \mathrm{C} / \mathrm{min}$ up to the buffer deposition temperature (typically $1450^{\circ} \mathrm{C}$ ) during which time the activity of the bed is observed and the flow of fluidizing gas is reduced in $500 \mathrm{~cm}^{3} / \mathrm{min}$ increments to a flow rate of $7,500 \mathrm{~cm}^{3} / \mathrm{min}$.

c. The set point for the automatic optical pyrometer (views the coater chamber) is adjusted to hold the bed temperature at the specified buffer deposition temperature, as measured using the tripod-mounted optical pyrometer (views the top of the bed). The pyrometer temperature is corrected for losses caused by a prism and sight glass.

d. Process gas flows for buffer deposition (acetylene and argon) are established and stabilized while flowing to the exhaust (bypassing the coater).

e. The process gas mixture and inert fluidizing gas are swapped using a specialized process gas switching valve.

f. Furnace temperature set point is held constant and temperature is controlled using the automatic optical pyrometer sighted on the outer surface of the coating chamber. The reaction produces soot, thus observation of the bed through the top of the furnace is not possible during buffer deposition.

g. At the specified time (typically 5 minutes), the process and inert fluidizing gases are switched. The flow rate for the inert fluidizing gas is increased before switching if required by the process run sheet.

2. $\mathrm{IPyC}$

a. Process gas flows for IPyC deposition (acetylene, propylene, and argon) are established and stabilized while flowing to the exhaust (bypassing the coater).

b. The temperature of the bed is lowered manually to the specified IPyC deposition temperature. The temperature is measured using the tripod-mounted optical pyrometer and the set point for the automatic optical pyrometer is adjusted to hold the bed temperature at the specified IPyC deposition temperature (usually about $1265^{\circ} \mathrm{C}$ ).

c. Once the temperature has stabilized, the process gas mixture and inert fluidizing gas are swapped using the specialized process gas switching valve.

d. Furnace temperature set point is held constant and temperature is controlled by the automatic optical pyrometer. The reaction produces soot, thus observation of the bed through the top of the furnace is not possible during IPyC deposition.

e. At the specified time (typically 10 - 14 minutes), the process and inert fluidizing gases are switched. The flow rate for the inert fluidizing gas is increased before switching, if required by the process run sheet. 
3. $\mathrm{SiC}$

a. The furnace is heated manually to the specified $\mathrm{SiC}$ deposition temperature, typically at a rate of $50-100^{\circ} / \mathrm{min}$.

b. Hydrogen flows; both fluidizing and carrier, for SiC deposition are established and stabilized while flowing to the exhaust (bypassing the coater). Exhaust gas is switched to flow through the scrubber.

c. As the temperature of the bed approaches the specified $\mathrm{SiC}$ deposition temperature, the hydrogen and inert fluidizing gas are switched.

d. The set point for the automatic optical pyrometer is adjusted to hold the bed temperature, as measured using the tripod-mounted optical pyrometer, at the specified $\mathrm{SiC}$ deposition temperature (usually about $1500^{\circ} \mathrm{C}$ ).

e. Once the temperature is stable, the carrier flow is switched from the bypass to the MTS bubbler. The bubbler temperature is checked to be $25^{\circ} \mathrm{C}$.

f. Temperature of the bed is checked using the tripod-mounted optical pyrometer and set point adjusted if necessary. This step is repeated every $5-10$ minutes for the duration of $\mathrm{SiC}$ deposition.

g. At the specified time (typically 140 minutes), the carrier gas to the MTS bubbler is switched to bypass, terminating MTS flow.

4. $\mathrm{OPyC}$

a. The furnace is switched to manual control, the furnace power reduced, and the furnace cooled to the specified OPyC deposition temperature.

b. As the furnace cools, the process gas mixture (hydrogen) and inert fluidizing gases are swapped. The flow rate for the inert fluidizing gas is increased prior to switching if required. Exhaust gas is switched to flow through the soot filter.

c. The set point for the automatic optical pyrometer is adjusted to hold the bed temperature, as measured using the tripod-mounted optical pyrometer, at the specified $\mathrm{OPyC}$ deposition temperature (usually about $1290^{\circ} \mathrm{C}$ ).

d. Process gas flows for $\mathrm{OPyC}$ deposition (acetylene, propylene, and argon) are established and stabilized while flowing to the exhaust (bypassing the coater).

e. The process gas mixture and inert fluidizing gas are swapped using the specialized process gas switching valve.

f. Furnace temperature set point is held constant and temperature is controlled by the automatic optical pyrometer. The reaction produces soot, thus observation of the bed through the top of the furnace is not possible during OPyC deposition.

g. At the specified time (typically $\sim 10$ minutes), the process and inert fluidizing gases are switched. The flow rate for the inert fluidizing gas is increased before switching if required.

h. The furnace is switched to manual control, the furnace power set to zero output, and the furnace is allowed to cool unassisted.

\subsubsection{Fuel Element Manufacturing Equipment}

Once the particles have been coated and inspected, the next step is to form the fuel element. Over the years, several fuel element forms have been considered, but two are now of contemporary interest to US HTGR licensing: fuel compacts in prismatic graphite blocks and fuel pebbles. An important goal of fuel element fabrication is to minimize the amount of uranium outside the 
particles by limiting the number of defective particles from the manufacturing process, minimizing the damage done to particles during the element forming process, and minimizing the uranium impurities in the fuel element feedstock materials.

The fuel element (compact or pebble) is formed from the fuel particles, which may or may not be overcoated with matrix material prior to compacting, and the fuel element matrix material. The matrix material is a mixture of binder (resin or pitch), graphite flour, additives, and graphite shim (if required for compacts made by the injection process). The binder may be a thermosetting type (resin) that becomes rigid with exposure to elevated temperatures or a thermoplastic type (often a pitch) that always softens and flows with exposure to elevated temperatures.

Fuel element fabrication may be cast into two broad categories. In the first category the particles, matrix, and any shim material are first mixed together and then molded to shape at temperature. In the contemporary version of this, the particles are first overcoated with matrix material in a special mixer. The matrix material used is a highly viscous mixture of binder and graphite powder that does not flow. The fuel form is made by pouring the overcoated particles into a mold and applying pressure; heat and a small amount of solvent are also sometimes applied to allow the matrix material to deform and fill in the voids between particles. Either thermosetting or thermoplastic binder may be used, but thermosetting resin is often chosen, as the "green" element will then not slump upon further heating. This process is generally limited to particle packing fractions of no more than roughly $40-50 \%$.

Figure 4-4 illustrates the general process; it will work for either compacts or pebbles. Small amounts of unfueled matrix material may be added during the process as well. To add the unfueled outer layer of a pebble, the fueled center is fabricated as described above, then surrounded by more unfueled matrix material, placed in a larger spherical mold, and formed as before. The result is a "green" fuel element ready for carbonizing.

The second process is the injection method. With this process, the (bare) particles and any shim are first put into a mold and compressed by a piston. Next a flowable mixture of binder (usually pitch) and graphite flour is injected into the mold and allowed to harden by cooling the mold for thermoplastic binder or elevating the temperature to the set point for thermosetting binder. After the element has hardened, it is ejected from the mold (see Figure 4-5). This method has often used thermoplastic pitch to get the desired matrix and fabrication properties. Because this method needs a flowable mixture, less filler material can be used in the matrix, making it weaker. However, much higher particle packing fractions can be accommodated, roughly 50$60 \%$. 


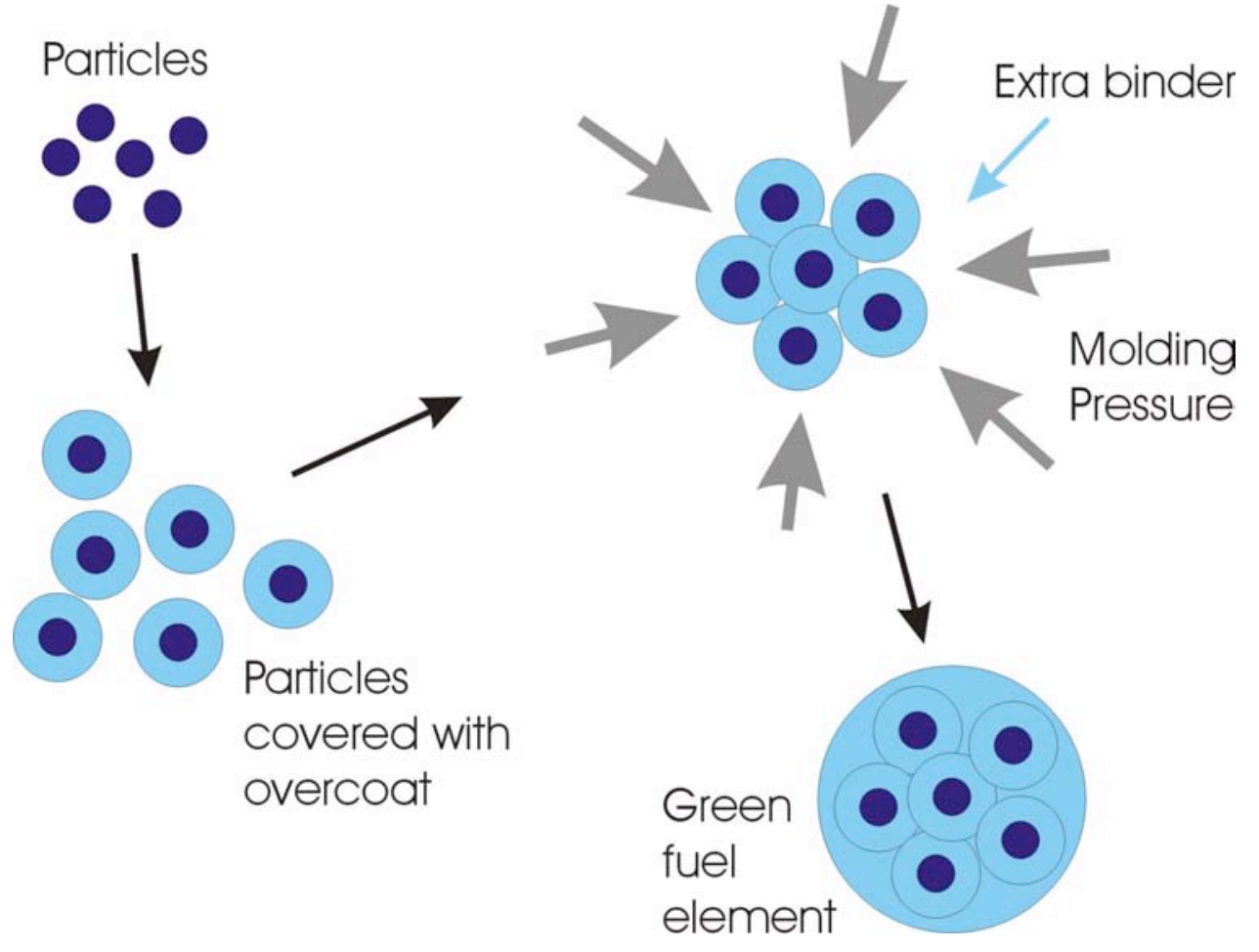

Figure 4-4. Illustration of the overcoated particle fuel element forming process. The mold is designed for the fuel form; piston and well for compacts, spherical mold for pebbles.

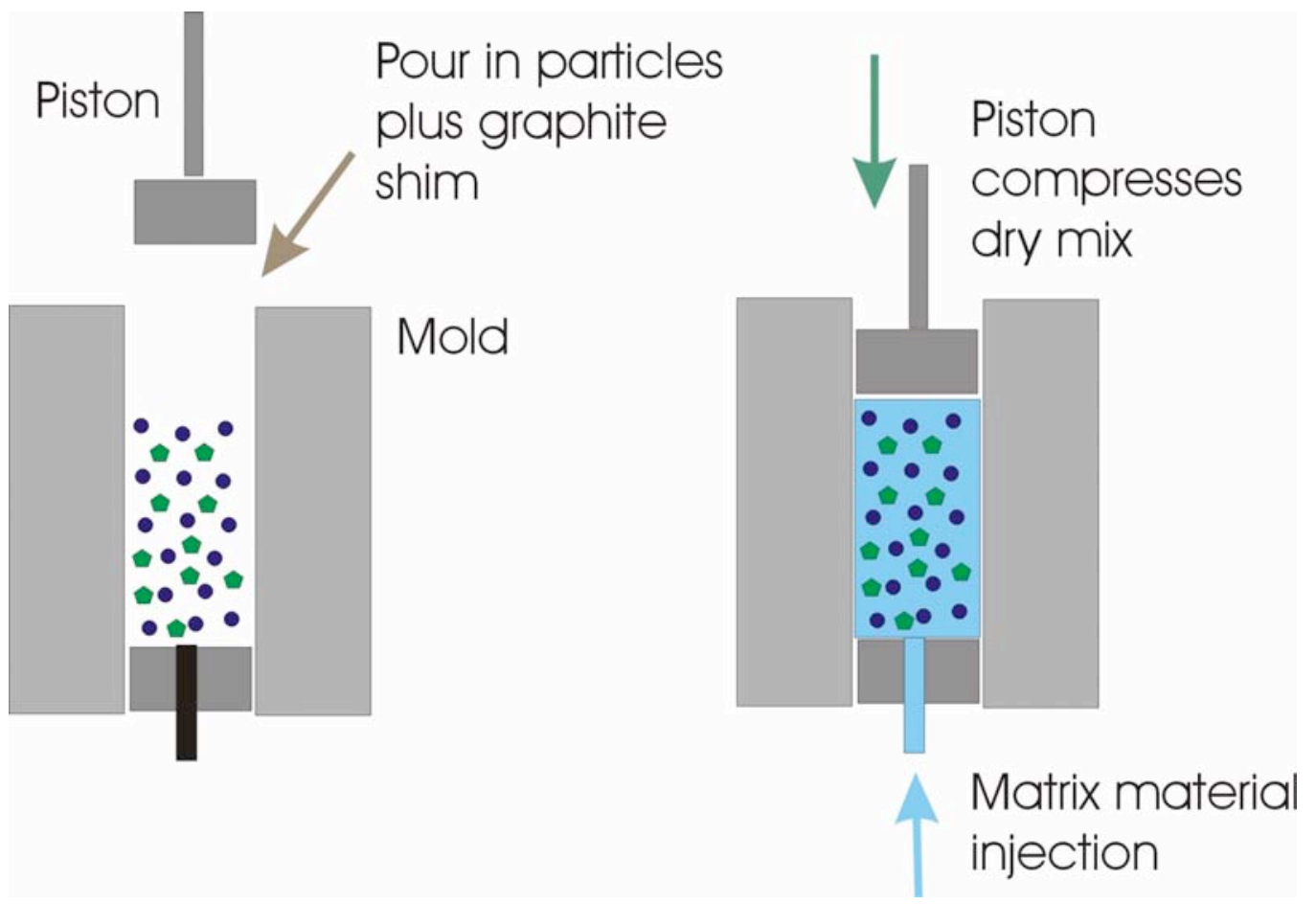

Figure 4-5. Illustration of the injection method, generally used only for compacts. 
Both methods can damage particles by crushing and care needs to be taken to control the forces and packing fraction. Another variable is the matrix mix and the resulting viscosity. The resin is the glue (binder) that holds the mixture together, the graphite flour or flakes is the filler material that forms the foundation of the element, and the additives make the mixture free flowing (if necessary) and limit the adhesion of the resin to the OPyC. High filler contents are desirable for good irradiation performance, but they don't flow as well and may result in greater particles damaged during forming.

An important factor of the fuel element fabrication process is the adhesion between the matrix material and the OPyC. If the adhesion is too strong, the $\mathrm{OPyC}$ will be damaged as the matrix material shrinks during irradiation. This is less important with the overcoating process because of the low percentage of binder and high filler content, but is more important for the injection process because of its high binder content and lower viscosity, which gives it better penetration ability. To limit the binder penetration into the OPyC, additives are added to the matrix material. These additives vaporize during the carbonizing process.

To summarize:

1. The overcoated fuel forming process

a. uses a low percentage of binder and a high percentage of filler,

b. produces a relatively strong and dense matrix,

c. exhibits fewer problems with $\mathrm{OPyC}$ penetration,

d. and limits particle packing fractions to below $40-50 \%$.

2. The injection process

a. has a high binder content and a low filler content,

b. flows well and is designed for injection molding,

c. produces a less dense and weaker matrix,

d. uses additives that must be used to limit penetration into the $\mathrm{OPyC}$,

e. and supports higher packing fractions of $50-60 \%$.

The required strength of the fuel element depends on its application. A pebble, which is repeatedly dropped several meters, requires greater strength than a fuel compact that is surrounded by a fixed graphite block. Thus, element strength is a parameter that can be part of a design trade off - say, for higher packing fraction.

The next step after the green element has been made is carbonizing. The green fuel elements are baked in an inert atmosphere furnace at approximately $800^{\circ} \mathrm{C}$ to carbonize the binder material and vaporize and remove any process additives. Fuel elements made with thermosetting resin are carbonized free standing, as the resin will not re-soften. Elements made with thermoplastic resin (pitch) are packed in beds of aluminum oxide to support them as they will slump (i.e. deform) as the resin softens with the temperature increase.

During the carbonizing process, care must be taken not to introduce impurities either from the furnace atmosphere or bakeout bed. Metals like iron and chrome can diffuse through the carbon layers and attack the SiC layer. To limit problems with impurities, the fuel elements can be purged with $\mathrm{HCl}$ after carbonizing. The $\mathrm{HCl}$ converts many impurities to volatile chlorides that leave the fuel element at processing temperatures. It is, however, a waste disposal problem.

Finally, the fuel elements are baked at 1650 to $1950^{\circ} \mathrm{C}$ to their final form. The purpose of this high temperature firing is to further the carbonization, improve the crystallinity of the matrix 
binder, and to remove any residual volatile impurities. Short times, $\sim 1$ hour, at these temperatures do not appear to affect the $\mathrm{SiC}$ (slight grain growth) or IPyC (slight increase in optical anisotropy). Impurity control during high firing is important because at these high temperatures, impurities can quickly diffuse through the matrix and pyrocarbons to the $\mathrm{SiC}$ and damage it. Impurities can come from the initial matrix mix, the carbonizing bed, the firing furnace, and from handling equipment. Figure 4-6 illustrates the fuel element baking steps.

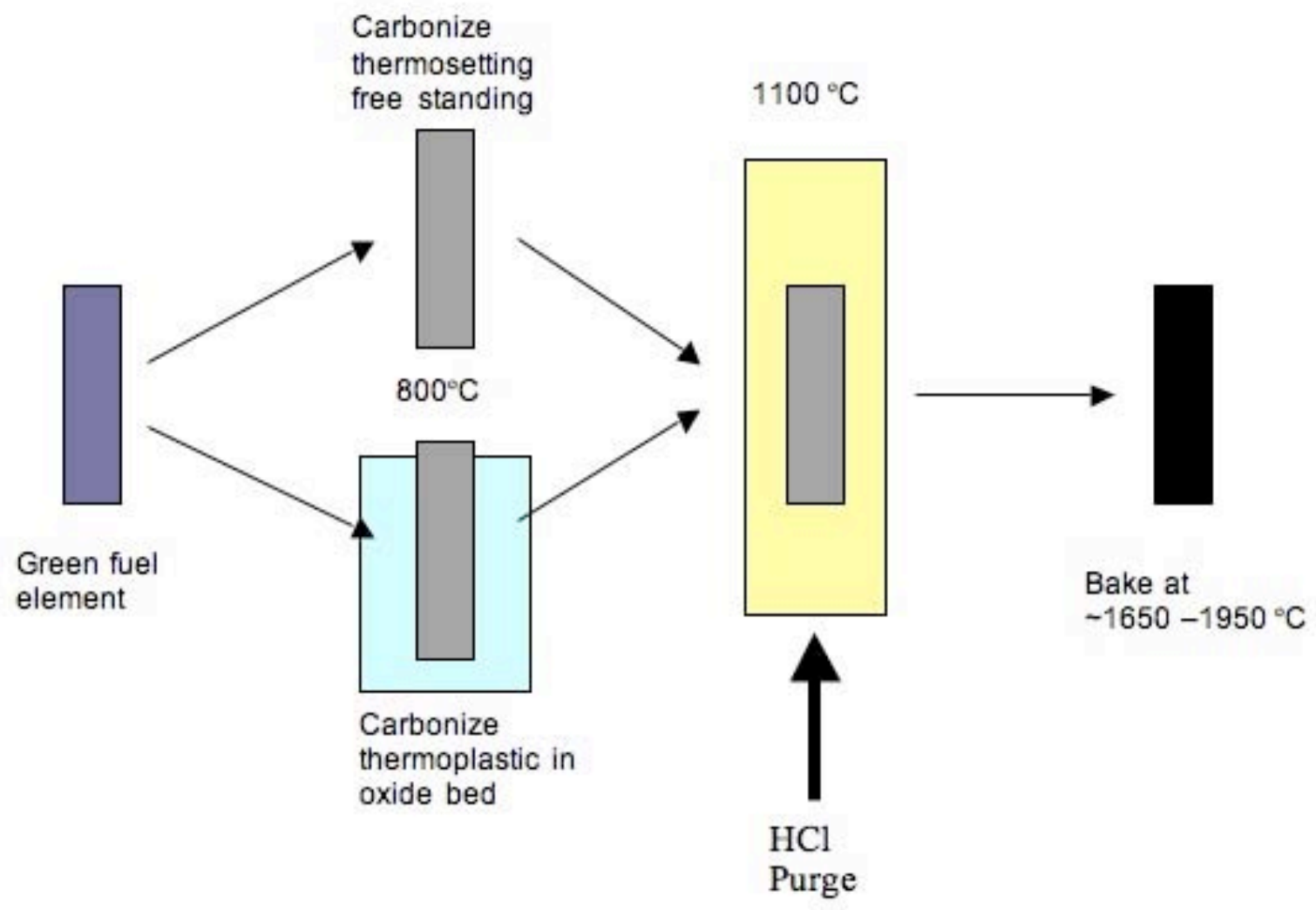

Figure 4-6. Green fuel element bakeout process. The HCl purge is optional.

In general three pieces of equipment are necessary to make fuel compacts:

1. Equipment to mix the fuel and matrix material which can either be done just prior to pouring the fuel and shim (graphite filler) into the mold (injection method) or by overcoating the fuel particles in a specialized device.

2. A molding and pressing unit which compresses the matrix and fuel together via a piston like force often with applied heat (overcoated method) or a die and piston which more lightly compresses the particle and shim mix while injecting the matrix mix under pressure into the particle bed.

3. A furnace for first carburizing the fuel form and then treating it at high temperature.

The process of overcoating particles is usually done in some variation of a "candy coater" device. A rotating drum (slightly off horizontal axis) is partially filled with powdered matrix 
material (somewhat dampened with solvent) and fuel particles. As the drum rotates, the particles become coated with matrix material. After some period of time, the particles are removed and may be screened for size depending on the specific process design. The selected particles move on to the next step and the rejected ones are either placed back into the coater or washed in a solvent to remove the coating and are then redone. The actual design and operation depend on the size of the particles and matrix properties since the particles must roll in a snowball like manner to be properly coated.

Several variables must be controlled in this process. The matrix mix, the residual solvent (or added solvent), matrix particle size, heat, and speed of drum rotation are some of the major variables to be controlled. The thickness and density of the applied matrix material determine the particle packing fraction so these two parameters are of particular interest.

For the injection process, particles and shim may be mixed together prior to pouring into a mold or during the pouring process. Since the shim particles control the packing fraction and particle spacing to some degree, the composition and size of the shim particles are important. The shim may or may not be round and it may or may not be composed of formable material.

For overcoated particles, the molds for the fuel form may be a thick membrane that is compressed to form the pebbles or a piston unit (single or double acting) and die for the compacts. Heat and/or solvent may be used to soften the matrix for forming. Three issues are important; the first is that the mold or die is properly filled, the second is that the forming pressure is controlled to minimize particle damage, and the third is that the fuel form can be released from the mold without excessive force that may damage particles as well.

The injection mold dies are filled with particles and shim and a plunger applies a controlled force to the particle bed. The liquid matrix material is then injected into the particle bed under pressure and the die either cooled (thermoplastic material) or heated (thermosetting material). When the compact is solid, it is ejected from the die. Just as with the overcoated particles, control of the pressure throughout the process is important as it is a driver for breaking fuel. Production sized units are usually composed of several molds/dies.

Carburization of the fuel elements is done in two ways. For thermosetting matrix material, the elements may be placed on graphite holders and loaded into the furnace; for thermoplastic material a different approach must be taken. The elements (usually compacts) are placed into a tray and the region around the compacts is filled with a refractory material such as alumina. This is necessary because the elements will slump as the melting point of the matrix is reached. The alumina packing helps the elements hold their shape until they are carburized. In either case, a primary issue is the control of impurities that may be introduced by either the furnace atmosphere or the alumina packing. A purge system of some kind removes the off gases. Transition metal impurities will damage $\mathrm{SiC}$ at high temperatures. Once the process is complete, the elements are removed from the holders; if they were in an alumina bed, any alumina sticking to the side of the element must be brushed off.

High temperature firing is accomplished by placing the elements in graphite holders in a high temperature furnace. Of primary interest at this stage is the purity of the furnace atmosphere and the time at temperature to ensure the treatment is complete, but not damaging to the fuel. If transition metals are present at significant levels (hundreds of ppm) they can migrate to the SiC and damage it. By monitoring the particle damage through the process, the fabricator can gain insight into the specific steps that are leading to greater than expected damage. 


\subsection{Identification of Important Fuel Processing Parameters}

One of the issues surrounding CFP fuel is the need, at least at the present time, to specify and track the process parameters in addition to specification of the final fuel properties. This is done because the product parameters that are measured may not be sufficient to ensure irradiation performance if the material is produced outside of the well-studied process parameter space explored in the fuel development process. For quality control purposes, requirements for record keeping of the process parameters are similar to that for the measured product parameters.

The process parameters monitored are generally those related to the material microstructure. Historical irradiation experience has demonstrated the importance of controlling the microstructure, but to date it has not been shown that the product parameter specifications are adequate to completely ensure the desired performance. Thus, process parameters are necessary, but not sufficient to control fuel quality. The process parameters outlined below, in conjunction with the product parameters, are those that appear to be important for fuel performance. However, one should be cautioned that these elements come from a general evaluation of historical programs and a specific fuel design may only require a subset of these parameters or additional parameters not mentioned.

There are two classes of process parameters that need to be differentiated. The first are process parameters that need to be controlled to ensure that product parameters are met. These are the most common and failure to meet them usually leads to a defective product that can be identified by the QC/QA process and rejected. Their application is thus straightforward.

A second class of process parameters also needs to be tightly controlled, but deviations from these parameters are not readily (to date) observed in the finished product. Thus, it may not be possible to determine if the product is defective by post manufacturing measurements prior to use. Since the safety of an HTGR depends highly on fuel performance, these process parameters take on special importance. It is believed that these process issues control subtle microstructure details that are either difficult to measure or not fully understood. A fuel specification should highlight those process parameters that fall under this second category.

\subsubsection{Kernels}

While process parameters are important for kernel fabrication, there are no specific kernel process parameters that appear to require special attention; the measured parameters appear to be sufficient. Kernels generally are specified by measurable parameters and process specifications are less important. However, as kernels become more complex, this may change. If the designers move beyond $\mathrm{UO}_{2}$, it may be important that the composition phases are homogenously distributed within the kernel and the microstructure meets a certain standard.

Table 4-1. Typical specified process parameters for kernels

\begin{tabular}{|l|l|l|}
\hline Critical Parameter & Typically Specified Criteria & Example - AGR-1 \\
\hline $\begin{array}{l}\text { Processes related to } \\
\text { kernel phases }\end{array}$ & $\begin{array}{l}\text { None at present, but may be of interest } \\
\text { in the future. }\end{array}$ & $\begin{array}{l}\text { The distribution of } \mathrm{UC} \text { and } \mathrm{UO}_{2} \text { phases may } \\
\text { be important. Currently, it is desired that the } \\
\text { phases be homogenously distributed and that } \\
\text { the phase islands be relatively small. }\end{array}$ \\
\hline $\begin{array}{l}\text { Processes related to } \\
\text { kernel composition }\end{array}$ & $\begin{array}{l}\text { None at present, but may be of interest } \\
\text { in the future. }\end{array}$ & \\
\hline
\end{tabular}




\subsubsection{Buffer Layer}

Even though the buffer layer is not a structural layer, process parameters are specified for this layer because it is an important carbon layer. The layer needs to be porous so that it can perform its gas collection function and the shrinkage rate must be moderate so it does not crack severely. Carbon layers are generally difficult to precisely define and characterize, thus the need for additional process control.

\section{Table 4-2. Typical specified process parameters for buffer}

\begin{tabular}{|l|l|l|}
\hline Critical Parameter & Typically Specified Criteria & Example - AGR-1 \\
\hline $\begin{array}{l}\text { Coating gas } \\
\text { temperature }\end{array}$ & Average bed temperature & $1450 \pm 25^{\circ} \mathrm{C}$ \\
\hline Coating gas fraction & Ratio of coating gas to total gas flow & $0.60 \pm 0.10$ \\
\hline Coating rate & $\begin{array}{l}\text { Average layer thickness over deposition } \\
\text { time }\end{array}$ & $\sim 20 \mu \mathrm{m} / \mathrm{min}$ \\
\hline
\end{tabular}

\subsubsection{IPyC Layer}

The IPyC is an important structural carbon layer with specific microstructural needs. It is important during both fabrication (to prevent $\mathrm{HCl}$ from reaching the kernel) and during irradiation to control the stresses on the $\mathrm{SiC}$ layer. This layer has been implicated in fuel failures and both process control and product parameters are believed to be necessary to predict its properties under irradiation.

Table 4-3. Typical specified process parameters for IPyC

\begin{tabular}{|l|l|l|}
\hline Critical Parameter & Typically Specified Criteria & Example - AGR-1 \\
\hline $\begin{array}{l}\text { Coating gas } \\
\text { temperature }\end{array}$ & Average bed temperature & $1265 \pm 25^{\circ} \mathrm{C}$ \\
\hline Coating gas fraction & Ratio of coating gas to total gas flow & $0.30 \pm 0.03$ \\
\hline Coating gas ratio & Ratio of propylene over acetylene & $0.85 \pm 0.09$ \\
\hline Coating rate & $\begin{array}{l}\text { Average layer thickness over deposition } \\
\text { time }\end{array}$ & $\sim 3.0 \mu \mathrm{m} / \mathrm{min}$ \\
\hline
\end{tabular}

\subsubsection{SiC Layer}

The $\mathrm{SiC}$ is both a structural layer and a barrier to fission production diffusion. Like the IPyC layer discussed above, it has both process control and product parameters specified.

\section{Table 4-4. Typical specified process parameters for $\mathrm{SiC}$}

\begin{tabular}{|l|l|l|}
\hline Critical Parameter & Typically Specified Criteria & Example - AGR-1 \\
\hline $\begin{array}{l}\text { Coating gas } \\
\text { temperature }\end{array}$ & Average bed temperature & $1500 \pm 25^{\circ} \mathrm{C}$ \\
\hline Coating gas fraction & Ratio of MTS in $\mathrm{H}_{2}$ to total gas flow & $0.015 \pm 0.005$ \\
\hline Coating rate & $\begin{array}{l}\text { Average layer thickness over deposition } \\
\text { time }\end{array}$ & $\sim 0.25 \mu \mathrm{m} / \mathrm{min}$ \\
\hline
\end{tabular}




\subsubsection{OPyC Layer}

The OPyC layer is similar to the IPyC layer in terms of properties and is controlled in much the same way. It is less critical to particle failure than the IPyC, but has the additional function of binding the particle to the fuel form matrix.

Table 4-5. Typical specified process parameters for OPyC

\begin{tabular}{|l|l|l|}
\hline Critical Parameter & Typically Specified Criteria & Example - AGR-1 \\
\hline $\begin{array}{l}\text { Coating gas } \\
\text { temperature }\end{array}$ & Average bed temperature & $1290 \pm 40^{\circ} \mathrm{C}$ \\
\hline Coating gas fraction & Ratio of coating gas to total gas flow & $0.30 \pm 0.03$ \\
\hline Coating gas ratio & Ratio of propylene over acetylene & $0.85 \pm 0.09$ \\
\hline Coating rate & $\begin{array}{l}\text { Average layer thickness over deposition } \\
\text { time }\end{array}$ & $\sim 3.0 \mu \mathrm{m} / \mathrm{min}$ \\
\hline
\end{tabular}

\subsubsection{Fuel Elements - Spherical Pebbles and Cylindrical Fuel Compacts}

Fuel elements are produced in the final stage of the fabrication process and process control is important both for the fabrication of the element and to avoid damage to the fuel particles. There is a tradeoff between the properties that lead to stable elements (high pressures, high temperatures) and particle damage (too high a pressure and temperature). Stability under irradiation is a major concern and this is driven by the microstructure.

Table 4-6. Typical specified process parameters for cylindrical compacts or spheres.

\begin{tabular}{|l|l|l|}
\hline Critical Parameter & Typically Specified Criteria & Example - AGR-1 fuel compact \\
\hline Molding pressure & Maximum molding pressure & $<60 \mathrm{MPa}$ \\
\hline Carbonization & Maximum heating rate & $<350{ }^{\circ} \mathrm{C} / \mathrm{hr}$ in $\mathrm{He}$ \\
& Bake temperature & $950 \pm 50{ }^{\circ} \mathrm{C}$ \\
& Bake period & $1.0 \pm 0.4 \mathrm{hr}$ \\
& Approximate cooling rate & Furnace cool \\
\hline Final heat treatment & Maximum heating rate & $<20^{\circ} \mathrm{C} / \mathrm{min}$ in vacuum \\
& Bake temperature & $1650-1850{ }^{\circ} \mathrm{C}$ (Spheres may go as high as \\
& Bake period & $\left.1950^{\circ} \mathrm{C}\right)$ \\
& Approximate cooling rate & $60 \pm 10 \mathrm{~min}$ \\
& & $\sim 20^{\circ} \mathrm{C} / \mathrm{min}$ to $<700^{\circ} \mathrm{C}$ then furnace cool \\
\hline
\end{tabular}




\subsection{Kinds and Periodicity of Process Parameter Data Collected}

Figure 4-7 shows a copy of one style of a TRISO coating run log sheet. This sheet is used to log process parameters during an uninterrupted TRISO coating run for research batches of fuel. The left most column of the log sheet lists all the process steps in a TRISO coating run. The other columns are for recording the various process parameter data collected. The data are entered on the log during each segment in the coating process and monitored periodically during each step in the coating process. The process parameters are monitored periodically during the coating steps. Due to the short duration of the carbon coating steps ( $<15$ minutes), the process parameters are observed almost continually ( every 1-2 minutes). During the $\mathrm{SiC}$ coating segment, which is on the order of 140 minutes in duration, the process parameters are observed less frequently, approximately every 10 minutes. The process parameters are usually stable during the coating segments. Varying values of any process parameter during coating are an indicator of problems with the coating run and are noted as such on the log sheet.

In a high volume production facility, it is very likely that this collection process will be automated and stored in a database. In any event, the data shown must be recorded often enough to assure that the process is stable. An inspector should look for a drift in the flows or temperatures as well as abrupt changes in the parameters; the table entries should be compared against historical values.

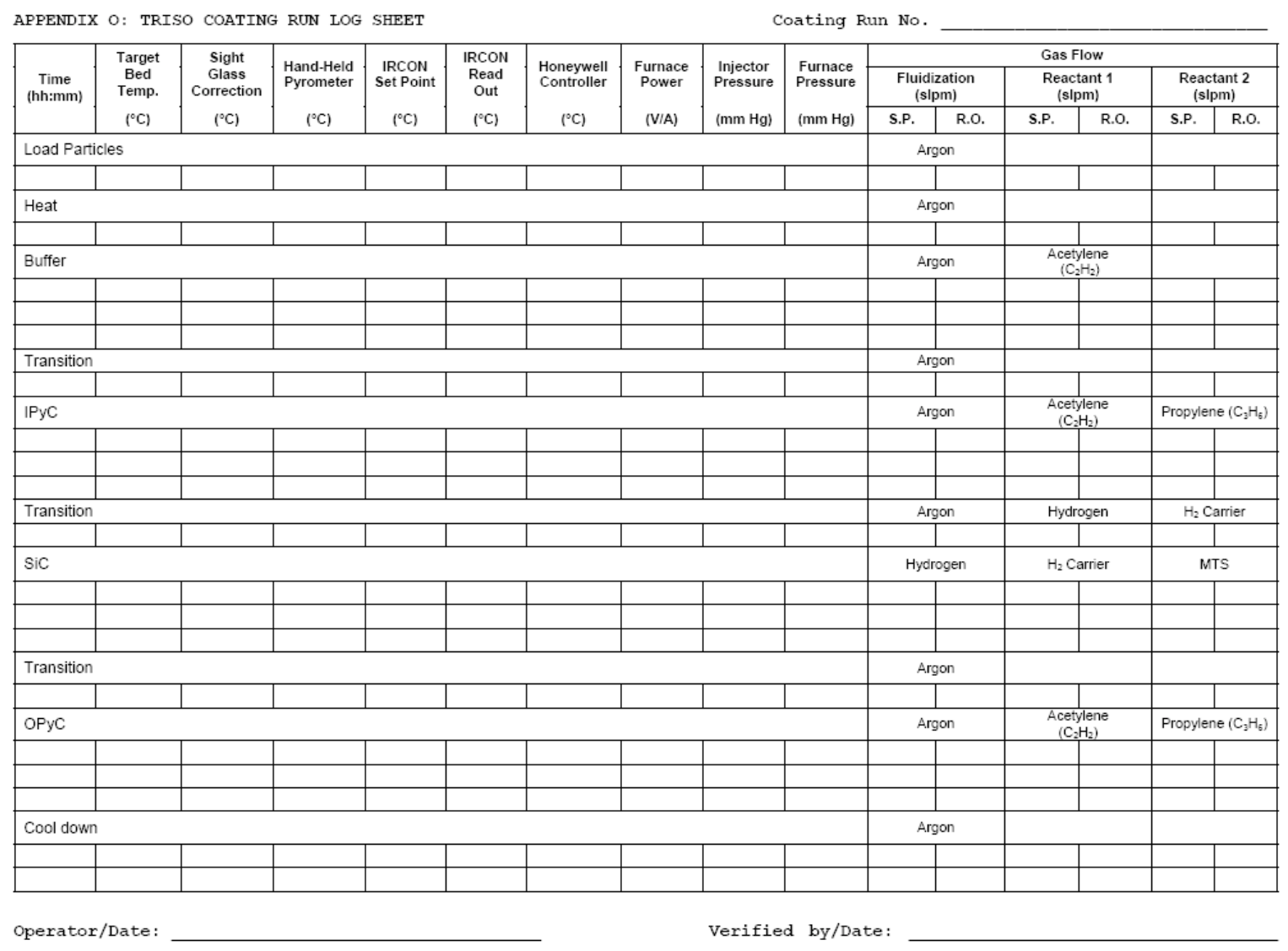

Figure 4-7. AGR-1 TRISO coating run log. 


\subsection{Relative Priority of Fuel Process Parameters}

The most critical parameters are those related to the particle coating as the particle is the basis of the fuel system and the microstructure of the coating layers are the most difficult to characterize. In this regard, one needs to note:

1. The gas flow rates

2. The gas composition (fraction/ratios)

3. The coater temperatures

4. The layer deposition rates

The second area of concern is the formation of the fuel elements. One needs to know:

1. The element pressing forces

2. The pressing temperature

3. The carburizing and high firing temperatures

Physical dimensions can be recovered by destructive testing, but flow rates, temperatures, and physical forces cannot be easily (if at all) determined by inspection. Another important process parameter to track is the particle failure fraction as a function of each processing step. This, along with the processing parameters, will help reveal an area for concern.

\subsection{Reference Documents}

Information in Section 4 has been summarized from the documents listed in Table 4-7. For more detailed information, one should review those documents. The fuel specifications associated with the Advanced Gas Reactor (AGR) Fuel Development and Qualification Program are based on an accumulation of the knowledge gained by previous coated particle fuel programs and represent the most up to date approach.

Certain documents listed below are for official internal NRC use only and their distribution is restricted to NRC unless approved by both NRC and DOE. These documents are labeled with an asterisk $\left(^{*}\right)$. 
Table 4-7. List of reference documents.

\begin{tabular}{|c|c|c|}
\hline Document Title & Reference & Description \\
\hline $\begin{array}{l}\text { Status of Qualification of High- } \\
\text { Temperature Reactor Fuel } \\
\text { Element Spheres }\end{array}$ & $\begin{array}{l}\text { Nucl. Tech. } 69 \\
\text { (1985) } 44 .\end{array}$ & \multirow{4}{*}{$\begin{array}{l}\text { A set of documents detailing the general } \\
\text { development and fabrication of pebble type fuel. To } \\
\text { date, this has been the most successful large scale } \\
\text { CFP program }\end{array}$} \\
\hline $\begin{array}{l}\text { Spherical Fuel Elements for } \\
\text { Advanced HTR Manufacture and } \\
\text { Qualification by Irradiation } \\
\text { Testing }\end{array}$ & $\begin{array}{l}\text { J. Nucl. Mater. } 171 \\
\text { (1990) 1-18. }\end{array}$ & \\
\hline $\begin{array}{l}\text { Long Time Experience with the } \\
\text { Development of HTR Fuel } \\
\text { Elements in Germany }\end{array}$ & $\begin{array}{l}\text { Nucl. Eng. and } \\
\text { Design, } 217(2002) \\
141-151 .\end{array}$ & \\
\hline $\begin{array}{l}\text { Fuel Elements for the High } \\
\text { Temperature Pebble Bed Reactor }\end{array}$ & $\begin{array}{l}\text { Nucl. Eng. and } \\
\text { Design } 34 \text { (1975) 93- } \\
108 .\end{array}$ & \\
\hline $\begin{array}{l}\text { Performance Evaluation of } \\
\text { Modern HTR TRISO Fuel }\end{array}$ & $\begin{array}{l}\text { HTA-IB-05/90 (July } \\
\text { 1990). }\end{array}$ & $\begin{array}{l}\text { This report documents the performance of the high } \\
\text { quality German fuel. }\end{array}$ \\
\hline $\begin{array}{l}\text { Research and development on } \\
\text { HTGR fuel in the HTTR project }\end{array}$ & $\begin{array}{l}\text { Nucl. Eng. and } \\
\text { Design, } 233(2004) \\
163-172 .\end{array}$ & Description of HTTR fuel fabrication technologies \\
\hline $\begin{array}{l}\text { Design and manufacture of the } \\
\text { fuel element for the } 10 \mathrm{MW} \text { high } \\
\text { temperature gas-cooled reactor }\end{array}$ & $\begin{array}{l}\text { Nucl. Eng. and } \\
\text { Design, } 218(2002) \\
91-102 .\end{array}$ & \multirow[t]{2}{*}{$\begin{array}{l}\text { Manufacturing technologies for the HTR-10 } \\
\text { spherical fuel element }\end{array}$} \\
\hline $\begin{array}{l}\text { Manufacture and characteristics } \\
\text { of spherical fuel elements for the } \\
\text { HTR-10 }\end{array}$ & $\begin{array}{l}\text { Nucl. Eng. and } \\
\text { Design, } 236(2006) \\
643-647 .\end{array}$ & \\
\hline Coated-Particle Fuels & ORNL-4324 (1968) & A historical document about CFP fuel development \\
\hline $\begin{array}{l}\text { Preparation of Spherical, Dense } \\
\text { Uranium Fuel Kernels with } \\
\text { Carbon }\end{array}$ & $\begin{array}{l}\text { Radiochimica Acta } \\
95 \text { (2007) 225-232 }\end{array}$ & \multirow[t]{2}{*}{$\begin{array}{l}\text { Recent descriptions of the preparation of uranium } \\
\text { fuel kernels using the internal gelation process. }\end{array}$} \\
\hline $\begin{array}{l}\text { *Production of Depleted } \mathrm{UO}_{2} \\
\text { Kernels for the Advanced Gas- } \\
\text { Cooled Reactor Program for Use } \\
\text { in TRISO Coating Development }\end{array}$ & $\begin{array}{l}\text { *ORNL/TM- } \\
2004 / 123\end{array}$ & \\
\hline $\begin{array}{l}\text { *Preliminary AGR Fuel } \\
\text { Specification }\end{array}$ & $\begin{array}{l}* \text { INL EDF-4198 } \\
(2004)\end{array}$ & $\begin{array}{l}\text { Preliminary list of important product parameters } \\
\text { and specified values with brief technical } \\
\text { justification. Also lists and discusses important } \\
\text { product parameters and specifications. }\end{array}$ \\
\hline $\begin{array}{l}\text { *AGR-1 Fuel Product } \\
\text { Specification and Characterization } \\
\text { Guidance }\end{array}$ & $\begin{array}{l}* \text { INL EDF-4380 } \\
(2004-6)\end{array}$ & $\begin{array}{l}\text { Provides acceptance criteria for AGR-1 fuel } \\
\text { product. Lists product parameter specifications. } \\
\text { Also lists some process parameter specifications } \\
\text { and guidance for additional characterization. }\end{array}$ \\
\hline *AGR-2 Fuel Specification & $\begin{array}{l}* \text { INL SPC-923 } \\
(2007)\end{array}$ & $\begin{array}{l}\text { Provides acceptance criteria for AGR-2 fuel } \\
\text { product. Lists product parameter specifications. } \\
\text { Also lists some process parameter specifications. }\end{array}$ \\
\hline $\begin{array}{l}\text { *AGR-3 \& } 4 \text { Fuel Product } \\
\text { Specification }\end{array}$ & $\begin{array}{l}\text { *INL EDF-6638 } \\
(2006)\end{array}$ & $\begin{array}{l}\text { Provides acceptance criteria for AGR-3 and AGR-4 } \\
\text { fuel product. Lists product parameter specifications. } \\
\text { Also lists some process parameter specifications. }\end{array}$ \\
\hline
\end{tabular}




\section{CALIBRATION TESTING EQUIPMENT AND CALIBRATION INSPECTION PROCEDURES FOR CRITICAL PRODUCT AND PROCESS PARAMETERS}

Verification and documentation of the calibration of process monitoring equipment and inspection equipment is a critical activity to ensure the quality of coated particle fuel. This activity must be part of the Quality Assurance program. The task is very similar to that required for LWR fuel. However, the large requirement for process knowledge currently required to ensure good performance of TRISO fuel places an additional importance on the calibration of the process monitoring equipment, since final fuel property measurements are not sufficient, at the present time, to verify the integrity of the final product. In the case of HTGR fuel, equipment calibration is intimately coupled to the process knowledge requirement and neither of these two can be recovered after the fact, should a serious issue arise.

Because small variation in certain process conditions, such as process temperature, can have a dramatic effect on the product, it is important to have a calibration verification schedule that takes into account the stability of the equipment, as well as the potential impact of equipment going out of calibration. Activities or means to verify that a piece of equipment is performing adequately and with the allowed calibration window should be identified as part of the operating procedure.

Equipment calibration also has an important safety and environmental function especially in the coating area because of the large amount of explosive gases and the large volume of effluent. Malfunctions in these areas are magnified by the potential hazards to the workers, plant, and neighboring areas. Thus, the impact of equipment calibrations can extend beyond the fuel performance requirement for process control. Again, this issue is similar to that encountered in LWR fuel plants, but troubles in equipment calibration may cascade more quickly in an HTGR fuel plant.

\subsection{Calibration Needs}

Routine calibration of the equipment used in coated particle fuel manufacture and characterization and the documentation of this calibration should be part of an operational Quality Assurance plan. This QA plan should specify the detailed requirements. In this section, calibration needs for fabrication and inspection equipment relevant to the manufacture of coated particle fuel are discussed.

\subsubsection{Kernel Fabrication Equipment}

Kernel fabrication process control is essential to maintain high process yields, but is not as critical to the performance of the final product, as is the case for the coating process discussed in Section 5.1.2, where some properties which may affect performance may not be determined by quality control measurements. The critical kernel product parameters can be determined by direct measurement. One possible exception is the need for uniformity in the microstructure of the kernel, due to the fact that the kernel stoichiometry and density are measured as averages on large samples, rather than on individual kernels. The analyses for stoichiometry and density determine mean value but do not determine the distribution of the measured property within the 
batch (see discussion in Section 7.4). Inspections can be performed to verify uniform microstructure, but some reliance rests on the control of the production process.

Key kernel process control equipment requiring calibration includes temperature monitoring equipment, mass and volume measurement equipment, and sol-gel droplet formation equipment. Control of the feedstock is also critical to the process, but this would fall under the responsibility of the analytical characterization laboratory providing the data on the chemical content of the feedstock. Feedstock chemistry is not a parameter that is directly measured during the kernel fabrication.

The kernel fabrication process is discussed in Section 4.1.1. Temperature monitoring equipment is needed to control the temperature of the kernel precursor broth, which must be chilled to remain stable. Temperature control is also important for the drop column, where temperature plays a key role in the sol-gel process. The temperature and length of the aging process for the wet gel spheres are important to quality and yield of uranium fuel kernels. After sphere formations, temperature control is critical for the furnaces used for calcining and sintering. Calibration of temperature monitoring equipment should be performed by trained and qualified technicians using standard procedures and/or manufacturer's instructions to verify readings are within allowable tolerances over the entire operating range.

Mass and volume measurements used to obtain proper chemistry in the mixtures and solutions used in the kernel fabrication process can affect the final properties of the kernels. Analytical balances should be calibrated using NIST traceable mass standards over the entire operating range. Mass determination as a means of tracking nuclear material is also an important part of a Nuclear Material Control and Accountability program and it is typically required that verification of analytical balance calibration be performed on as short as a 24 hour cycle. Glassware such as volumetric flasks and graduated cylinders should be obtained with certification of NIST traceability from the supplier. Glassware should be inspected for damage before use, but calibration recall (or equipment replacement) periods can be relatively infrequent, because volume change is not expected outside of the case of physical damage to the glassware.

Calibration verification of temperature, mass, and volume measurement equipment will be performed using common industrial or laboratory procedures. Procedures for calibration and verification of droplet formation equipment will likely be more unique to the process. Beyond the requirement for uniformity in its operation, the importance of the controlled operation of the droplet formation equipment is more of an issue of the ability to produce a high yield of the desired product than a requirement to ensure the performance of the kernels produced. Critical components of the droplet formation equipment are the metering pump, the delivery needle, and the vibration system. The exact geometry of the delivery needle should be specified and verified by the supplier, but in practice needles are also tested in operation for proper function (uniform droplet formation and less pronounced side streams). If properly maintained (flushed and cleaned between use), the requirement for needle replacement should be infrequent, with the most common cause for replacement being physical damage due to handling. The correct function of the needle is apparent through observation of droplet formation and yield of appropriately sized spheres. Solution delivery and needle vibration also affect droplet formation. The metering pump and vibration frequency generator should be calibrated using the manufacturer's procedures. Vibration frequency is a parameter that can easily be varied to maintain production of spheres of appropriate size. 


\subsubsection{Coating Fabrication Equipment}

Irradiation performance of TRISO particle coatings is complex and difficult to control based on fuel product parameters alone. The inner pyrocarbon layer, in particular, has a complicated microstructure which may not completely be predicted by the measured parameters of anisotropy and density, especially for process conditions outside of the proven range. The dynamics of the fluidized bed coating system is also complex and fuel properties and uniformity can be affected by the fluidization of the particles during coating. Therefore, current fuel specifications include acceptable parameter ranges for such process parameters as temperature and coating gas ratios, in order to limit the possible microstructural variation and defect mechanisms. This reliance on process conditions for ultimate fuel performance places an extra importance on control and documentation of the processes by the coating manufacturer to ensure that quality of the coated particle fuel. Proper calibration is a key part in establishing that the coating process is well controlled.

Coating temperature has a strong effect on most of the critical coating properties and must be controlled accurately. Coating temperature can be difficult to monitor. The coating processes include endothermic and exothermic reactions, which result in a constant variation within the bed and a particle surface temperature that is different from the temperature at the coating furnace wall. Inserting a probe into the bed of fluidized particles can disturb the fluidization dynamics and may result in damage to the particles bouncing of the probe. Optical pyrometers can be used at some stages to monitor particle temperature, but the soot generated during carbon coating prevents optical measurement at many points in the process. Monitoring of the coating temperature is best done using a combination of methods. The furnace shell temperature can be monitored and used in a feedback circuit to control the temperature of the furnace wall. A relationship must be established between the temperature of the wall and the temperature at or near the surface of the particles where the coating process is occurring. To establish this relationship, an optical pyrometer can be used during $\mathrm{SiC}$ deposition and before and after carbon deposition to measure the average temperature of the particle bed. An internal thermocouple may also be used to establish the relationship between coating temperature and furnace temperature, but this may need to be done for test cases and then the thermocouple removed during production. Establishment and control of this temperature relationship between the point of measurement and the point of coating can essentially be considered as part of the calibration of the temperature monitoring devices, and should therefore be well documented and periodically verified. Deposition of coatings on the inside furnace walls may change the thermal conductivity between the furnace wall and coating gas, so cleaning or replacement of furnace internals may be necessary to prevent change in the established relationship. Variation in the coating gas ratios and flow rates can also be expected to change this temperature relationship, so care must be taken there as well. Optical pyrometers can be calibrated using certified thermocouples and standard procedures. Thermocouple calibration should be performed by trained and qualified technicians using standard procedures and/or manufacturer's instructions to verify readings are within allowable tolerances over the entire operating range. Note that both the thermocouple meter and the probe must be checked. Thermocouples operating in the temperature ranges typical for deposition of TRISO coatings can be expected to have a short lifetime, so calibration verification cycles of the thermocouple probes should reflect this expected degradation. A prudent manufacturer will use multiple monitors to attain better reliability through redundancy. Combining thermocouples and optical pyrometers to monitor the temperature in the bed and 
outside the furnace wall is good practice because pyrometers are less prone to drift compared to a thermocouples, which directly experience the elevated temperatures and thermal cycling.

Total gas flows and coating gas ratios are integral to the coating process. These parameters affect the bed fluidization dynamics, defect production mechanisms, coating temperatures, and coating microstructure. Total gas flow and coating gas ratio is typically controlled by metering each supply gas. The modern method for monitoring gas flow is to use mass flow controllers. Mass flow meters operate on the principle that when a gas passes over a heated surface, heat is transferred from the surface to the gas. The amount of electric current required to keep the surface at a constant temperature is a measure of the velocity of the gas. Since the amount of heat transferred depends only on the mass and velocity of the gas these meters measure the true mass flow and have the advantage of measuring flow rates without requiring corrections for changes of temperature and barometric pressure. Flow values from these meters are usually given in standard cubic centimeters per minute, which is the volume occupied by a given mass of a gas at standard temperature and pressure as specified by the manufacturer. Since mass flow meters are not volume displacement devices, they require calibration on at least a quarterly basis against a primary or intermediate standard flow measuring device such as a bubble meter or a wet test meter. AGR-MFCCALIBRATE-SOP-01 (Table 5-1) is an example of a procedure using a wet test meter to calibrate a mass flow controller. Note that this calibration procedure requires that the wet test meter have its calibration periodically certified, as well as the temperature and pressure monitoring devices also used.

The gas distributor at the base of the fluidized bed coating chamber is a critical component that affects the fluidization and local temperatures in the coating bed. The design and manufacture of this component must be carefully controlled and key dimensions, such as orifice diameter, must be certified. Operation of the coating furnace can change the shape and diameter of the orifice(s) in the distributor due to build up of deposits. Depending on the extent of this deposit formation, the distributor must be periodically replaced, possibly after every run. Consideration of the effect of changes in the critical dimensions of the distributor and the need for re-certification of these dimensions must be taken into account if the distributor is used for multiple runs.

\subsubsection{Spherical Pebble and Cylindrical Fuel Compact Fabrication Equipment}

Critical equipment requiring calibration for the fabrication of the fuel elements include analysis equipment for determining the relative amount of each constituent (mass or volume measurement), the compacting press (force or length measurement), and the carbonization and heat treatment furnaces (temperature measurement). Calibration of furnace temperature monitoring equipment should be performed by trained and qualified technicians using standard procedures and/or manufacturer's instructions to verify readings are within allowable tolerances over the entire operating range. High temperature furnaces also often require an overtemperature limiting device, which also must have its calibration periodically verified for safety reasons.

The graphite matrix in the fuel element is made up of a mixture of resin and graphite. Furthermore the graphite may be a mix of natural and synthetic material, in order to optimize thermal conductivity versus irradiation stability. An example is the A3 matrix originally used in the German spheres and currently used in the US cylindrical compacts, which consists of $64 \mathrm{wt} \%$ natural graphite, $16 \mathrm{wt} \%$ synthetic graphite, and $20 \mathrm{wt} \%$ resin. The matrix constituents are typically weighed out and mixed prior to overcoating or other compacting processes. The amount 
of matrix and coated particles added to the die in order to form fuel elements with a desired uranium loading, size, and density is also typically controlled by weight. Analytical balances should be calibrated using NIST traceable mass standards over the entire operating range. Mass determination as a means of tracking nuclear material is also an important part of a Nuclear Material Control and Accountability program and it is typically required that verification of analytical balance calibration be performed on as short as a 24 hour cycle. For large production processes, volume metering may be used in place of weighing the various components. Calibration of volume metering devices would likely involve a procedure where metered materials are weighed with a calibrated balance to determine the mass of material dispensed.

The process variable for the compacting press will depend on the method. The fuel elements may be pressed to a target force, dimension, or combination of the two. Force gauges must be of the proper range in order to read the force applied during compacting. The force gauges must be calibrated using a certified load cell. Cylindrical compacts are typically pressed in a cylindrical die with fixed diameter. The distance between the two cylindrical rams can be used to determine when to stop pressing. There are various ways to determine this distance, either by direct measurement or by relative displacement of the pistons of an electric servo press. Calibration to a NIST traceable length standard by an appropriate procedure would be required, regardless of the method used.

\subsubsection{Characterization Equipment}

There is a long list of required calibrations for the equipment used to characterize coated particle fuel. In general, all measurements must be traceable to a recognized standard such as those available through the National Institute of Standards (NIST). Calibration verification intervals must take into account the stability of each measurement device.

Mass determination using analytical balances is probably the most often performed procedure in a coated particle fuel characterization laboratory. Mass determination feeds into many of the product parameter analyses and is also critical for inventory tracking to satisfy Nuclear Materials Control and Accountability (NMC\&A) requirements. Analytical balances should be calibrated over the entire operating range using certified mass standards. Typically, balances are checked at $0,1 / 4,1 / 2,3 / 4$, and full range. Balances should be calibrated after allowing for a warm-up period to obtain instrument stability. Balances should also be calibrated in the location of operation. Transportation of a balance to another area of operation may require recalibration due to the sensitive nature of these devices. For cost reasons, secondary mass standards are often certified using a primary mass set which has been certified by NIST. Proper mass standard calibration for high accuracy mass sets will include compensation for environmental conditions. Daily verification of the calibration of an analytical balance before use is a fairly simple routine that helps to document and ensure the accuracy of the measurement and may be required by the NMC\&A program. AGR-CHAR-VAL-04 (Table 5-1) is an example of a daily verification procedure used at ORNL.

Table 5-1 lists a few ORNL procedures used for calibration of optical microscopes and mercury porosimeters. The mercury porosimeter is essentially a volume measurement device. Volume is measured indirectly using a capacitance technique. The glass penetrometer cells used with the porosimeter must each be individually calibrated by measuring the capacitance of the cell filled with various known volumes of mercury. 
Optical microscopes used to obtain quantitative measurements must be calibrated at each magnification using a certified stage micrometer to determine the size of each pixel in the digital image. Some manufacturers only recommend calibration at one magnification, followed by use of a fixed multiplier for each objective/lens combination. This approach should be verified using the stage micrometer to determine if the accuracy of the manufacturers stated magnification for each component is sufficient to give the required accuracy in the derived calibration. Depending on the optics used, there may also exist a significant non-linearity across the field of view of the image. Even for the best microscope optics, this effect is unavoidable due to the fact that the digital camera uses a planar detector and the optics project a curved image, resulting in slight magnification of the image at the edges of the detector. This non-linearity can be included in the calibration to increase accuracy of the measurement. Other instruments, such as electron microscopes or x-ray imaging devices, require similar calibration if used for quantitative imaging. Standards for electron microscopes are available from many commercial vendors. Xray imaging devices can be calibrated by certified pin gauges or metal spheres.

Liquid gradient density columns use certified floats of various density to determine the density gradient in the column. These floats are typically calibrated using a titration method to prepare a solution in which the floats are suspended with zero buoyancy, followed by accurate density determination of the liquid. ASTM D1505-98 (Table 5-1) describes two float calibration procedures. Density float calibration requires a well controlled test environment and is usually provided by the density float supplier. It is typically more feasible to periodically replace floats with new ones than to have the calibration of existing floats verified. Density floats can be expected to have a long useful lifetime, if they are not physically damaged. Because several floats are used together in a density column, deviation from the expected relative position of one of the floats in the column is a useful indicator of float failure. Density columns also require measurement of particle and float position. This is best done using a height gauge attached to a survey telescope. Periodic calibration of the height gauge is required.

Section 3.2.5 describes an optical ellipsometer (called the 2-MGEM) recently developed at ORNL to measure pyrocarbon anisotropy. This ellipsometer was developed to replace the optical polarimeters that were used in the past (and are still used in some countries) to measure pyrocarbon anisotropy. As part of the development and subsequent benchmarking of the 2MGEM, a series of anisotropy standards were identified. Aluminum surface mirrors are good standards with zero diattenuation $(\mathrm{N}=0)$. Polarized light incident at normal incidence on an aluminum mirror should reflect with no change to the polarization state, yielding a measurement of $\mathrm{N}=0$ or $\mathrm{OAF}=1$. Tests of some polarimeters used at other facilities showed that the polarimeters were measuring OAF values significantly greater than 1 for the aluminum mirror. This offset is due to polarization effects in the optics of the measurement device. Historically, this effect has not been accounted for. However, an easy correction can be applied using the measured value for the aluminum mirror to calculate a calibration correction for the optical system. Prior to measuring a pyrocarbon sample, an aluminum mirror is placed in the sample position. A calibration routine using the aluminum mirror is built into the operation of the ellipsometer and details can be found in the Applied Optics paper referenced in Table 5-1. Calibration of the polarimeter requires establishment of a correction factor based on the measurement obtained on the mirror. Details of the correction are dependent on the polarimeter used. Another useful anisotropy standard is single crystal rutile (TiO2) with the c-axis in-plane. The value of the diattenuation for rutile can be calculated based on its optical properties and the wavelength of the light used in the analysis. In practice, the aluminum mirror is used as a 
calibration standard and the rutile is used as an independent check on the operation of the calibrated system. Typical results with the 2-MGEM yield a measured diattenuation for rutile that is within the measurement uncertainty $( \pm 0.001)$ of the calculated value.

Various analytical chemistry instruments may be used to determine the concentration of certain elements (e.g., U, C, O, and important impurities) in the kernels, particles, or final fuel elements. Many standard solids and solutions are commercially available for use with mass spectrometers and related instruments. These should be calibrated according to manufacturer's, or other approved procedures. Calibration requirements for mass and volume measurement equipment used in conjunction with the analytical chemistry equipment to perform the various analyses should also considered.

Dimensional inspection equipment (e.g., vernier calipers, micrometers, height gauges, ring gauges, laser systems, etc.) may be used to measure size and shape of the final fuel elements. This equipment should be calibrated on a regular basis using approved procedures. Daily verification of operation, particularly for electronic gauges, can be performed with standard gage blocks, which are commercially available in many shapes and sizes. The calibrated surfaces of these gage blocks can be compromised by use, therefore, these too should be inspected and replaced or recalibrated on a regular basis.

\subsection{Relative Priority of Calibration Procedures}

Because of the reliance on certain process conditions to ensure good fuel performance, an inspector might concentrate on calibrations relevant to those processes identified in the manufactures specification as conditions for acceptance of the fuel. As mentioned in Section 5.1.2, coating temperature is of particular importance and both calibration of the measurement equipment as well as procedures used to ensure that the measured values are properly related to the temperature at the coating surface should be considered. A record of high temperature thermocouple performance and failure requiring replacement should be obtained and compared to the required recall period for those thermocouples.

Calibration and verification of the instrument used to measure anisotropy is a weakness prevalent in historical coated particle fuel manufacture. The fuel manufacturer should be able to demonstrate an improved calibration procedure, especially if using a polarimeter of the type used in the past. 


\subsection{Reference Documents}

Information in Section 5 has been summarized from the documents listed in Table 5-1. For more detailed information, one should review those documents.

Certain documents listed below are for official internal NRC use only and their distribution is restricted to NRC unless approved by both NRC and DOE. These documents are labeled with an asterisk $\left(^{*}\right)$.

Table 5-1. List of reference documents.

\begin{tabular}{|l|l|l|}
\hline Document Title & Reference & Description \\
\hline $\begin{array}{l}\text { *Standard Operating Procedure } \\
\text { for Mass Flow Controller } \\
\text { Calibration }\end{array}$ & $\begin{array}{l}\text { *AGR- } \\
\text { MFCCALIBRATE- }\end{array}$ & $\begin{array}{l}\text { An ORNL procedure for calibration of mass flow } \\
\text { controllers using a wet test meter. }\end{array}$ \\
\hline $\begin{array}{l}\text { *Procedure for Calibration of } \\
\text { Quantachrome Poremaster 60 }\end{array}$ & $\begin{array}{l}\text { *AGR-CHAR-CAL- } \\
06\end{array}$ & $\begin{array}{l}\text { An ORNL procedure for calibration of the } \\
\text { penetrometer volume used in a mercury porosimeter }\end{array}$ \\
\hline $\begin{array}{l}\text { *Procedure for Calibration of } \\
\text { Images Acquired with Leica DC- } \\
\text { 480 Camera on Leica MZ-16 } \\
\text { Stereoscope }\end{array}$ & 09 & $\begin{array}{l}\text { An ORNL procedure for calibration of an optical } \\
\text { stereoscope using a stage micrometer }\end{array}$ \\
\hline $\begin{array}{l}\text { *Procedure for Calibration of } \\
\text { Images Acquired with Leica DC- } \\
500 \text { Camera on Leica DMRX } \\
\text { Microscope }\end{array}$ & *AGR-CHAR-CAL- & $\begin{array}{l}\text { An ORNL procedure for calibration of an optical } \\
\text { microscope using a stage micrometer }\end{array}$ \\
\hline $\begin{array}{l}\text { Standard Test Method for Density } \\
\text { of Plastics by the Density- } \\
\text { Gradient Technique }\end{array}$ & ASTM D 1505-98 & $\begin{array}{l}\text { ASTM standard describing the preparation and use } \\
\text { of a typical liquid gradient density column }\end{array}$ \\
\hline $\begin{array}{l}\text { *Procedure for Validation of } \\
\text { Operation Mettler Toledo XS204 } \\
\text { Analytical Balance }\end{array}$ & *AGR-CHAR-VAL- & $\begin{array}{l}\text { Procedure used to validate analytical balance before } \\
\text { use }\end{array}$ \\
\hline $\begin{array}{l}\text { Normal-incidence generalized } \\
\text { ellipsometry using the two- } \\
\text { modulator generalized } \\
\text { ellipsometry microscope (2- } \\
\text { MGEM) }\end{array}$ & $\begin{array}{l}\text { Appl. Optics 45 } \\
(2006) \text { 5479-5488 }\end{array}$ & $\begin{array}{l}\text { Paper containing explanation of operation, } \\
\text { including calibration, of 2-MGEM }\end{array}$ \\
\hline
\end{tabular}




\section{MAINTENANCE PROCEDURES FOR FUEL FABRICATION PROCESS EQUIPMENT}

Effective preventative maintenance of fuel fabrication process equipment is needed to support efficient plant operation and is generally recognized as good business practice. However this maintenance is also an important aspect of ensuring fuel quality and operational safety. Equipment that deviates from it's expected operation could result in processing conditions that are outside of the normal operating range. Good control of processing conditions is especially important due to the reliance on process specifications for quality control in the current fuel specifications. Some aspects of the coated particle fuel quality and performance depend on process controls because of an inability to directly measure a critical property (such as is the case for buffer and IPyC density) or because of an incomplete understanding of all aspects of the property/performance relationship. This section describes some of the known maintenance issues for fabrication equipment currently used for the manufacture of coated particle fuel. Required maintenance procedures will be specific to the equipment and processes used. A fuel manufacturer is required to have a maintenance plan and tracking system to cover all required maintenance of critical manufacturing equipment.

\subsection{Maintenance Needs}

Routine maintenance of commercial equipment used in coated particle fuel manufacture and characterization shall generally be performed as recommended by the manufacturer. Specialized fabrication equipment, such as that described in Section 4.1, may require additional periodic maintenance as discussed in the following sections.

\subsubsection{Kernel Fabrication Equipment}

Figure 6-1 and Figure 6-2 show an internal gelation process used to make laboratory-scale quantities of uranium dioxide kernel microspheres. In this process, a chilled mixture of aciddeficient uranyl nitrate (ADUN) and hexamethylenetetramine (HMTA)-urea are loaded into the broth pot. The chilled feed solution is dispersed as droplets through a vibrating needle into silicone oil at $60^{\circ} \mathrm{C}$ to cause gelation to occur. The gelled spheres pass through the serpentine tube to a collector.

At the end of each production run, the electropolished stainless steel needle and the glass observation tube must be cleaned with dilute nitric acid and then washed with deionized water. The 3/16-in. tube of polyvinyl chloride (PVC) from the chilled broth pot to the vibrator to the glass observation tube requires periodic replacement. The serpentine tube from the bottom of the forming column to the collector is replaced when the gel spheres begin to stick too much to the PVC tubing or when the flow rate decreases below an acceptable amount. The collector and gelforming column are cleaned with dilute nitric acid and deionized water when the uranium buildup becomes excessive. The broth pot is also occasionally cleaned with nitric acid and deionized water. The silicone oil circulating through the forming column is passed through a filtration system. 


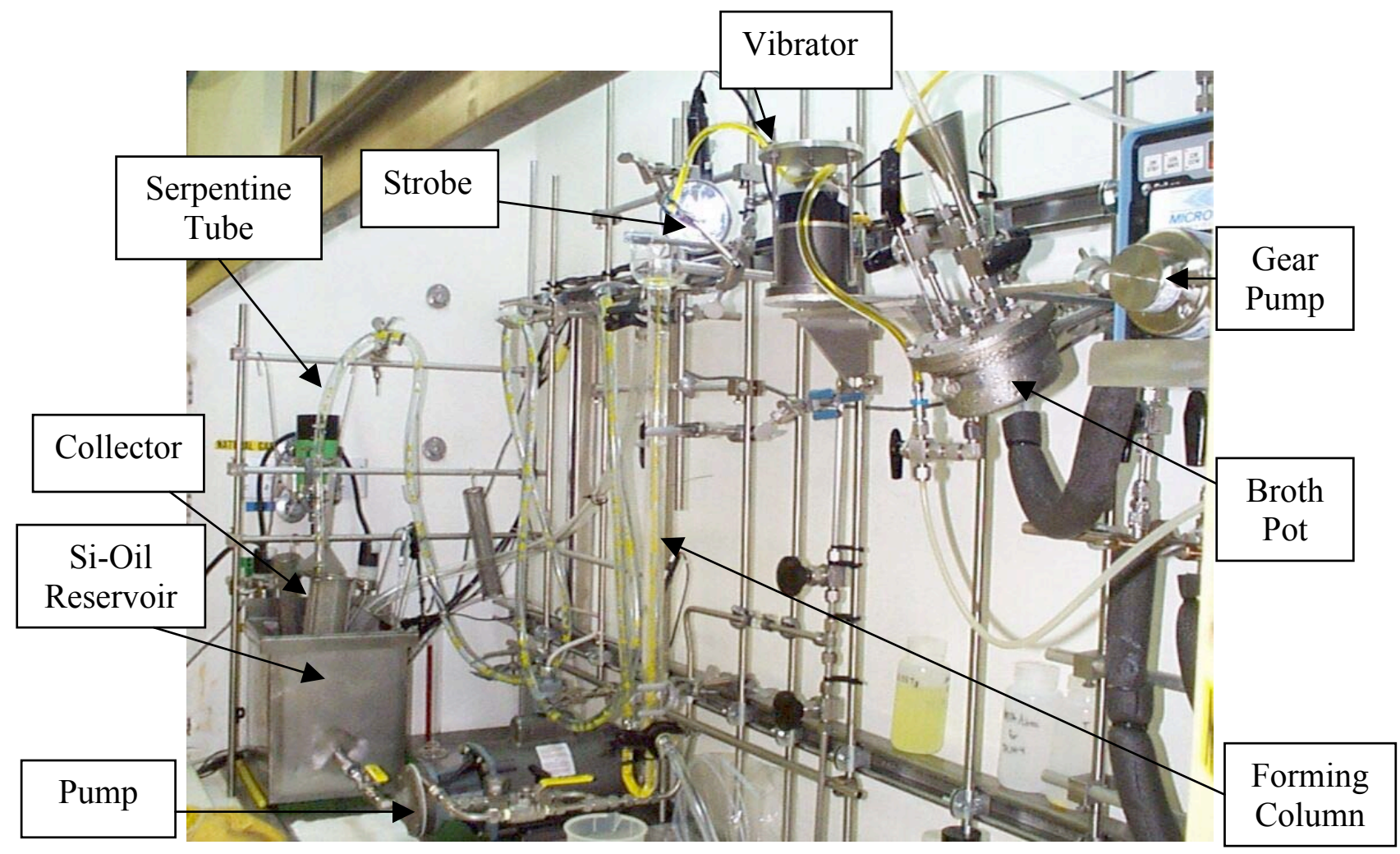

Figure 6-1. Laboratory-scale equipment for converting chilled broth into uniform gel spheres.

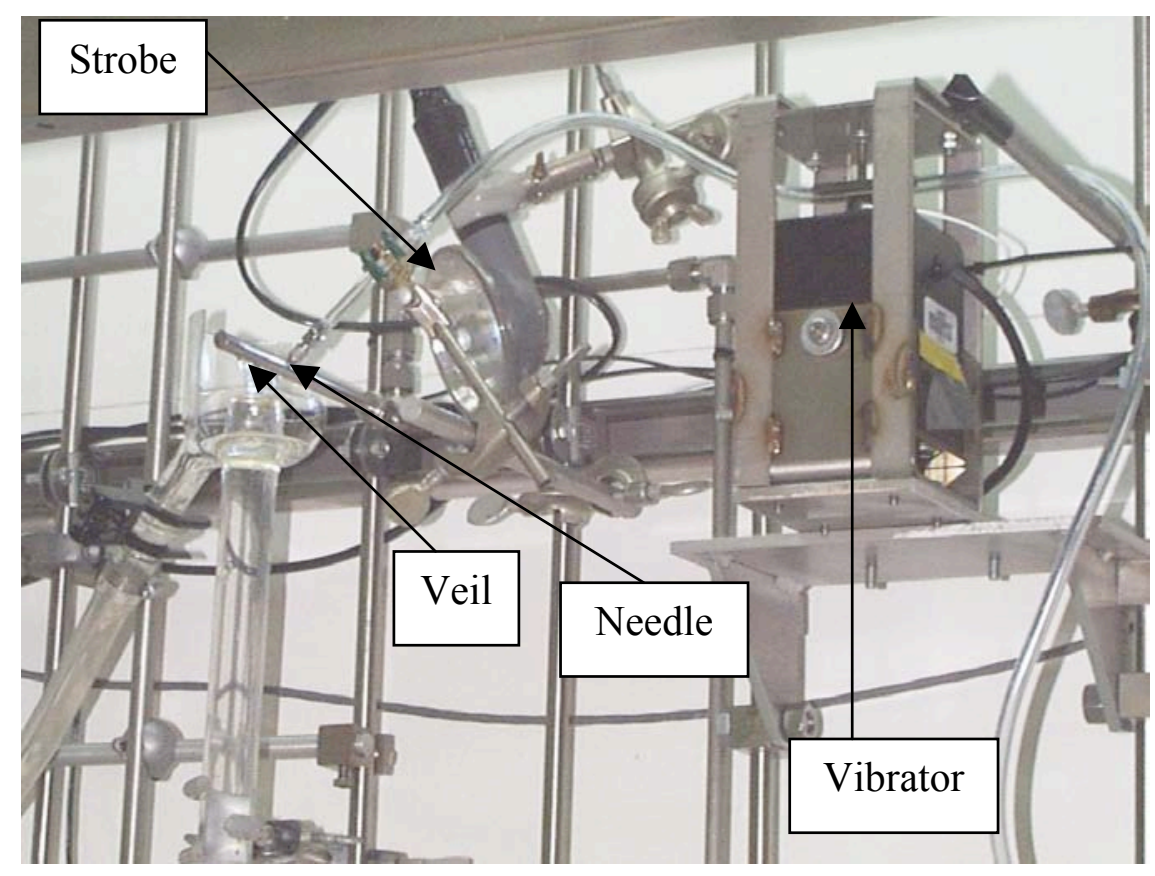

Figure 6-2. Electrodynamic shaker, needle, and gel-forming column 


\subsubsection{Particle Coating Equipment}

Maintenance of the fuel particle coating equipment consists mainly of controlling the accumulation of by-products from the coating process. The process control system, which is shown in schematic form in Figure 6-3, requires little periodic maintenance providing some preventative measures are taken. The furnace itself, an example of which is shown in cutaway view in Figure 6-4, requires cleaning after each coating run. The following sections discuss in general the routine maintenance and preventive maintenance operations for a typical $50 \mathrm{~mm}$ coating furnace system. Each coating system is unique, and some maintenance steps will be different depending on the design and configuration of that specific system.

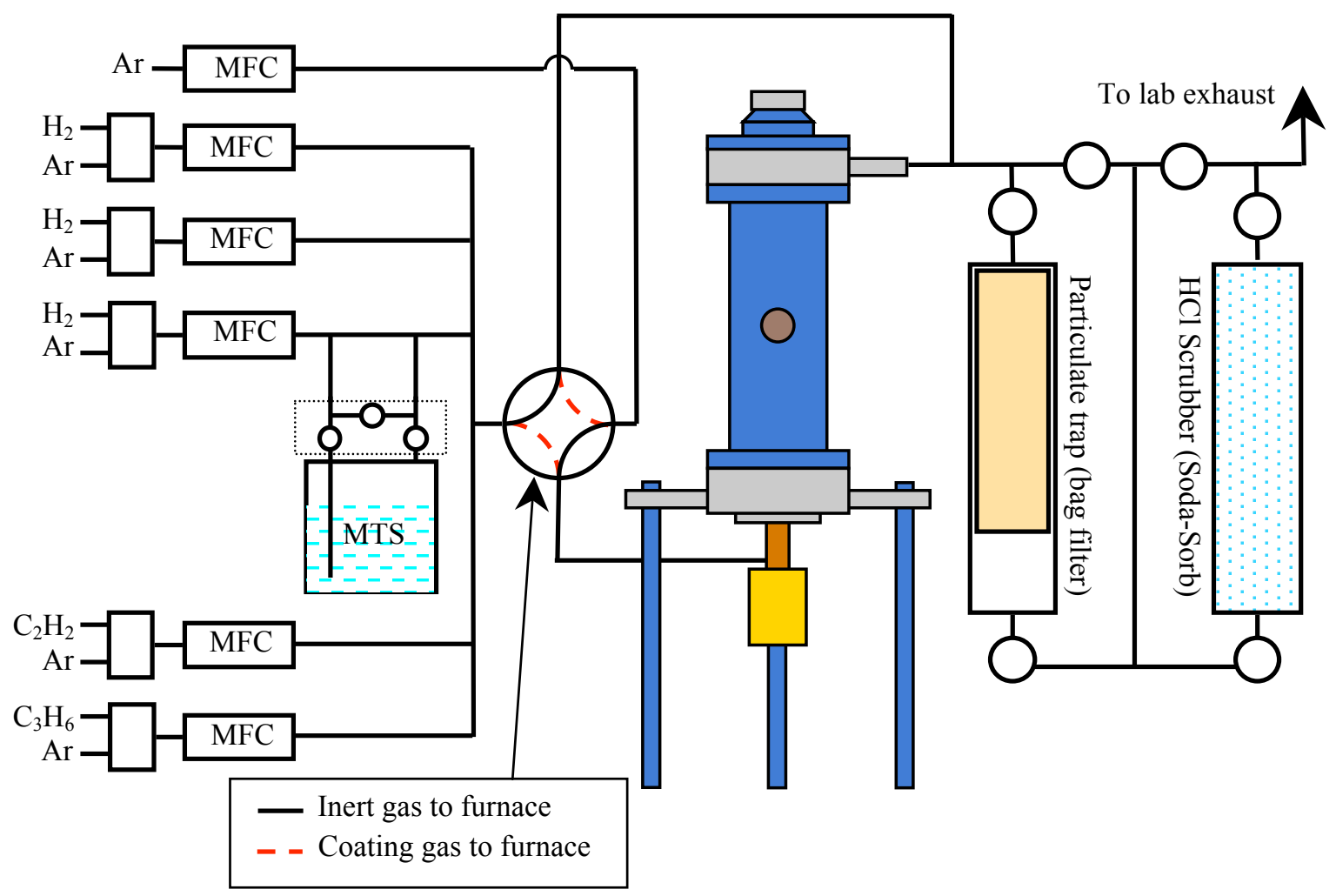

Figure 6-3. Schematic flow diagram of ORNL coating system. MFC = mass flow controller, MTS = methyltrichlorosilane. 


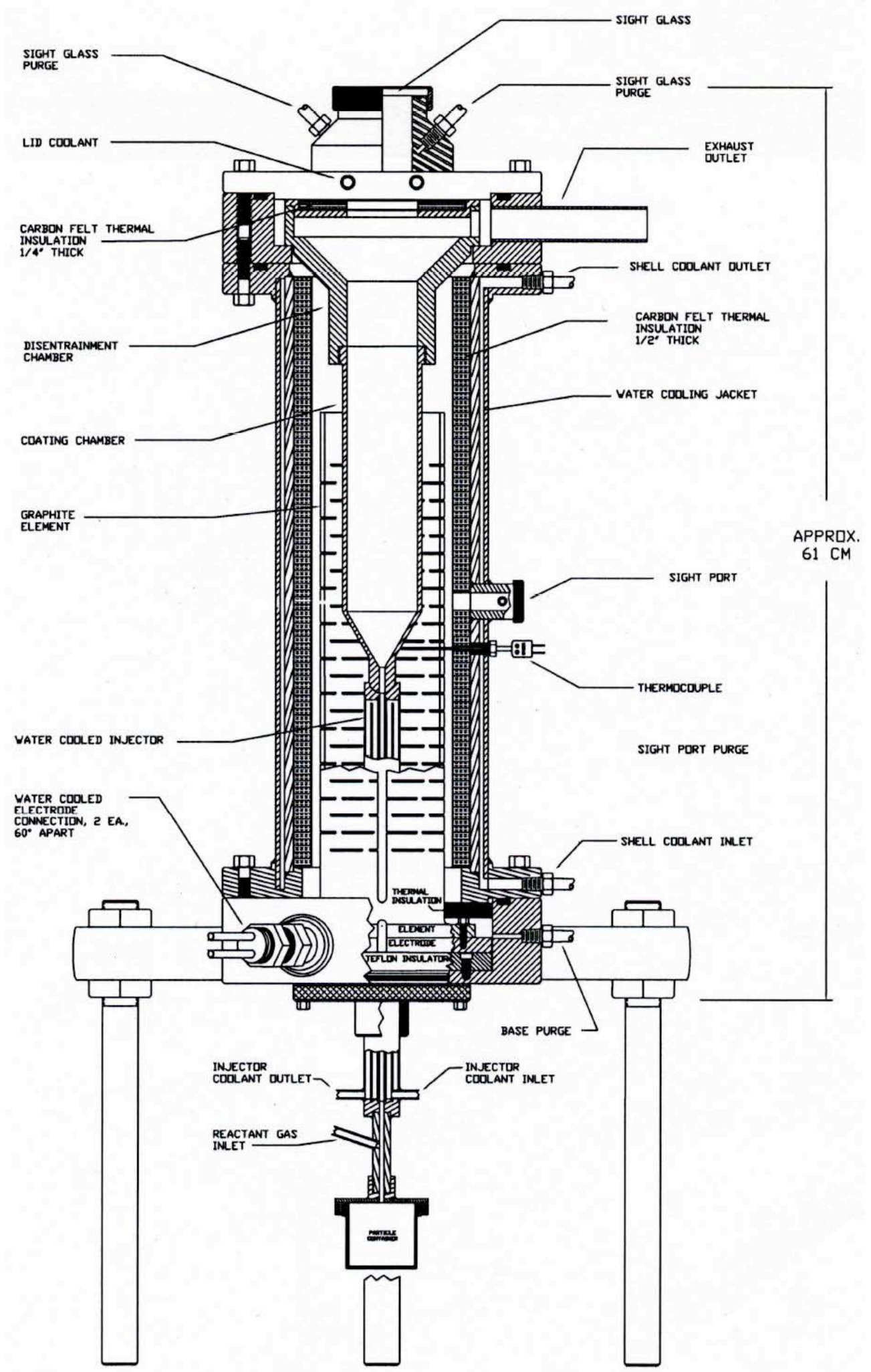

Figure 6-4. Detailed drawing of a 50-mm laboratory-scale FB-CVD furnace. 


\subsubsection{Coating Furnace Maintenance}

The fluidized bed chemical vapor deposition process for applying the carbon layers in TRISO particles utilizes the hydrocarbon gases acetylene and propylene. The gases are decomposed at elevated temperature to form a pyrolytic carbon coating on the particles with hydrogen and carbon soot as byproducts of the reaction. The soot is typically deposited on the inner surfaces of the water-cooled furnace lid, the graphite coating chamber and its lid, the gap around the top of the furnace, and on the inner surfaces of the exhaust lines (Figure 6-4). The sooty film of carbon deposited on the internal parts of the furnace must be removed after each coating run. The soot that builds up on the inner surface of the unit can clog exhaust ports causing an unacceptable increase in back pressure in the coating furnace. Also, the soot can fall back into the coating chamber during the $\mathrm{SiC}$ deposition and become inclusions in the $\mathrm{SiC}$ layer. These carbon inclusions represent defects in the $\mathrm{SiC}$ and are to be minimized to the maximum extent possible.

For the $50 \mathrm{~mm}$ coating furnace shown in Figure 6-4, the particle coater cleaning procedure involves partial disassembly of both the upper and lower portions of the furnace. The outer furnace lid is removed allowing access to and removal of the disentrainment chamber and its lid, and the conical coating chamber. Once removed the outer furnace lid and the graphite disentrainment chamber and its lid are cleaned using a brush and HEPA vacuum cleaner to remove the carbon soot film from all surfaces. The brush and vacuum are also used to remove the soot buildup from the accessible internal surfaces of the coating furnace and the opening to the exhaust port of the furnace. Due to carbon and $\mathrm{SiC}$ deposits on the inlet of the conical coating chamber, it can not be cleaned sufficiently for re-use. Therefore, it is discarded and replaced after each TRISO coating run. Note that the carbon soot is friable and potentially contains radioactive contamination, so appropriate safety measures must be taken.

Once the top of the furnace has been cleaned, the water cooled gas injector and its pass through plate are removed from the bottom of the furnace. Carbon soot is brushed and vacuumed off the components as well as the inner surfaces of the lower portion of the furnace. In addition to carbon soot, it is common to find partially coated particles in the bottom of the furnace. These particles are removed along with the carbon soot. While the furnace is open, the heating element and thermocouple can also be inspected.

After cleaning the bottom of the furnace and its components, they are reinstalled, taking care to ensure that the sealing surfaces are clean and free of debris. Then, with the bottom of the furnace assembled, the new conical coating chamber, the disentrainment chamber and its lid, and the outer furnace lid are reinstalled, again taking care to ensure that sealing surfaces remain clean.

It is important not to leave a coating furnace disassembled for extended periods of time. This can lead to condensation of moisture on the inside surfaces of the furnace, which can lead to corrosion of the metallic components. In addition, once the furnace is reassembled, it is a good practice to maintain a slow inert gas purge to keep the furnace clean for the next use.

\subsubsection{Process Gas Control System Maintenance}

The process gas control system (Figure 6-3) consists of the coating gas and MTS vapor supply system (upstream of the furnace) and the exhaust gas handling system (downstream of the furnace). The gas supply system components require little maintenance provided that they are adequately purged with inert gas prior to and following a coating run. The mass flow meters and gas supply piping are purged with argon gas for several minutes both before and after use with the reactive coating gases. This preventative maintenance significantly increases the useful life 
of the mass flow controllers and keeps the inner surfaces of the supply piping free of condensed species. The elements of the gas supply system that do require periodic attention are the inventories of the process reactants and the inert purge gas. Prior to a coating run, it must be determined that there are adequate inventories to complete the full coating run.

The exhaust gas handling system consists of the exhaust gas piping, the particulate trap (soot filter), and the $\mathrm{HCl}$ scrubber (soda-sorb acid neutralizer). Due to the amount of soot produced during carbon deposition, a disposable filter is used to capture the soot prior to the exhaust gas entering the facility off gas system. The condition of the soot filter can be monitored by tracking the back pressure in the coating furnace during operation. The furnace back pressure is monitored periodically during the coating run. An increase in furnace back pressure of approximately 5\% indicates that the soot filter needs to be replaced prior to the next coating run. When the soot filter is replaced, the exhaust gas piping needs to be inspected and cleaned as needed to ensure that soot build up does not restrict the gas flow.

During $\mathrm{SiC}$ deposition, $\mathrm{HCl}$ is generated as a byproduct of the deposition reaction and is exhausted from the coating furnace. The $\mathrm{HCl}$ should be neutralized by a soda-sorb scrubber (or equivalent) prior to entering the facility off gas system. The scrubber is a packed bed of indicator grade soda-sorb granules. The indicator grade soda-sorb changes color as it is used. The walls of the scrubber are transparent so the operator can observe when the soda-sorb needs to be changed. The entire scrubber can be designed as a disposable unit to simplify this maintenance step.

\subsubsection{Fuel Element Fabrication Equipment}

The overcoating and compacting process described in Section 4.1.3 consists of five major steps: (1) production of the matrix precursor, (2) overcoating, (3) compacting, (4) carbonization, and (5) heat treatment. Each of these five major processes incorporates one piece or multiple pieces of equipment. The maintenance requirements for each piece of equipment are summarized here.

Production of the matrix precursor involves mixing two types of graphite with a liquid resin in the presence of a solvent. The vessel used to hold the graphite, resin, and solvent is then placed on a jar mill and rotated for a period of time. The vessel used to hold the matrix can either be cleaned or discarded. Periodic maintenance involved with the jar mill includes replacing and or lubricating the rubber covers to the rotating axles that hold the jar that contains the matrix.

Overcoating is the process of tumbling TRISO particles with the matrix precursor in order to build up a layer around each individual TRISO particle. Overcoating is performed in a stainless steel vessel that is rotated via an electric motor. A solvent is delivered to the vessel via a syringe pump that runs into an ultrasonic atomizer. There are no routine maintenance requirements for the electric overcoater, syringe pump, or atomizer. The syringe used in the syringe pump must be changed out if the rubber seals begin to deteriorate, which may take up to 6 months of continuous use. The stainless steel overcoater must be cleaned with a solvent after a series of overcoating runs.

After overcoating is completed the overcoated particles are sized via sieves on an electronic sieve shaker. The sieve shaker requires no routine maintenance. The sieves themselves must be cleaned of particles using a fiber brush or pressurized air between each use or even during use, depending on the degree of clogging that occurs and the amount of material being processed. Blocking of the sieve holes by particles severely affects the performance of the sieve. Completely removing all trapped particles from a sieve can be tedious, but it is especially 
important if they are used for different production lots. The sieves must also be visually inspected for damage prior to every use.

After sieving, the overcoated particles are tabled in order to remove highly aspherical overcoated particles or matrix debris. The tabler is made of stainless steel and is vibrated electronically. No routine maintenance is required for this unit, other than cleaning of the table surface with a solvent to remove carbon dust so that particles can move freely.

A hydraulic press and steel die are typically used to fabricate cylindrical compacts. The hydraulic reservoir used to apply force during compacting must be filled with the proper weight oil, and the piston must be checked for leaks prior to each use.

A tube furnace with flowing helium may be used to carbonize the compacts. Residue builds up inside the quartz tube, especially at the edges of the heated zone. After each use this residue must be wiped out. Despite this periodic cleaning, some carbonaceous residue that can not easily be removed accumulates on the inside of the tube, so it needs to be changed out if the accumulations become large enough to affect the insertion and withdrawal of the sample boats. The volume of helium in the tank used to deliver helium to the tube furnace must also be checked prior to every run. If the bottle does not contain a sufficient quantity of helium to complete the run it must be changed out or supplemented. Ultra-high purity (UHP) helium is used for compact carbonization.

The carbonized compacts are subjected to a final heat treatment of $1800^{\circ} \mathrm{C}$ (up to $1950^{\circ} \mathrm{C}$ for spheres) under vacuum. The vacuum pump used to apply the vacuum should be monitored for performance. If a change in vacuum performance is noted, changed out of the pump oil may be required.

\subsection{Relative Priority of Maintenance Procedures}

Certain maintenance issues may have a direct effect on fuel quality and thus would be considered higher priority to the coated particle fuel inspection. The kernel processing equipment maintenance described in Section 6.1.1 is mostly related to functionality and efficiency of the process. Of higher priority would be maintenance issue related to the coating process. The cleaning procedure to remove soot and residual particles is of the utmost importance. Excessive carbon soot build up in the coating furnace can exacerbate defects caused by the trapping of this soot within or between the coating layers. This can lead to weakened or totally failed fission product retention layers. These types of defects are not likely to be removed by the tabling and sieving typically performed to enhance the coated particle quality. Trapped particles are also an important quality control concern because they can become freed during subsequent coating runs and become inadvertently included in subsequent batches. Of secondary, but still high importance is maintenance of the inlets and outlets for the process gases. Changes in the gas delivery can be directly correlated to the properties of the coatings. Compacting equipment maintenance, as described in Section 6.1.3, is also mostly related to functionality. However, proper maintenance and cleaning of the sieves is a priority in order for them to perform their quality control purpose and in order to prevent cross contamination of different process lots. 


\section{SAMPLING METHODS, STATISTICAL ANALYSIS METHODS AND ACCEPTANCE CRITERIA}

This section describes the sampling and statistical methods used to determine if a material lot demonstrates acceptable values for the critical product parameters discussed in Section 2. A material lot can be a single batch or composite of multiple batches of kernels, coated particles, or final fuel elements or any subset thereof for which a determination of product acceptance is being performed. One hundred percent inspection of the TRISO coated particles and fuel elements is not feasible because of the vast number of coated particles and compacts used in the reactor and because some analyses are destructive in nature. For this reason, standard QC statistical sampling and analysis methods are used to determine the properties of a large material lot based on analysis of a smaller subset of the lot that is a representative sample of the parent lot. Fuel specifications allow for statistical sampling and specify criteria by which the results of the statistical analyses are used to establish that the fuel meets the specification to an acceptable confidence level.

\subsection{Sampling Methods}

The first step in applying statistical analysis methods to acquire quality control data is to obtain a sample from the lot of material being evaluated. This sample must be taken using an appropriate random sampling method in order to ensure that the sample is representative of the parent lot.

Simply pouring material out of a container is usually not sufficient and should be avoided due to the fact that stratification can occur (e.g., heavier particles may migrate to the bottom of a container). Numerous methods may be used for random sampling. Three common methods used for coated particle fuel are scoop sampling, chute riffling, and rotary riffling. Scoop sampling is the technique of pouring particles into a pan, stirring the particles to homogenize the lot, and then scooping small quantities of particle from various regions in the pan. Note that taking one scoop of particles out of the top of a container is not a good scoop sampling technique. Scoop sampling is not a preferred method, but it may be sufficient for some measurements, depending on the sample size versus lot size and allowable measurement uncertainty. In most cases, chute riffling should be considered the minimum acceptable method for obtaining a random sample. Rotary riffling is recommended over chute riffling, because it is typically more efficient and about an order of magnitude more accurate in terms of the randomness of the sample obtained.

For macro sized items such as fuel compacts or spheres, random selection can be performed using random number generators or tables. Every fuel compact or sphere in the entire lot being inspected is assigned a number. Each compact or sphere to be analyzed is selected by a sequential series of random numbers, where each assigned number appears once and only once in the list. The random number list can be prepared as part of the product inspection plan, if the number of items in the lot to be tested is foreknown. Lots with excessively large populations could be selected by grouping and randomly selecting a group, then randomly selecting individual items from that group. However, the grouping must also be done by a random process. 


\subsubsection{Chute Riffling}

An example of a chute riffler is shown in Figure 7-1. The general concept is to deliver a flow of particles to a series of chutes that direct the particles to two collection bins. The delivery stream is typically fanned out to evenly deliver the particles into multiple chute entrances typically arranged in a row, where alternate chutes lead to the left or right bin. This device is also called a chute splitter, because it divides the sample into roughly two equal halves. Chute rifflers can be designed to feed into more than one bin, typically by stacking the process that splits the feedstock in half. One issue that can be of particular concern with standard chute rifflers is the likelihood of samples becoming temporarily lodged inside of the chute assembly, resulting in subsequent cross contamination between different particle lots. This results in the need for disassembly and cleaning between uses.

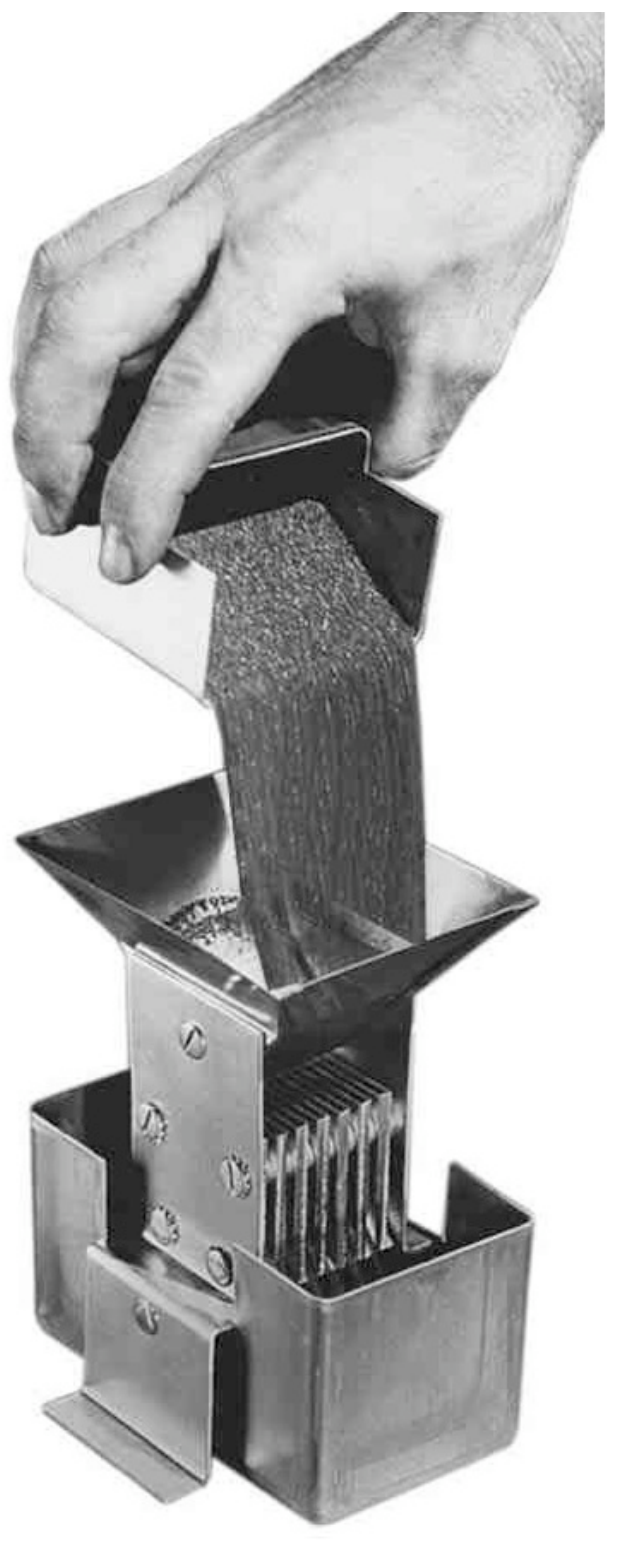

Figure 7-1. Standard miniature chute splitter (image taken from http://www.lavallab.com/sample-division/sample-splitter.htm). 


\subsubsection{Rotary Riffling}

There are many types of rotary riffler designs. The general concept is to deliver particles in a slow steady stream to a train of individual receptacles. The receptacles are arranged in a circle and either the delivery nozzle or receptacles are rotated so that a very small fraction of the feedstock is delivered to each receptacle during each pass. If the delivery time into each receptacle is constant, then the result in an equal splitting of the feedstock. A 10 receptacle rotary riffler such as that shown in Figure 7-2 provides a convenient factor of 10 reduction in sample size for each pass through the riffler. This simplifies preparation of a specific target sample size and is more efficient than the factor of 2 provided by the chute splitter discussed above. The delivery region for the rotary riffler in the figure is enclosed to prevent ejection of particles. Open rifflers available commercially are not recommended because of the tendency of small, low mass particles (especially uncoated kernels) to dance around due to static charge.

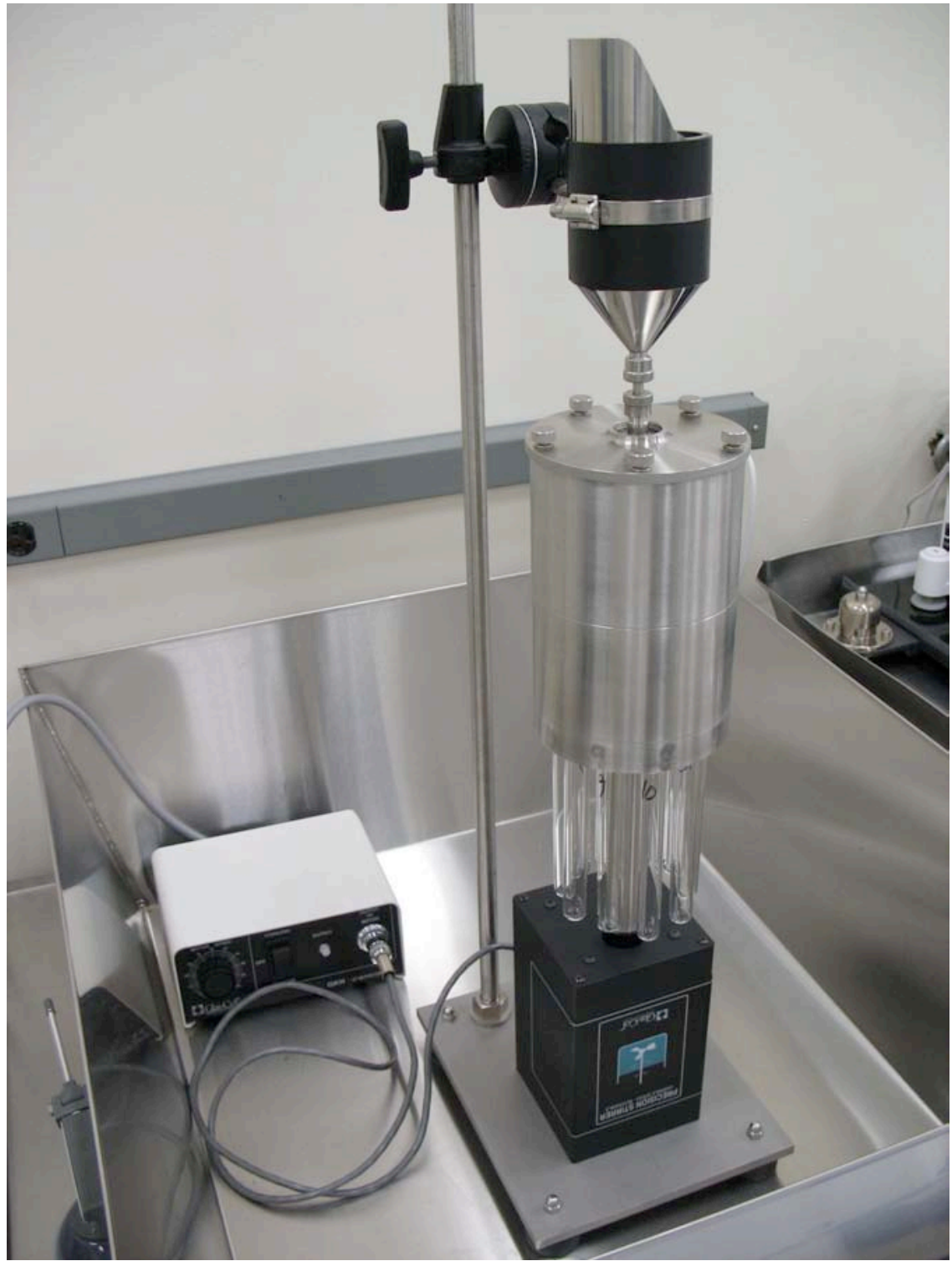

Figure 7-2. Rotary riffler for coated particle fuel QC designed by ORNL. 


\subsection{Statistical Methods}

There are two basic types of material properties of interest for coated particle quality control. A variable property is described by a numerical value (e.g., thickness or density). An attribute property is a classification of an item in the lot as defective or nondefective versus a given standard (e.g., above or below an acceptable cut-off value for aspect ratio or existence of an unacceptable $\mathrm{SiC}$ layer). Variable sampling and attribute sampling statistical methods are used by coated particle fuel fabricators to determine the properties of a parent lot based on analysis of a small random representative sample.

\subsubsection{Variable Sampling}

For variable sampling, each item of a sample is measured and a mean and standard deviation are calculated. These values are then used to determine if the parent lot can be predicted to meet the specified criterion up to a specified confidence level (typically 95\%). The two relevant variable property criteria found in coated particle fuel specifications are an acceptable range for the mean and a tolerance limit on the fraction of particles beyond one or two bounding critical limits.

\subsubsection{Student's-t Test for Criteria on the Mean}

Equations 7-1 and 7-2 are used to determine the confidence interval on the mean. A and B are the minimum and maximum predicted values for the mean of the parent lot up to the specified confidence level. If $\mathrm{A}$ is greater or equal to the specified minimum mean value and $\mathrm{B}$ is less than or equal to the specified maximum mean value, then the parent lot satisfies the specification.

$$
\begin{aligned}
& A=\bar{x}-\frac{t_{n-1} \sigma_{x}}{\sqrt{n}} \\
& B=\bar{x}+\frac{t_{n-1} \sigma_{x}}{\sqrt{n}}
\end{aligned}
$$

The mean $(\bar{x})$ and the standard deviation $\left(\sigma_{\mathrm{x}}\right)$ are obtained from the measurement performed on a sample of $n$ items. The term $t_{n-1}$ is the Student's-t value for $n-1$ degrees of freedom. The Student's-t value is also dependent on the specified minimum confidence level and whether the test is one-tailed or two-tailed. A two-tailed test is invoked if both the upper and lower limits must be simultaneously satisfied. If there is only one limit or each limit is considered independently, than the test is one-tailed. This detail should be specified in the fuel specification. Tables for the Student's-t value can be found in many statistics references or can be called by a function in Microsoft Excel.

\subsubsection{Tolerance Factor Test for Criteria on the Distribution}

Equations 7-3 and 7-4 are used to predict the population in the tails of the parent lot distribution for the measured parameter to a given confidence level. $\mathrm{C}$ is the minimum value for which all but the fraction of the population specified by the tolerance limit is above. $\mathrm{D}$ is the maximum value for which all but the fraction of the population specified by the tolerance limit is below. If $\mathrm{C}$ is greater than the critical lower limit and D is less than the critical upper limit, then the parent lot satisfies the specification. 


$$
\begin{aligned}
& C=\bar{x}-k_{n} \sigma_{x} \\
& D=\bar{x}+k_{n} \sigma_{x}
\end{aligned}
$$

The tolerance factor $\left(\mathrm{k}_{\mathrm{n}}\right)$ is dependent on the number of items measured $(\mathrm{n})$. The tolerance factor is also dependent on the specified tolerance limit, the specified minimum confidence level, and whether the test is one-tailed or two-tailed. Tables and equations for the tolerance factor can be found in many statistics references.

\subsubsection{Deviation from the Normal Distribution}

The derivations of the Student's-t test and tolerance factor test involve an assumption of a normal (or Gaussian) distribution. Any measured sample will always deviate to some degree from perfect normality. Only severe deviations from normality will impact the Student's-t test for the mean. As might be expected, the tolerance factor test for the distribution, which tries to determine the population in the tails of the distribution, is more sensitive to the shape of the distribution. Effects of non-normal distributions are discussed in the reference ORNL/TM$2005 / 542$.

Because of the possible impact of the distribution on the accuracy of the statistical sampling results, the sample distribution must be considered. There are many ways of determining deviation from normality. Some of the common tests, such as the Shapiro-Wilks test, are overly stringent and actually impose a penalty as the sample size increases. Simpler and less stringent tests may be more appropriate, such as a simple graphical comparison to a Gaussian distribution. The fuel specification should include guidance on an acceptable check on normality for variable sampling.

\subsubsection{Attribute Sampling}

For attribute sampling, each item of a sample is inspected and a decision is made whether that item is defective or non-defective. The determination is based on the definition for the defect. This definition may be based on a control limit for a measured value (e.g., aspect ratio must be less than a specified value), a unique feature (e.g., missing layer), or any other standard by which each item can be judged. The number of defective items versus the total number of items inspected is used to determine if the parent lot can be predicted to meet the specified criterion up to a specified confidence level (typically 95\%). In a fuel specification, attribute property criteria consist of a control limit or definition for the defect and a tolerance limit for the allowable fraction of the population that is defective (maximum allowable defect fraction). The standard statistical method for attribute sampling for coated particle fuel QC is the binomial distribution test.

\subsubsection{Binomial Distribution Test for Criteria on the Defect Fraction}

Equation 7.5 is the fundamental equation for the binomial distribution.

$$
L_{c}=1-\sum_{i=0}^{n_{d}} \frac{n !}{i !(n-i) !} L_{t}^{i}\left(1-L_{t}\right)^{n-i}
$$


The confidence level $\left(\mathrm{L}_{\mathrm{c}}\right)$ is calculated for the detected number of defects $\left(\mathrm{n}_{\mathrm{d}}\right)$ out of the total number of analyzed items (n), using the allowable maximum defect fraction or tolerance limit $\left(\mathrm{L}_{\mathrm{t}}\right)$. If the confidence level is greater than the minimum allowed confidence level (typically $95 \%$ ), then the product is accepted. Commands based on equation 7-5 to calculate $\mathrm{L}_{\mathrm{c}}$ are available in Microsoft Excel. One can also approximate this form with a Poisson distribution for large $n$.

\subsection{Effect of Sample Size}

Sample size affects the accuracy of the measured value as well as the probability of incorrect assessment of the acceptability of the fuel versus the product specification. Any sample size short of $100 \%$ of the parent lot will result in some uncertainty. The parameters $\mathrm{t}_{\mathrm{n}-1}$ and $\mathrm{k}_{\mathrm{n}}$ decrease with increasing $\mathrm{n}$. It is clear from equations 7-1 through 7-4 that, for increasing $\mathrm{n}$, the maximum difference is reduced between the measured mean of the sample and the true mean of the parent lot. Increasing the sample size reduces the probability of false rejection of an acceptable product. Larger sample sizes also contribute to better determination of the distribution for determination of deviation from normality. Knowledge of the expected standard deviation is important when determining the minimum acceptable sample size. Larger standard deviations require larger sample sizes to obtain a well defined distribution and to minimize the probability of false rejection. There is however a point of diminishing return, where further increase in sample size does not greatly affect the uncertainty of the analysis. Interestingly, for the sampling methods discussed, the level of sampling uncertainty is only a factor of the number of items measured and is not affected by the fraction of the parent lot sampled. This means that it is more efficient to sample larger parent lots. A manufacturer should develop a fuel product sampling plan, such as those listed in Table 7-1, to provide guidance as to appropriate sample sizes for each specified parameter, or a method of determining sample size based on the results of the analysis should be stated. Section 3 of EDF-4542 provides a description of one method using a probability of rejection power curve that can be used to determine the appropriate sample size for a given parameter.

In attribute sampling, the required sample sizes are much larger and inversely proportional to the tolerance limit. The number of items that must be inspected also depends on the number of defects detected. A typical sampling plan will calculate in advance the maximum allowable number of defects for a given minimum sample size for which the binomial distribution will yield the minimum specified confidence level. If the maximum number of allowable defects is exceeded, then the product can be rejected or additional items can be inspected to reduce the probability of a false rejection. A typical sampling plan will include multiple stage inspections.

\subsection{Cautions for Applying Statistical Sampling Methods}

Certain assumptions are made in the application of the sampling methods described above. These assumptions should be noted in a sampling plan and caution should be used to ensure that these assumptions are not violated. For instance, the Student's-t and tolerance factors tests rely on the assumption that the measured parameter is well controlled by the process and the distribution of the measured parameter is the parent lot does not deviate greatly from Gaussian. For the attribute test, errors due to a hypergeometric distribution can arise if the sample size is large relative to the lot size, if the lot consists of few items, or if the defect number is large relative to the sample size. 
Some sampling procedures may be limited by what is reasonably achievable using current characterization technology. The statistical methods described in this chapter require an independent measurement of each item. Some characterization methods perform a single measurement on the entire sample. Examples of these are chemical analysis of kernel stoichiometry and porosimetry analysis of open porosity or envelope density. These analyses evaluate, at best, the average value of a critical parameter, but do not resolve the value for each individual particle in the sample. When applying and interpreting the statistical analysis, the entire measured sample must be considered as one item (one measurement per item). Multiple samples must be measured to get $\mathrm{n}>1$ and apply the statistical methods to derive a confidence interval. This does not greatly impact variable sampling of the mean because each measured sample would produce a good average value due to the large number of particles in the sample and the standard deviation between the measurements on multiple samples would be very low, which would offset the larger Student's-t value and smaller n. However, variable sampling of the distribution can be significantly misinterpreted. Because there is no resolution at the individual particle level, the tolerance factor test can not be applied to determine the distribution. For example, a kernel batch with a bimodal distribution of $50 \% \mathrm{X}$ density and $50 \% 3 \mathrm{X}$ density will reproducibly yield a measurement of $2 \mathrm{X}$ density for each multi-kernel sample measured. Five measurements of different samples would yield a mean of $2 \mathrm{X}$ and a very low standard deviation. The Student's-t test will correctly predict the mean of the parent lot but will grossly under predict the population in the tails of the distribution. Without additional data, a false conclusion could be drawn that all the kernels have a density very close to $2 \mathrm{X}$. In cases where groups of particle are to be used to obtain a single measurement, such as kernel stoichiometry, kernel or buffer density, and pyrocarbon open porosity, if conclusions are to be drawn regarding the individual particles, complimentary inspections must be performed to resolve the true distribution at the particle level.

Inspection plans should be clear as to how measurements are made, how the data is interpreted, and how the results are to be applied. Improper application of inspection methods can lead to false determinations of fuel quality. 


\subsection{Reference Documents}

Information in Section 7 has been summarized from the documents listed in Table 7-1. For more detailed information, the reader should consult those documents. Table 7-1 contains a list of sampling plans used for the AGR program as well as several summaries of the application of appropriate statistical methods to satisfy a coated particle fuel specification. Details of the statistical methods can be found in a standard statistics textbook.

Certain documents listed below are for official internal NRC use only and their distribution is restricted to NRC unless approved by both NRC and DOE. These documents are labeled with an asterisk $\left(^{*}\right)$.

\section{Table 7-1. List of reference documents.}

\begin{tabular}{|l|l|l|}
\hline Document Title & Reference & Description \\
\hline $\begin{array}{l}\text { *Statistical Methods for Material } \\
\text { Characterization and Qualification }\end{array}$ & $\begin{array}{l}\text { *ORNL/TM- } \\
2005 / 542\end{array}$ & $\begin{array}{l}\text { This document describes the statistical methods used } \\
\text { for fuel QC in detail, and provides examples of their } \\
\text { application. Tables of Student's-t and tolerance } \\
\text { factors are also provided. }\end{array}$ \\
\hline $\begin{array}{l}\text { *Statistical Methods Handbook } \\
\text { for AGR Fuel Materials }\end{array}$ & $\begin{array}{l}\text { *INL/EXT-05- } \\
00349\end{array}$ & $\begin{array}{l}\text { This document provides information on the } \\
\text { application of statistical methods to fuel QC. }\end{array}$ \\
\hline $\begin{array}{l}\text { *Statistical Sampling Plan for } \\
\text { AGR Fuel Materials }\end{array}$ & *INL EDF-4542 & $\begin{array}{l}\text { This example of a sampling plan is complimentary to } \\
\text { the AGR-1 Fuel Product Specification. }\end{array}$ \\
\hline $\begin{array}{l}\text { *Statistical Sampling Plan for } \\
\text { AGR-2 Fuel Materials }\end{array}$ & *INL PLN-2691 & Sampling plan used for AGR-2 irradiation test \\
\hline $\begin{array}{l}\text { *Statistical Sampling Plan for } \\
\text { AGR-3 and -4 Fuel Materials }\end{array}$ & *INL EDF-6917 & Sampling plan used for AGR-3 and -4 irradiation test \\
\hline $\begin{array}{l}\text { *Evaluation of NP-MHTGR } \\
\text { Performance Test Fuel Quality } \\
\text { Control Data }\end{array}$ & *EGG-NPR-10130, & $\begin{array}{l}\text { This document describes the statistical methods used } \\
\text { for the NPR program. }\end{array}$ \\
\hline $\begin{array}{l}\text { Research and development on } \\
\text { HTGR fuel in the HTTR project }\end{array}$ & $\begin{array}{l}\text { Nucl. Eng. and } \\
\text { Design, 233 (2004) } \\
163-172 .\end{array}$ & $\begin{array}{l}\text { This paper briefly describes the sampling for the } \\
\text { HTTR project. }\end{array}$ \\
\hline
\end{tabular}




\section{TRAINING AND QUALIFICATION OF FUEL FABRICATION FACILITY STAFF}

The production of HTGR coated particle fuel has many differences from the production of LWR fuel. These differences stem from the significant differences in fuel design concepts and fuel fabrication inspection methods. The HTGR fuel fabrication facility itself has many significant differences due to:

1. The much higher uranium enrichment $(\sim 20 \%$ versus $\sim 5 \%)$ of the fissionable material in the uranium fuel kernel and its close proximity with a moderator (carbon) which may make nuclear criticality issues more important. Also, an aqueous method is used for kernel production.

2. The use of sol-gel technology rather than powder technology for the production of the fuel kernel.

3. The use of chemical vapor decomposition (CVD) techniques for the application of the coating layers. This process can result in a high volume soot laden effluent.

4. The use of carbon technology for the manufacture of fuel element forms.

5. The large quantity of potentially explosive gases (used for coating) that will be consumed in the facility during the fuel production.

6. Relatively small fuel coating batch sizes ( $\sim 5 \mathrm{~kg}$ or less) due to the physics of the coaters.

7. Heavy reliance on statistical methods for quality control acceptance inspections and testing for the extremely large number of fuel particles (billions) and compacts or pebbles (many hundred thousand) manufactured for an HTGR core rather than near $100 \%$ inspection methods used for the much small number (tens of thousands) of fuel rods manufactured for an LWR core.

8. A large number of very specialized inspection and testing techniques.

9. The heavy reliance on process control specifications and knowledge for the manufacture of the fuel.

Both LWR and HTGR fuel production facilities require specialized staff. However, the greater complexity of HTGR fuel production, the issues associated with inspection and process control, and the singular importance of fuel particle integrity to plant safety performance require a higher level of staff training and accountability.

In many respects training and qualification of coated particle fuel fabrication staff will enlist the issues and needs that all nuclear programs require:

1. Training programs shall include all important topics, quality assurance principles, procedures, accident responses, diagnostics, teamwork, and experience. ${ }^{1}$

2. Learning objectives should provide measurable requirements and standards for evaluating performance.

3. Guidelines and qualification checklists should be used to ensure uniformity of lessons

\footnotetext{
${ }^{1}$ Current HTGR coated particle fuel production technology involves significant human involvement and intervention in both the fuel fabrication process and in the control of quality. Research and development is underway to more highly automate HTGR fuel production in order to increase productivity and quality and to reduce costs. The inspection guidance in this section reflects the current state-of-the-art in terms of the relative reliance on human performance vs. automation for the production of high quality HTGR fuel. This guidance would be expected to change as fuel fabrication facilities become more highly automated.
} 
and on the job training.

4. Instructors should maintain and improve their knowledge and teaching skills; feedback should be used to gauge lesson and instructor effectiveness.

5. Training programs should include drills to ensure that personnel can respond correctly to off-normal manufacturing situations and emergencies.

6. Facility process equipment design and operation, safety, and regulatory requirements should be part of the indoctrination.

It is likely that any training program will be part of the facility operational acceptance review process and possibly the licensing process.

\subsection{Qualification and Training Scope}

Technological competency is generally based on both general and specific expertise and demonstrated proficiency in the technical work task. While each organization has its own means for evaluating competency, the following methods are generally included:

1. Review of education level and prior training

2. Review of work experience

3. Review of task specific training and experience

4. Demonstrated competency in the specific and related tasks (often by following written procedures)

The staff member's general education level and prior training are seen as a foundation or background for integration of the knowledge and/or skills required to do the assigned task. In an HTGR fuel fabrication facility, this usually consists of a technical education or several years of experience in a technical area, a general understanding of the operation of a nuclear materials facility, and a basic understanding of the hazards involved in such facilities.

Work experience is generally more focused and it is desirable for it to be closely related to the tasks at hand, although an exact match is not necessary. For example, experience in a nuclear laboratory is more relevant than experience in filling out paperwork for someone who will be conducting hands-on fuel fabrication work. On the other hand, a background in statistics is more relevant for someone who will analyze the results of fuel quality measurements. Even so, it is still important to have the general knowledge of a nuclear facility so that an understanding of the facility needs and limitations is firmly in mind.

Even with a strong background in nuclear facilities and technical analysis, the techniques involved in HTGR fuel production are so specialized that additional training is often necessary. This training will usually be composed of two parts. The first part is the theory of operation and the analysis of the task topic. The engineer or technical specialist would receive the most indepth training while the equipment operator or technician would receive a more general introduction. The second part is the actual operation of the equipment and hazards associated with the task. This training would be more hands-on and focused on the technician doing the actual work. It is likely that a certain amount of practice time will be necessary before the technician and engineer can collect and process the data in an error free and timely manner; this constitutes the task specific experience.

Finally, a minimal level of competency in the task must be demonstrated. This is usually accomplished in three steps. The first step involves a description of the activity and an 
appropriate level of theory. This is usually done in a classroom setting. The second step involves the demonstration and execution of the task under the guidance of an experienced person or instructor, usually following a procedure of some sort. The third step is then a test of competency. Once the staff member has demonstrated that the task can be accomplished without trouble, the staff member then runs a known sample of some sort through the task to see if a known answer can be duplicated. For example, inert material may be coated to determine if layers of proper thickness are being coated or an analytical task may process a sample of known impurity level to determine if correct values are recovered.

Table 8-1 shows suggested instructor competence levels for some selected positions. The actual instructor qualification will vary with the trainee and subject, but generally the instructor is expected to be more accomplished and experienced than the trainees. The instructor may be inhouse or hired from the outside.

Table 8-1. Suggested Instructor Competency Levels for Fuel Fabrication Areas.

\begin{tabular}{|c|c|c|}
\hline Trainee & Subject To Be Taught & Instructor's Qualifications \\
\hline Craftsperson & $\begin{array}{l}\text { Equipment installation and } \\
\text { maintenance }\end{array}$ & $\begin{array}{l}\text { Familiarity with the equipment design and operation } \\
\text { Knowledge and experience with the maintenance safety } \\
\text { hazards } \\
\text { Understanding of performance and quality issues } \\
\text { Understanding of the facility's conduct of operations }\end{array}$ \\
\hline $\begin{array}{l}\text { Fabrication } \\
\text { Engineer/Technician }\end{array}$ & $\begin{array}{l}\text { Fuel fabrication: } \\
\text { Kernels } \\
\text { Coatings } \\
\text { Compacting } \\
\text { Handling } \\
\text { Storage }\end{array}$ & $\begin{array}{l}\text { Familiarity and experience with the equipment design } \\
\text { and operation, especially with the specifics of the } \\
\text { fabrication step, such as sol-gel, CVD, } \\
\text { matrix/overcoating/press operation, and particle handling } \\
\text { issues } \\
\text { Knowledge and experience with the safety hazards and } \\
\text { how to monitor for potentially dangerous situations } \\
\text { Understanding of specific performance and quality issues } \\
\text { as well process monitoring needs. } \\
\text { Understanding of the facility's conduct of operations }\end{array}$ \\
\hline $\begin{array}{l}\text { Inspection and Quality } \\
\text { Engineer/Technician }\end{array}$ & $\begin{array}{l}\text { Fuel and compact } \\
\text { inspection: } \\
\text { Kernels } \\
\text { Coatings } \\
\text { Compacts } \\
\text { Analytic techniques }\end{array}$ & $\begin{array}{l}\text { Familiarity and experience with the analytic theory of } \\
\text { operation, apparatus design, and operation, especially } \\
\text { with the specifics required for HTGR work } \\
\text { Knowledge and experience with sample preparation, } \\
\text { potential problems, and false indications } \\
\text { Knowledge and experience with the safety hazards and } \\
\text { how to monitor for potentially dangerous situations } \\
\text { Understanding of the appropriate statistical measures and } \\
\text { their application. } \\
\text { Acceptable documentation means. } \\
\text { Understanding of the facility's conduct of operations }\end{array}$ \\
\hline Facility Management & $\begin{array}{l}\text { Industrial Hygiene \& } \\
\text { Facility Safety } \\
\text { Nuclear Materials } \\
\text { Accountability, Control, } \\
\text { and Storage } \\
\text { Fuel Fabrication } \\
\text { Quality Assurance, } \\
\text { Control, and } \\
\text { Documentation }\end{array}$ & $\begin{array}{l}\text { Familiarity and experience with nuclear facility } \\
\text { operations } \\
\text { Background in chemical and nuclear hazards } \\
\text { Familiarity with HTGR fuel fabrication and QC } \\
\text { Familiarity with nuclear criticality concerns } \\
\text { Management experience with high hazard facilities } \\
\text { Experience with a highly regulated environment } \\
\text { Familiarity with appropriate environmental concerns } \\
\text { Understanding of the facility's conduct of operations } \\
\text { Experience with the preparation of safety and regulatory } \\
\text { documents }\end{array}$ \\
\hline
\end{tabular}


The major areas of fuel production are:

1. Kernel fabrication, which starts with broth preparation and continues to sintering and final culling.

2. Coating, which starts with the bare kernel and applies all the layers.

3. Compacting, which starts with overcoating followed by carbonization and final heat treatment.

4. Inspection and quality control, which begins with the raw materials and continues to the final product. This area will require both general chemical and material analysis methods and the specialized methods for HTGR fuel inspection.

5. Documentation, which assumes special importance because of the role of process knowledge in the acceptance of the final product.

It is very likely that these areas will require specialized HTGR fuel fabrication training and the following sections will discuss the requirements in greater detail. The inspector should also note that in a highly automated facility much of the "process knowledge" may be programmed into the software of the advanced digital controls that runs the plant's manufacturing processes, so fuel facility operators need to understand these software programs.

Supporting these areas are:

1. Plant Management

2. Quality Assurance

3. Nuclear Materials Accountability

4. Criticality Control

5. Waste and Scrap Handling

In addition, because the role of safety is important in such a facility given the radiological and chemical hazards:

1. Radiological Safety

2. Chemical Process Safety

3. Criticality Safety

Chemical and fire safety may be a greater issue in an HTGR fuel facility than in an LWR fuel facility since an HTGR fuel fabrication facility involves volatile and potentially combustible materials.

\subsubsection{Kernel Fabrication}

A basic knowledge of the sol-gel and sintering process for producing the kernels will be required for the technicians conducting the day to day operations and a detailed knowledge of the actual process used will be required of the engineering staff. In addition, the staff will need to be well versed in the areas of quality assurance, nuclear material accountability and criticality control.

Kernel fabrication may be broken down into 3 areas depending on the specific process and layout design:

1. Kernel formation and drying

2. Kernel initial sintering

3. Kernel stoichiometry adjustment (heavy metal to oxide and/or carbide ratio) 
If this breakdown is used, the division of labor may require less individual overall knowledge about kernel fabrication knowledge; training would be concentrated on one of the specific areas. The following assumes that the kernel line staff would require a general knowledge of the overall process.

The background required for the engineering staff would be:

1. Degree in Chemical/Materials Engineering or equivalent

2. Experience in the Sol-gel process

3. Experience in high temperature chemical equilibrium

4. Experience with nuclear facilities and nuclear material handling

5. Indoctrination with the HTGR quality/safety culture

The background for the technicians:

1. Experience and/or training on the specific Sol-gel process

2. Experience with ceramic processing furnaces

3. Experience with nuclear facilities and nuclear material handling

4. Indoctrination with the HTGR quality/safety culture

The background for craftspeople:

1. Skills in the labor area of interest

2. Experience with pumps, valves, and wiring of such apparatus

3. Experience with nuclear facilities and the work rules

4. Indoctrination with general nuclear quality/safety culture

In addition to this basic background, the staff will have to be trained on the specific issues associated with the actual production facility, such as sub-plant layout, temperatures of broths, composition of broths and columns, vibrating nozzles, furnace operating conditions, chemical hazards, nuclear controls, and specific process and quality indications.

From the point of view of the inspector, the following is of specific interest:

1. Does the staff understand the basic process?

2. Does the staff understand the process and safety issues associated with the operation of the kernel line?

3. Does the staff understand the waste handling needs?

4. Does the staff know what the important safety and quality indicators are and what to do if they drift from the operating point?

As a general point, the staff should be aware of human factors issues and proper procedure writing so that errors, safety violations, and waste can be minimized.

\subsubsection{Particle Coating Fabrication}

The coating process is perhaps one of the most difficult parts of fuel production and carries with it a large burden of the process knowledge demand. The coatings are difficult to inspect and the performance of the fuel depends on their microstructure. A basic knowledge of the chemical vapor deposition (CVD) process will be required for the technicians conducting the day to day operations and a detailed knowledge of the actual process used will be required of the 
engineering staff. Since a considerable amount of maintenance is required for the coating apparatus, an understanding of the internals of the apparatus and the maintenance procedures will be required as well. In addition, the staff will need to be well versed in the areas of nuclear material accountability and criticality control as batches of kernels and coated particles will be assembled and handled during the process.

The background required for the engineering staff:

1. Degree in Chemical/Materials Engineering or equivalent

2. Experience with the CVD process and effluence handling

3. Experience with the necessary control and monitoring systems

4. Experience with explosive gas handling

5. Experience with nuclear facilities and nuclear material handling

6. Indoctrination with the HTGR quality/safety culture

The background for the technicians:

1. Experience and/or training with the specific CVD process and the controls

2. Explosive gas handling and safety

3. Experience with nuclear facilities and nuclear material handling

4. Indoctrination with the HTGR quality/safety culture

The background for craftspeople:

1. Skills in the labor area of interest

2. Familiarity with coater construction and maintenance methods

3. Explosive gas handling and electrical safety

4. Experience with nuclear facilities and the work rules

5. Indoctrination with general nuclear quality/safety culture

In addition to this general background, the operating staff will have to be trained on the specific issues associated with the actual production facility, such as coater temperatures, gases, flow rates, effluent filtering, chemical hazards, nuclear controls, and specific process and quality indications.

From the point of view of the inspector the following is of specific interest:

1. Does the staff understand the basic coating process?

2. Does the staff understand the process and safety issues associated with the operation of the coater?

3. Does the staff understand the issues associated with the large quantities of explosive gases?

4. Does the staff understand the need to properly handle the effluent from the coater?

5. Does the staff know what the important safety and quality indicators are and what to do if they drift from the operating point?

6. Does the staff understand the important process knowledge issues and how to monitor and document them? 
As a general point, the staff should be aware of human factors issues and proper procedure writing so that errors, safety violations, fire hazards, environmental concerns, and waste can be minimized.

\subsubsection{Compact/Pebble Fabrication}

Overcoating particles and compacting them into either cylindrical compacts or spherical pebbles occurs at a high value point in the fuel fabrication process; thus it is important that this sub process be conducted properly for both economic and quality control purposes. Since this task is centered around carbon technology, a background in carbon and graphite materials is of particular interest.

In addition, the staff will need to be well versed in the areas of nuclear material accountability and criticality control as batches of compacts or pebbles will be accumulated in the process.

The background required for the engineering staff:

1. Degree in Chemical/Materials/Carbon Engineering or equivalent

2. Experience with the overcoating and compacting process

3. High temperature carbon processing and impurity control

4. Experience with nuclear facilities and nuclear material handling

5. Indoctrination with the HTGR quality/safety culture

The background for the technicians:

1. Experience and/or training with matrix preparation methods and particle handling

2. Experience with the presses and furnaces and their maintenance and proper operation

3. Experience with nuclear facilities and nuclear material handling

4. Indoctrination with the HTGR quality/safety culture

The background for craftspeople:

1. Skills in the labor area of interest

2. Mechanical and electrical familiarity with overcoating coating apparatus, the presses, and the components of the firing furnace

3. Experience with nuclear facilities and the work rules

4. Indoctrination with general nuclear quality/safety culture

In addition to this general background, the operating staff will have to be trained on the specific issues associated with the actual production facility, such as the overcoating method, matrix preparation, impurity control, press operation, and furnace operations.

From the point of view of the regulator the following is of specific interest:

1. Does the staff understand the basic overcoating and compacting process?

2. Does the staff understand the goal to avoid breaking particles?

3. Does the staff understand the process and safety issues associated with the operation of the overcoating and compacting equipment?

4. Does the staff understand the need to properly protect the compacts or pebbles from high temperature exposure to impurities?

5. Does the staff know what the important safety and quality indicators are and what to do if they drift from the operating point? 
As a general point, the staff should be aware of human factors issues and proper procedure writing so that errors, safety violations, environmental concerns, and waste can be minimized. Of particular interest are problems that lead to particle damage or breakage and their early identification.

\subsubsection{Inspection and Quality Control}

While all fuel facilities have quality control methods and statistical metrics, HTGR fuel fabrication takes them further. The methods required for inspection are often difficult and complex, requiring special equipment and mathematical methods. Statistical methods and process control form the backbone of fuel acceptance criteria and will be scrutinized to a high degree. The personnel in this area will have to be familiar with a wide variety of analytic techniques and the proper application of statistical methods. Even if much of this work is conducted elsewhere, the fuel facility staff will still need to be able to evaluate the results.

The background required for the engineering staff:

1. Degree in Chemical/Materials Engineering or equivalent

2. Experience with the methods and equipment for quality control and analytic evaluation as well as their limitations

3. Experience with the statistical methods, how to apply them, and how to report them in a meaningful way

4. Experience with nuclear facilities and nuclear material handling

5. Indoctrination with the HTGR quality/safety culture

The background for the technicians:

1. Experience and/or training in the specific analytic methods and how to prepare the samples and report the results

2. Calibration methods

3. Experience with nuclear facilities and nuclear material handling

4. Indoctrination with the HTGR quality/safety culture

The background for craftspeople:

1. Skills in the labor area of interest

2. Familiarity with the necessary maintenance procedures and tools

3. Experience with nuclear facilities and the work rules

4. Indoctrination with general nuclear quality/safety culture

In addition to this general background, the staff will have to be trained on the specific issues associated with the actual production facility, how to handle the particles without damaging them prior to analysis, sample preparation methods, calibration methods, and the hazards associated with the analysis equipment and methods. Documentation and reporting will be important for this work area.

From the point of view of the inspector the following is of specific interest:

1. Does the staff understand the proper use and pitfalls of the analysis methods and equipment?

2. Does the staff understand the process and safety issues associated with the operation of 
the equipment?

3. Does the staff understand the proper application of the quality measures and statistical tools?

4. Does the staff know what the important safety and quality indicators are for both the analysis and the equipment in use and what to do if they drift from the operating point?

5. Does the staff understand the important parameters to measure and how to monitor and document them?

As a general point, the staff should be aware of human factors issues and proper procedure writing so that errors, safety violations, and rework can be minimized. Since this area impacts the entire fuel fabrication process and generates much of the assurance of proper fuel performance, great care needs to be taken to ensure reliable results.

\subsubsection{Documentation}

At the present time, both product and process parameters are necessary to determine if the fuel meets the desired specifications. The process information must be collected as the process is occurring; it is generally not possible to go back and reconstruct the process from the product, so care must be taken to collect and store this information from the start. Loss of this information is not just a matter of redoing a test; an entire batch of fuel may have to be scrapped if it lacks this pedigree.

Collecting the necessary documentation is not a separate task that requires more training; rather it is an awareness that the product is not complete without it. This is a matter of indoctrination and an operating culture about the way business is to be done. The inspector should quiz the staff and review the operating procedures to verify that process documentation is part of the normal conduct of operation.

Documentation is also important in the areas of configuration control. Process knowledge is useful within the limits of a specific design and operation of a process. If the design or operational method changes, the process knowledge may no longer be useful or of any value. Therefore, the regulator should verify that not only does the facility have a configuration control plan, but that this plan is tied into the process knowledge database. Loss of coordination of the two may render a batch of fuel unusable. This issue should not be overlooked by the management and facility staff.

\subsection{Training Program}

Generally, a training program is based on the following basic steps (see references):

1. The first step to conduct a needs analysis to determine if a training program will meet the needs of the facility. If the staff lacks the necessary background, a more formal and longer term education program may be necessary.

2. Next, design the training so that it meets the objective of the facility and process.

3. Develop the training in terms of a lesson plan, materials, and meeting times.

4. Establish the training requirements; decide what positions need a given type and level of training.

5. Implement the training through the classroom or by hands-on sessions.

6. Evaluation the training by determining if the desired behavior and skill levels are being reached. 
7. Finalize the training, reviewing several training cycles to determine the best combination of methods and resources.

The actual training program to be used by an HTGR fuel fabrication facility is beyond the scope of this document, but several items previously mentioned merit special note as they can be different from LWR fuel facilities:

1. The higher uranium enrichment of about $20 \%$ and its intimate mixture with a moderator (carbon) can make nuclear criticality issues more important. Also, an aqueous method is used for kernel production. The actual impact of this fact will depend on the design of the process and facility, but training should emphasize that fissile material control is important.

2. The large quantities of explosive gases (used for coating) that will be consumed in the facility during fuel production present an important chemical hazard and the training should note this.

3. The staff should be aware of the waste issues associated with the kernel line and how to handle the contaminated fluids.

4. The coaters will produce a large amount of soot and chemically contaminated effluent; the training should emphasize the potential environmental issues associated with the necessary filters.

5. The difficulties of handling the large numbers of small particles and the need to protect them from damage should be part of the training for all aspects of the process up to the formation of the compacts.

6. The complex quality control methods require a high level of training for the QC specialists but also some basic training for those producing the fuel.

7. The configuration and operation of the process line needs to be known at all times (even small deviations) as the process knowledge value depends on it.

8. Operating procedures may be demanding and complex.

9. The training should make clear the heavy reliance on process knowledge to specify the product and that this information must be collected during fabrication and stored. The information must be presented in a way that allows an inspector to recreate the processes and compare it to the specified one.

An important first part of training is to fill in the gaps in the staff's understanding of the process so they can coordinate their activities without impacting other parts of the process. Figure 8-1 through Figure 8-3 outline the three main areas that give a general overview of the fabrication process. Training in specific areas can then follow.

Inherent in the training and staffing of the facility is that the job task and training be matched to the level of the personnel. Table 8-1 outlines a general matrix of position versus expected skill level. An inspector should verify that the appropriate level of training and responsibility is connected with the personnel position and that lower level personnel are not given tasks and responsibilities beyond those they can be expected to reasonably execute. 


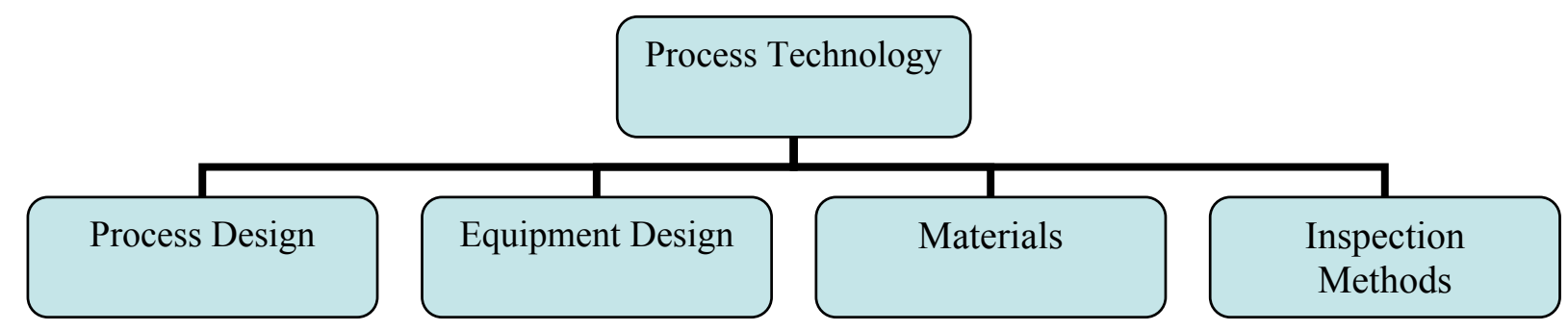

Figure 8-1. Process technology instructor topic flowchart.

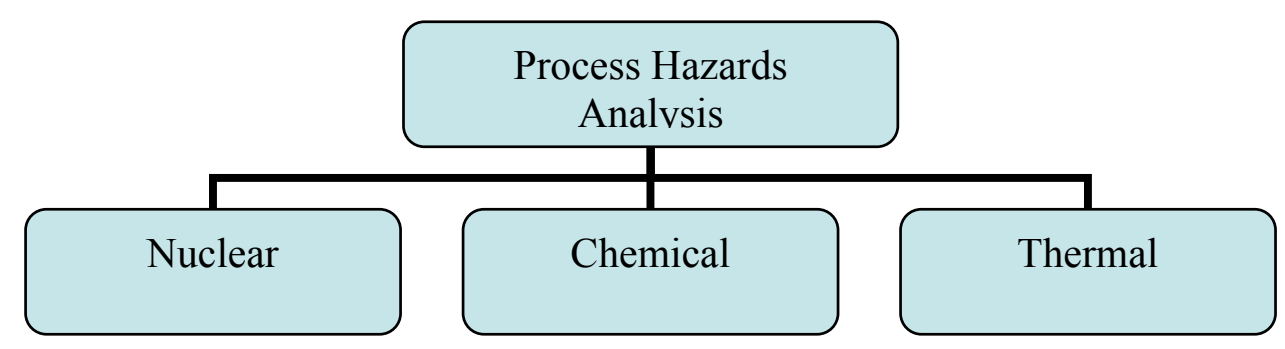

Figure 8-2. Process hazards instructor topic flowchart.

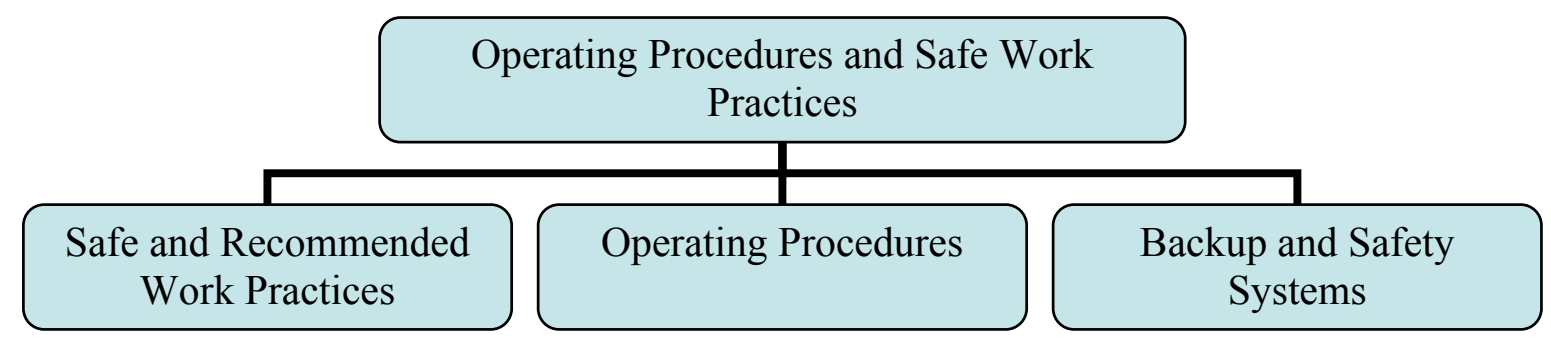

Figure 8-3. Operating, safety procedures, and practices instructor topic flowchart. 
Table 8-2. Position versus skill level matrix.

\begin{tabular}{|l|l|l|l|}
\hline Item & Craftsperson & Technician & Engineer/Manager \\
\hline $\begin{array}{l}\text { Scope of } \\
\text { Knowledge }\end{array}$ & Limited & Application to specific area & $\begin{array}{l}\text { General background in } \\
\text { science and physics as well } \\
\text { as depth in application area }\end{array}$ \\
\hline $\begin{array}{l}\text { Level of } \\
\text { Knowledge }\end{array}$ & Descriptive & $\begin{array}{l}\text { General comprehension; } \\
\text { considerable detail in } \\
\text { application area }\end{array}$ & $\begin{array}{l}\text { In-depth, especially in their } \\
\text { area of specialization }\end{array}$ \\
\hline $\begin{array}{l}\text { Intellectual } \\
\text { Responsibility }\end{array}$ & $\begin{array}{l}\text { Generally follows orders } \\
\text { generated by others }\end{array}$ & $\begin{array}{l}\text { Participates in equipment } \\
\text { installation, testing, and } \\
\text { troubleshooting. Writes } \\
\text { procedures and orders for } \\
\text { others. }\end{array}$ & $\begin{array}{l}\text { Designs and analyzes } \\
\text { equipment and processes; } \\
\text { performs physics and } \\
\text { engineering calculations. } \\
\text { Writes procedures and orders } \\
\text { for others. }\end{array}$ \\
\hline $\begin{array}{l}\text { Manual Skill } \\
\text { Level }\end{array}$ & High, primary work area & $\begin{array}{l}\text { Moderate, lacks craftsman's } \\
\text { expert skills }\end{array}$ & Generally not well developed \\
\hline
\end{tabular}

\subsection{Culture}

History has shown that successful facilities have a culture that promotes long term cooperation, identifies and corrects problems early, operates safely, and encourages communication, even that involving unpleasant facts. Because HTGR safety depends so strongly on the fuel, which requires both product and process knowledge to specify, the customer must have high confidence that the process data delivered for evaluation is correct because independent verification is often not possible. Product parameters can be reviewed by having a third party inspect samples of fuel, but process information can be impossible to backtrack. Thus, it is important for the facility to generate and reinforce a sound cultural environment. See Figure 8-4 for some suggested topics to explore.

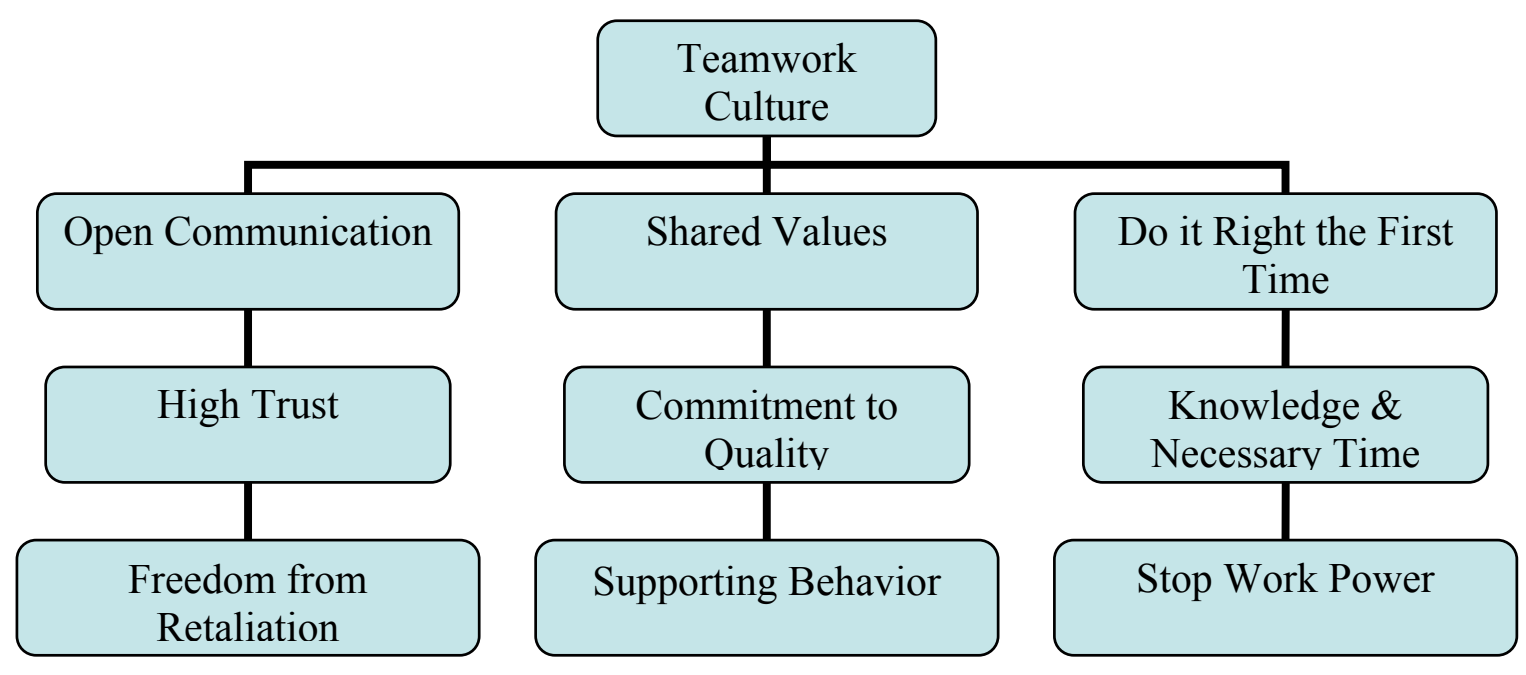

Figure 8-4. Some teamwork and quality fostering items. 


\subsection{Personnel Positions at an HTGR Fuel Fabrication Facility}

At this time, it is only possible to speculate as to the staffing of an HTGR facility. Historical positions can serve as a guideline, but it is likely that any new facility will be highly automated to control costs, increase throughput, and limit worker exposure to hazards. Figure 8-5 shows a brief generic organizational layout for a possible fabrication facility. After the general management level (which includes general facility maintenance concerns and security, both beyond the scope of this report), one might have four basic facility breakdowns:

1. Industrial Hygiene and Facility Safety would be concerned with the general safe operation of the facility, adherence to regulations, worker safety, control of exposures, and issues associated with contamination control and waste disposal. This group would have control over the conduct of work in the facility and the review of the design and operation of the process equipment. Staffing would be by personnel familiar with the appropriate regulations, nuclear facility operations, hazard analysis, contamination control, and waste disposal issues. This group would report to the highest management levels because of their overall importance to the facility.

2. Nuclear Materials Accountability, Control, and Storage would be concerned with the safe handling of special nuclear materials and their tracking through the facility/process. This group would conduct criticality assessments and monitor the movement of nuclear material to ensure freedom from criticality issues, compliance with material accountability, and real time knowledge of the facility inventory. It may or may not play a part in nonproliferation issues. Staffing would be by personnel familiar with nuclear criticality, material tracking and compliance issues and regulations, and have knowledge of storage and shipping regulations. This group would also report to the highest management levels.

3. The Fuel Fabrication area would be concerned with the actual fuel production process and would encompass the topics detailed in other parts of this document. It would be guided by the other groups to ensure safe operation and compliance with the appropriate regulations along with proper worker safety. It would receive feedback from the other three groups in the manner of continuous improvement. In the case of serious problems it would report to the highest level of management. This group will produce the product the facility was designed to make and maintain the equipment.

4. Quality Assurance, Control, and Documentation would be focused on the quality and measurement issues identified in this document. This group will support the Fuel Fabrication group and will have veto power over the product. It will also perform a nontraditional function, that of process documentation. Since the fuel is specified by both product and process specifications, this group will track both and combine them into a data package.

As an aside, the regulator should also be aware of the role played by the plant control and data management system as a highly automated plant may use such systems to perform process control and documentation. The plant management must understand the types of impacts "hidden" software decisions can have on fuel quality. 


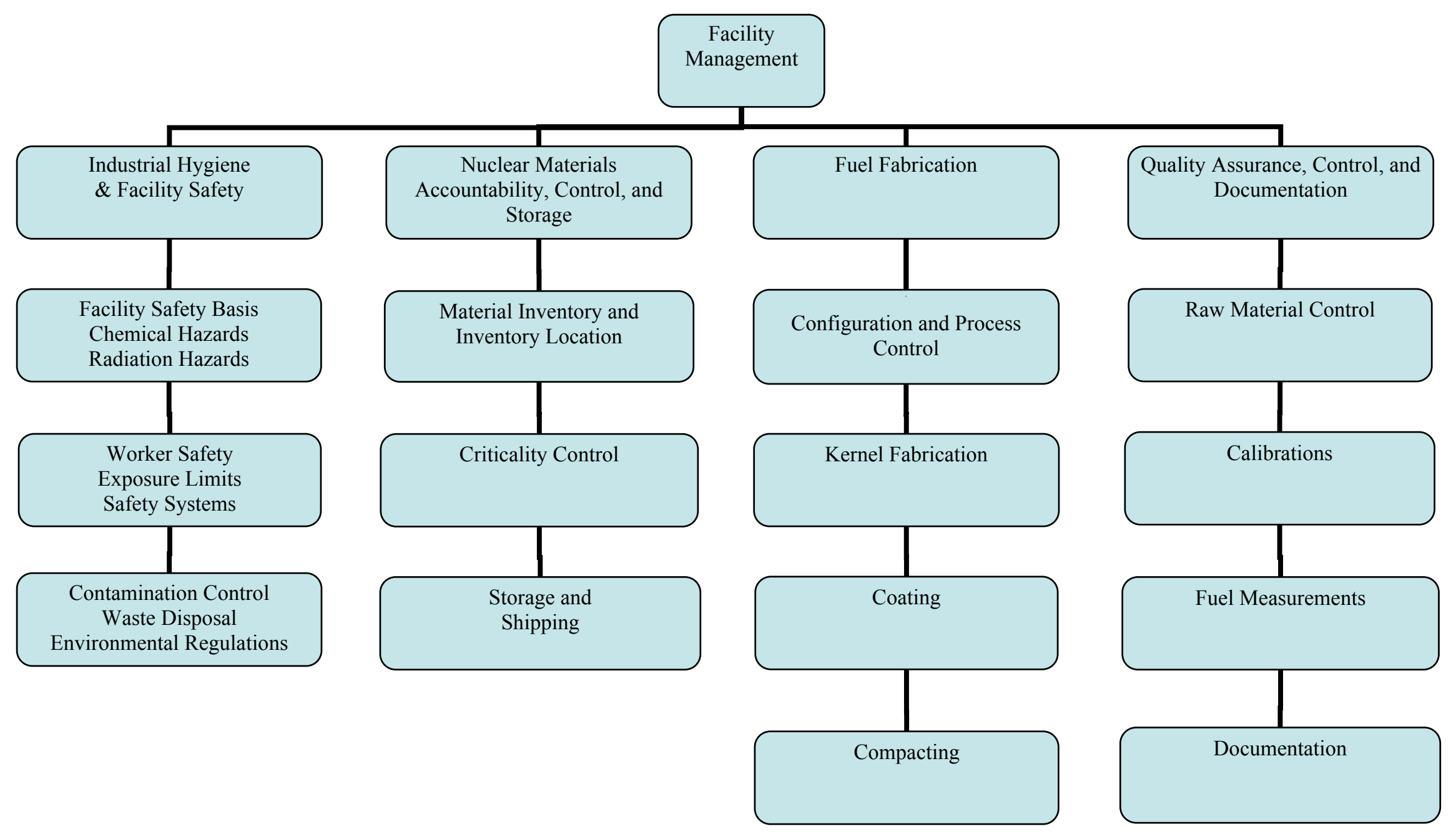

Figure 8-5. Basic Conceptual Fuel Fabrication Organization Chart 


\subsection{Summary}

An HTGR fuel fabrication facility will have many points in common with an LWR fuel facility, but there will also be many differences. The major differences are:

1. An all ceramic carbon based fuel design rather than a design based on ceramic pellets in a tube.

2. Higher uranium enrichment ( $20 \%$ versus $\sim 5 \%$ ) for the fuel.

3. The use of sol-gel, CVD, and carbon technology rather than powder and tubing technology for the production of the fuel kernel.

4. The large quantity of explosive gases (used for coating) that will be consumed in the facility during the fuel production.

5. Relatively small batch sizes $(\sim \mathrm{a}$ few $\mathrm{kg})$ due to the physics of the coaters.

6. A heavy reliance on statistical methods for quality control acceptance testing on a very large number of fuel compacts or pebbles rather than near $100 \%$ inspection methods for a much small number of fuel rods.

7. A large amount of very specialized inspection techniques.

8. The heavy reliance on process knowledge to specify the product.

These differences will impact the design of the facility and the approach taken to fuel fabrication as well as the approach taken to quality control. The final product will be determined by both product and process specifications. The facility training must emphasize this point and the proper data collection and documentation implemented.

The staffing of the facility will have many of the skills that would be common in an LWR facility, but it will also include additional specialties because of the complex nature of the fuel and the specialized inspection techniques.

One final note is that the culture of the facility will have to be that of "Do it Right the First Time" because incomplete process knowledge or the loss of process knowledge will be detrimental to fuel quality. The customer must have great faith that the fuel was manufactured in the specified way because HTGR reactor safety is highly dependent on fuel performance. 


\subsection{Reference Documents}

Table 8-3 lists a set of basic documents for a review of this topic. This topic is covered both individually and under quality control.

Table 8-3. Training and Qualification Documents

\begin{tabular}{|l|l|l|}
\hline \multicolumn{1}{|c|}{ Title } & \multicolumn{1}{|c|}{ Reference } & \multicolumn{1}{c|}{ Description } \\
\hline $\begin{array}{l}\text { ORNL Training and } \\
\text { Qualification SBMS } \\
\text { Documents }\end{array}$ & $\begin{array}{l}\text { ORNL Standards Based } \\
\text { Management System }\end{array}$ & $\begin{array}{l}\text { Describes the ORNL process } \\
\text { of training and qualifying } \\
\text { staff members }\end{array}$ \\
\hline $\begin{array}{l}\text { Standard Review Plan for the } \\
\text { Review of a License } \\
\text { Application for a Fuel Cycle } \\
\text { Facility }\end{array}$ & NUREG-1520 & $\begin{array}{l}\text { Describes issues related to the } \\
\text { licensing review of a fuel } \\
\text { fabrication facility }\end{array}$ \\
\hline $\begin{array}{l}\text { Management Concepts and } \\
\text { Safety Applications for } \\
\text { Nuclear Fuel Facilities }\end{array}$ & NUREG/CR-6287 & $\begin{array}{l}\text { Describes several } \\
\text { philosophies for the operation } \\
\text { of a fuel fabrication plant }\end{array}$ \\
\hline $\begin{array}{l}\text { Quality Assurance } \\
\text { Requirements for Nuclear } \\
\text { Facility Applications }\end{array}$ & ASME NQA-1-2000 & $\begin{array}{l}\text { Lists general quality issues } \\
\text { for nuclear facilities }\end{array}$ \\
\hline $\begin{array}{l}\text { Quality Assurance Plan for } \\
\text { the Advanced Gas Reactor } \\
\text { Program at Oak Ridge } \\
\text { National Laboratory }\end{array}$ & QAP-ORNL-AGR-01, Rev 5 & $\begin{array}{l}\text { Outlines the quality assurance } \\
\text { issues for a research sized } \\
\text { fuel fabrication program }\end{array}$ \\
\hline $\begin{array}{l}\text { Guidebook on Training to } \\
\text { Establish and Maintain the } \\
\text { Qualification and } \\
\begin{array}{l}\text { Competence of Nuclear } \\
\text { Power Plant Operations } \\
\text { Personnel }\end{array}\end{array}$ & IAEA-TECDOC-525, Rev 1 & $\begin{array}{l}\text { A good general outline of the } \\
\text { training and qualification } \\
\text { needs for a nuclear facility }\end{array}$ \\
\hline
\end{tabular}




\section{DRAFT NRC FUEL FABRICATION INSPECTION PROTOCOL}

The purpose of this section is to provide a selection of menu items that may be used to compose a general inspection checklist. While it is clear that the inspector will be reviewing issues associated with the licensing basis for the facility, the need for process knowledge associated with the fuel production adds another dimension to the examination. Not only will the inspector have to determine if the fuel plant is performing within the licensing basis, but he/she will have to determine if process information is being collected in the proper manner. Thus, an extra dimension is added to the inspection process.

The most relevant starting point for an inspection is the license (or application). This document forms the basis for plant design and operation and will be the reference guide for the inspection. The license application is reviewed in accordance with NUREG-1520, "Standard Review Plan for the Review of a License Application for a Fuel Cycle Facility", and this NUREG identifies several key areas for inspection. Areas of interest identified in NUREG-1520 and used as a model for this section are:

1. General Information

a. Facility and Process Description

b. Institutional Information

c. Site Description

2. Organization and Administration

3. Radiation Protection

4. Nuclear Criticality Safety

5. Chemical Process Safety

6. Fire Safety

7. Emergency Management

8. Environmental Protection

9. Decommissioning

10. Management Measures

Once these general areas have been examined, areas specific to coated particle fuel fabrication can be investigated. While all fuel plants have many areas in common, HTGR fuel has special needs in some areas and additional emphasis will be needed. Suggested areas for a more critical look are:

1. Process Knowledge Record Keeping On a Particle Batch Basis

2. Proper Calibration and Operation of the Complex Measuring Tools

3. Proper Operation of the Fabrication Line

4. Data Analysis Methods

5. Configuration Control of the Fabrication Apparatus

6. Control of Raw Materials and Contamination

Not all of these areas will be of equal interest to an inspector examining a completed fabrication plant. For example, the Site Description information is relevant prior to construction, but is of less interest in determining if the product is being made properly. 
One topic, Safeguards and Security, also needs to be investigated; however, this topic is beyond the scope of fuel fabrication issues and should be investigated by experts in security and nuclear safeguards.

\subsection{General Licensing Items}

Section 9 is divided into two sub-sections. Sub-section 9.1 discusses the general licensing items and sub-section 9.2 focuses on the specifics of HTGR fuel fabrication. There is a great deal of overlap between the two segments as failure to meet the most basic requirements for a fuel plant will almost certainly result in fabrication problems.

\subsubsection{General Information}

Since the inspections of interest will be taking place well after the completion of the plant, the primary purpose of these examinations will be to determine if any significant changes have taken place that would affect the licensing basis or require a change in inspection methods. Many of these items will only require a brief review, but they need to be addressed as they are part of the license and support the overall plant. See NUREG-1520 for more detailed discussions of the table entries in this and the following sections.

Possible inspection areas and suggested emphasis are listed in Table 9-1. The selection of items may very well depend on the last inspection period; a short period would make layout issues less relevant as there would have been little time for things to change. As usual, the primary issue is whether the plant is as described and is being operated in the specified manner.

Table 9-1. Possible General Inspection Items

\begin{tabular}{|r|l|}
\hline Item & \multicolumn{1}{c|}{ Inspection Topic/Area } \\
\hline \hline 1 & $\begin{array}{l}\text { Layout of plant showing the locations of the major facilities, material storage, roads, } \\
\text { railroads, and perimeter. The primary issue here is whether or not the plant matches the } \\
\text { license and design documentation. Undocumented modifications and new structures are } \\
\text { the likely concerns. }\end{array}$ \\
\hline 2 & $\begin{array}{l}\text { The proximity of facility buildings to the plant perimeter, the nearby population, and } \\
\text { brief description of the hazards presented by the buildings. The issue here is whether or } \\
\text { not the public and the environment are exposed to hazards that have not been reviewed } \\
\text { by the NRC or other relevant authorities. }\end{array}$ \\
\hline 3 & $\begin{array}{l}\text { A description of the plant, the purpose of each facility, the relationships between } \\
\text { facilities, and the rail/truck interfaces. The purpose is to determine if the plant is } \\
\text { functioning in the manner planned and to determine if any change in the functions of the } \\
\text { facilities or interfaces merits a new review. }\end{array}$ \\
\hline 4 & $\begin{array}{l}\text { A description of the materials used by the facility, the flow of the materials through the } \\
\text { plant, and the discharged waste products. The purpose is to compare the present } \\
\text { materials and waste products with those listed in the license documents. }\end{array}$ \\
\hline 5 & $\begin{array}{l}\text { The quantities of materials in storage and in process during normal operations as well as } \\
\text { their locations. Again, this is to see if any new hazards have been introduced (perhaps } \\
\text { inadvertently) in the plant. }\end{array}$ \\
\hline
\end{tabular}




\begin{tabular}{|r|l|}
\hline 6 & $\begin{array}{l}\text { A description of the overall management structure of the plant and their assigned } \\
\text { responsibilities. This examination will allow the inspector to review the chain of } \\
\text { command and determine if critical responsibilities have been properly assigned and have } \\
\text { the proper attention. }\end{array}$ \\
\hline 7 & $\begin{array}{l}\text { The overall corporate structure of the parent organization and how this impacts the } \\
\text { organization and operation of the fuel fabrication plant. A brief look will help determine } \\
\text { if ownership issues are up to date. }\end{array}$ \\
\hline 8 & $\begin{array}{l}\text { A brief description of the accidents listed in the Integrated Safety Analysis (ISA) and the } \\
\text { safety systems in place to mitigate them. The purpose of this inspection is to determine } \\
\text { if the identified ISA issues are being taken seriously and the required safety systems are } \\
\text { in working order. This inspection will likely involve a physical walk through and } \\
\text { perhaps some examination of some testing/calibration information. The goal is to } \\
\text { determine if a workable safety system is in place. }\end{array}$ \\
\hline 9 & $\begin{array}{l}\text { A brief history of any significant changes to the plant and their impacts on operation and } \\
\text { safety. The goal is to determine if the plant management is properly monitoring the } \\
\text { overall facility, keeping documentation up to date, and anticipating the problems that } \\
\text { changes may bring. }\end{array}$ \\
\hline 10 & $\begin{array}{l}\text { A review of the location of the overall facility to any external facilities or activities that } \\
\text { could present a hazard to the safe operation of fuel fabrication as presented in the } \\
\text { license. The goal is to determine if the placement of such facilities as an LNG plant, or } \\
\text { perhaps a chemical plant or oil refinery could present a direct or indirect impact on the } \\
\text { safe operation of the fuel fabrication facility as presented in the license. }\end{array}$ \\
\hline
\end{tabular}

Overall, the main goal of these inspections is to determine if the present configuration still meets the licensing criteria, if the plant management understands their facilities and safe operation, if the plant is being managed in a proactive manner, and to provide record documentation of this comparison. 


\subsubsection{Organization and Administration}

The purpose of this set of inspections is to determine if the plant is organized and administered as detailed in the licensing documentation and follows sound practices. The goal is to determine if management policies provide reasonable assurance that the safety of the workers, public, and environment can be protected both in the short and long term.

Table 9-2 is a list of possible organization inspection items from which to assemble an inspection plan for these issues.

\section{Table 9-2. Possible Organization and Administration Inspection Items}

\begin{tabular}{|c|c|}
\hline Item & Inspection Topic/Area \\
\hline 1 & $\begin{array}{l}\text { A general description of how the management policies ensure the maintenance of health, } \\
\text { safety, and environmental functions and what measures are used to determine the degree } \\
\text { of compliance. The goal is to determine if management has a formal up to date plan to } \\
\text { address these issues and has measures of performance to demonstrate that they are being } \\
\text { met or the degree of improvement required. This plan should include an adequate means } \\
\text { to track and manage these issues to ensure timely and accurate completion. }\end{array}$ \\
\hline 2 & $\begin{array}{l}\text { A description of the relationships between the Integrated Safety Analysis and the } \\
\text { management measures (items) for radiation, nuclear criticality, fire, and chemical safety } \\
\text { as well as their relationship to environmental monitoring and emergency planning. The } \\
\text { purpose of this inspection is to determine if the management plans and measures of } \\
\text { performance actually relate back to the identified hazards and monitoring needs and } \\
\text { provide a useful feedback tool for determining compliance with the regulations and } \\
\text { coordination with outside agencies. }\end{array}$ \\
\hline 3 & $\begin{array}{l}\text { A management organizational chart and a functional description of the key managerial } \\
\text { and technical positions. This should include operational, design/modifications, and } \\
\text { construction/repair groups. The goal of this review is to determine if key positions are } \\
\text { adequately staffed with qualified and competent personnel and that the ISA needs are } \\
\text { under active consideration. }\end{array}$ \\
\hline 4 & $\begin{array}{l}\text { A description of the controls, communications, and reporting that occurs between the } \\
\text { groups and the control hierarchy. Of particular interest are occurrence reporting, near } \\
\text { miss reporting, lessons learned, intra-group communications, stop work authority, and } \\
\text { restart authority. This review is focused on the ability of the organization to talk and } \\
\text { listen within itself and adopt new practices as they are required as well as quickly } \\
\text { respond to problems. }\end{array}$ \\
\hline 5 & $\begin{array}{l}\text { A description of the qualifications and training required for key management and } \\
\text { technical positions, as well as their responsibilities. The purpose is to determine if the } \\
\text { required qualifications and education of the position are commensurate with the } \\
\text { responsibilities and technical needs of the position. The goal is to make sure competent } \\
\text { staff is available to run the facility. }\end{array}$ \\
\hline 6 & $\begin{array}{l}\text { Written agreements and response responsibilities with off-site resources such as fire, } \\
\text { police, ambulance/rescue/medical services. The goal of this assessment is to determine if } \\
\text { the external needs of the ISA are being met and if the plant and local community are } \\
\text { effectively communicating with each other. }\end{array}$ \\
\hline
\end{tabular}




\begin{tabular}{|c|c|}
\hline 7 & $\begin{array}{l}\text { Written procedures for important functions, a master list of these procedures, and } \\
\text { methods to ensure that out-of-date procedures are not used. This is simply an inspection } \\
\text { of standard document control measures; the goal is to determine if an effective } \\
\text { mechanism is in place. Procedure based issues and events should be identified as such } \\
\text { and included in the review of the processes and systems reviewed in item } 4 \text {. }\end{array}$ \\
\hline 8 & $\begin{array}{l}\text { A Quality Assurance plan, a means to implement it, and audits or other measures of } \\
\text { compliance. The goal is to determine if the plant possesses the usual QA/QC discipline } \\
\text { and documentation required for nuclear operations. }\end{array}$ \\
\hline 9 & $\begin{array}{l}\text { A plan and method of Configuration Control along with a method to monitor } \\
\text { compliance with the plan. The purpose of this inspection is to determine if management } \\
\text { is tracking and monitoring the configuration of the plant and maintaining control of the } \\
\text { plant configuration and method of operation. }\end{array}$ \\
\hline 10 & $\begin{array}{l}\text { A method to identify best practices and implement them. This is part of sound } \\
\text { management practice; the major interest is in measures that improve safety and reduce } \\
\text { environmental issues. The goal is to determine if management is paying attention to the } \\
\text { actual operation of the facility and anticipating problems. This practice should extend in } \\
\text { some way to the capture of applicable operating experience best practices noted from } \\
\text { other similar fuel fabrication facilities. The inspector should factor in such lessons } \\
\text { learned in applicable reviews and look for indications that the facility is aware of } \\
\text { industry best practices and uses that knowledge to improve its own operation. }\end{array}$ \\
\hline 11 & $\begin{array}{l}\text { description of the training plan, a measure of its effectiveness, and feedback methods } \\
\text { ensure its continued value. The purpose is to evaluate the effectiveness of the training } \\
\text { an in developing staff. The inspector may wish to examine some past training plans } \\
\text { d/or records. }\end{array}$ \\
\hline 12 & $\begin{array}{l}\text { A description of the hours worked by facility staff, staffing challenges, long term } \\
\text { unfilled complement and other such labor related indicators. The goal is to determine if } \\
\text { the facility is operated by an adequate number of personnel, such that the staff is not } \\
\text { overworked into fatigue or other such hazards to safe operation. Also, the inspector } \\
\text { should be attuned to harmful organizational strife, work imbalances across the } \\
\text { organization affecting quality, significant widespread morale or other workforce } \\
\text { difficulties that could affect quality and safety. }\end{array}$ \\
\hline 13 & $\begin{array}{l}\text { In addition to the plan and method of Configuration Control, a similar plan and method } \\
\text { is needed for ensuring the integrity of the Design Basis of the facility, its structures, } \\
\text { systems, components and the processes that constitute design bases. The goal is to } \\
\text { ensure that the original technical development of the hard systems and components, as } \\
\text { well as key processes are adequately captured and managed. }\end{array}$ \\
\hline
\end{tabular}

The overall purpose of these inspection items is to determine if a credible and responsive management is in place that can run the facility on a day to day basis, anticipate problems, improve performance, and quickly respond to accident conditions.

\subsubsection{Radiation Protection}

The purpose of these inspections is to determine if an effective radiation protection plan is being implemented and steps are being taken to ensure its continued effectiveness. One difference of 
particular note in an HTGR fuel facility is the use of higher enrichment uranium; thus, airborne and contamination issues might be more severe.

Table 9-3 lists a selection of items that might be included in the radiation protection portion of an inspection plan.

\section{Table 9-3. Possible Organization and Administration Inspection Items}

\begin{tabular}{|c|c|}
\hline Item & Inspection Topic/Area \\
\hline 1 & $\begin{array}{l}\text { Description of a radiation protection plan that meets the measures in } 10 \text { CFR Parts } 19 \text {, } \\
20 \text {, and } 70 \text { and is in accordance with } 10 \text { CFR } 20.1101 \& 20.2102 \text { (See NUREG- } 1520 \\
\text { listings). The purpose of this inspection is to show the existence of a sound plan that } \\
\text { meets the regulations; the use of higher enrichment uranium may require a more } \\
\text { stringent plan than is commonly used in an LWR fuel plant. Also, the potential hazards } \\
\text { associated with the use of explosive gases in the coaters may complicate the plan. }\end{array}$ \\
\hline 2 & $\begin{array}{l}\text { Description of the means to keep the radiation protection plan up to date, incorporate } \\
\text { lessons learned, and to implement both the plan and any changes. This is simply to } \\
\text { ensure that management is monitoring the radiation protection issue and responding to } \\
\text { evolving needs. }\end{array}$ \\
\hline 3 & $\begin{array}{l}\text { Description of how radiation protection is integrated with the ISA and any emergency } \\
\text { management plans both with internal and external responders. In particular, the staff } \\
\text { should be aware of the safety issues associated with the radioactive material and } \\
\text { explosive gases in the coater region of the plant. The goal of this inspection is to } \\
\text { determine if the radiation protection issues are integrated with the ISA and the radiation } \\
\text { protection group is able to respond to the identified accident scenarios. The inspector } \\
\text { may wish to review the results of past emergency exercises. }\end{array}$ \\
\hline 4 & $\begin{array}{l}\text { Description of the means to prepare procedures and radiation work permits as well as } \\
\text { control them and ensure that up to date procedures and permits are used. This is simply } \\
\text { part of work and document control. The purpose is to determine if this control } \\
\text { mechanism is in place and if the staff is following it. The inspector may wish to examine } \\
\text { some recent and past permits and procedures to verify compliance. }\end{array}$ \\
\hline 5 & $\begin{array}{l}\text { Description of the required qualifications and training of the radiation protection } \\
\text { personnel as well as the means used to keep them up to date. The goal is to ensure } \\
\text { competent staff is in place. The inspector may wish to examine past training and } \\
\text { qualification records, as well as certification records, as appropriate. }\end{array}$ \\
\hline 6 & $\begin{array}{l}\text { Description of the ALARA plan and means in place to comply with the stated goals as } \\
\text { well as the general control of radioactive material and the use of personal protective } \\
\text { equipment. The purpose of this inspection is to determine if proper (industry standard) } \\
\text { methods and techniques for working with radioactive material and controlling its spread } \\
\text { are in place and being followed. }\end{array}$ \\
\hline 7 & $\begin{array}{l}\text { Description of the training and indoctrination used to inform and educate non-radiation } \\
\text { protection personnel in the safe handling and conduct of operations with radioactive } \\
\text { materials. The goal of this inspection is to determine if the general staff is aware of the } \\
\text { radiation hazards and understands the proper techniques for handling radioactive } \\
\text { material in their work area. See Section } 8 \text { for a list of topics. }\end{array}$ \\
\hline
\end{tabular}




\begin{tabular}{|c|l|}
\hline 8 & $\begin{array}{l}\text { Description of the programs used to conduct surveys and monitor radioactive materials, } \\
\text { document radiation levels, and monitor occupational exposures. The purpose of this } \\
\text { inspection is to determine if radiation monitoring is being conducted in the proper } \\
\text { manner and the results recorded in compliance with the regulations. This review should } \\
\text { extend into the equipment used for such monitoring activities, proper application of } \\
\text { equipment types, calibration and maintenance, etc. Also, consistency of methods and } \\
\text { techniques should be addressed. }\end{array}$ \\
\hline 9 & $\begin{array}{l}\text { Description of the independence of the radiation protection function, the stop work } \\
\text { authority, and the reporting path. The goal of this inspection is to determine if the } \\
\text { radiation protection group has the necessary independence to perform their regulatory } \\
\text { duties and that they are properly integrated into the overall plant management structure. }\end{array}$ \\
\hline 10 & $\begin{array}{l}\text { Description of how the radiation protection function interfaces with the facility training } \\
\text { and facility communications organizations. The goal is to determine how changes in } \\
\text { radiological conditions (both acute and chronic) are communicated beyond the radiation } \\
\text { protection organization to facility staff in a timely manner. }\end{array}$ \\
\hline
\end{tabular}

\subsubsection{Nuclear Criticality Safety}

An HTGR fuel plant is likely to have two important differences from an LWR fuel plant regarding nuclear criticality safety. These are the use of higher enrichment uranium (greater than $5 \%$ ) and the mixture of a moderator (carbon) in the final fuel form. The use of water and organic based process solutions in the kernel production segment also introduces a moderator into the fabrication process. The inspector will have to be aware of the possible differences in the approach to criticality control between the two types of fuel production facilities.

Table 9-4 lists some possible items for the development of the criticality safety portion of an overall inspection plan.

\section{Table 9-4. Possible Nuclear Criticality Safety Inspection Items}

\begin{tabular}{|r|l|}
\hline Item & \multicolumn{1}{c|}{ Inspection Topic/Area } \\
\hline \hline 1 & $\begin{array}{l}\text { Description of the Nuclear Criticality plan and its compliance with 10 CFR 70.61, 70.62, } \\
\text { 70.64, and 70.65 as well as complying with existing industry standards (see NUREG- } \\
1520 \text { listings). Because of the higher enrichment and the integral presence of } \\
\text { moderators, the inspector should note if facility management realizes that the potential } \\
\text { hazards could be greater than that of an LWR fuel plant, what those different hazards } \\
\text { are, and how they should be addressed differently from an LWR plant. }\end{array}$ \\
\hline 2 & $\begin{array}{l}\text { Methods for protecting against the occurrence of an identified accident sequence that } \\
\text { could lead to a criticality accident. The inspector should note if the plan measures are in } \\
\text { actual practice in the plant and if the workers understand the potential hazards involved } \\
\text { in handling the more highly enriched material. }\end{array}$ \\
\hline 3 & $\begin{array}{l}\text { Description of the relevant safety parameters, procedures, and controls and how they are } \\
\text { implemented. The goal is to determine if the criticality plan is being followed and if the } \\
\text { plant is being operated in a predictable and in a safe manner. }\end{array}$ \\
\hline
\end{tabular}




\begin{tabular}{|c|l|}
\hline 4 & $\begin{array}{l}\text { Description of the method used to show that the criticality evaluations used to examine } \\
\text { normal and credible accidents are acceptable and will allow the plants to maintain } \\
\text { subcritical status throughout all fabrication processes. This area is largely covered in the } \\
\text { formal review process and the main concern of the inspector is that any new situations } \\
\text { or changes are properly documented and reviewed. The goal is to determine if the } \\
\text { criticality program is active and if management is actively monitoring operations. }\end{array}$ \\
\hline 5 & $\begin{array}{l}\text { Description of the training and indoctrination methods used to instruct the workers about } \\
\text { criticality safety, the criticality plan and any changes in the plan, and the proper actions } \\
\text { in the case of an inadvertent criticality event. The inspector may wish to examine the } \\
\text { training program and training records to determine if the workers are properly informed } \\
\text { about the overall hazards and the risks associated with their specific work area. }\end{array}$ \\
\hline 6 & $\begin{array}{l}\text { Management controls to demonstrate that any changes or modifications impacting } \\
\text { criticality issues will be properly evaluated prior to implementation. This is part of the } \\
\text { design basis determination process and configuration control process, but because of its } \\
\text { importance it should be specifically called out. }\end{array}$ \\
\hline 7 & $\begin{array}{l}\text { Emergency management of situations that violate criticality safety measures. The } \\
\text { inspector should determine if these measures are properly integrated into the ISA and } \\
\text { any emergency plans. The goal is to see that the situation is properly identified, that } \\
\text { there is a safe egress path, and that it will be properly managed. }\end{array}$ \\
\hline 8 & $\begin{array}{l}\text { A description of the criticality related quality process controls governed by the Quality } \\
\text { Assurance Plan. The goal is to ensure that the facility recognizes the importance of the } \\
\text { careful application of proven and continual process auditing practices at appropriate } \\
\text { stages of the overall fabrication process. This is especially significant in the case of a } \\
\text { fabrication process that does not have years of operating experience (like LWR } \\
\text { facilities) where "process" quality control becomes the predominant consideration for } \\
\text { criticality safety over "product" quality control. }\end{array}$ \\
\hline
\end{tabular}

HTGR fuel plant criticality safety methods are not expected to be greatly different than that in an LWR fuel plant, but the fabrication process and final fuel form are quite different so a one-to-one correspondence is not possible. Only a careful study of the specific plant configuration will identify the hazards and best practices, so the inspector should be careful about exclusively applying past knowledge gained from work with lower enriched LWR fuel.

\subsubsection{Chemical Process Safety}

The purpose of inspections in this area is to determine if the plant provides adequate protection against chemical hazards related to the handling, storage, and processing of the licensed materials. The plant design, maintenance, and operation must protect against conditions that could compromise safety and lead to an increased risk of both chemical hazards and the concomitant radiation hazards.

While both an HTGR and LWR fuel plant have a considerable amount of chemical processing at the front end, the HTGR plant will go further as kernel formation and coating are rather complex tasks requiring special solution chemistry (sol-gel for the kernels) and chemical vapor deposition processing at high temperatures (coating). 
Table 9-5 is a listing of possible items that may be included in the chemical safety portion of an inspection protocol.

\section{Table 9-5. Possible Chemical Process Safety Inspection Items}

\begin{tabular}{|c|c|}
\hline Item & Inspection Topic/Area \\
\hline 1 & $\begin{array}{l}\text { Description of the process information, accident sequences, and mitigation responses } \\
\text { for identified accidents. Relevant adherence to } 10 \text { CFR } 70.64 \text { and } 10 \text { CFR } 70.72 \text { (see } \\
\text { NUREG- } 1520 \text { listings). Most of this should be covered in the license application and } \\
\text { the goal of the inspector is to see if the identified scenarios have been incorporated into } \\
\text { the operation of the plant. }\end{array}$ \\
\hline 2 & $\begin{array}{l}\text { Description of the management plans and responses for the identified situations and the } \\
\text { flexibility to handle unexpected situations. The goal is to determine if management } \\
\text { understands and can handle the accident situations. The inspector may wish to examine } \\
\text { safety drills, general knowledge, and written procedures to determine the adequacy of } \\
\text { the preparation. }\end{array}$ \\
\hline 3 & $\begin{array}{l}\text { Description of the methods used to monitor and identify potentially unstable and } \\
\text { dangerous situations. The purpose of this inspection is to determine if the proper } \\
\text { information is being collected in a timely manner to monitor the safety status of the } \\
\text { plant and if management has specific measures in place that would issue warnings or } \\
\text { alarms, both in the local work area, and to the plant in general. Also, the goal is to } \\
\text { determine how this is integrated into the ISA. }\end{array}$ \\
\hline 4 & $\begin{array}{l}\text { Description of the safety measures, safety culture, personal protective equipment, } \\
\text { engineering controls, and administrative controls used in day-to-day operations to } \\
\text { ensure safe operation. The goal is to determine if the workers are performing their tasks } \\
\text { in a safe and predictable manner and if these activities are being properly monitored in a } \\
\text { healthy safety culture that is adverse to unsafe work practices. Also, if possible, } \\
\text { determine if adequate margins exist to accommodate unexpected situations. }\end{array}$ \\
\hline 5 & $\begin{array}{l}\text { Description of the relevant record keeping, posting of chemical hazard material data } \\
\text { sheets, training of the staff, and reporting of problems and releases. The purpose of this } \\
\text { is to determine if the proper documentation is being kept, if the hazards are } \\
\text { communicated to the staff, and if the staff understands the safe handling, usage, and } \\
\text { storage of the chemicals and what to do in off normal situations. }\end{array}$ \\
\hline 6 & $\begin{array}{l}\text { Examination of the special means used to control chemical hazards such as shields, } \\
\text { doors, and interlocks. The inspector may wish to walk through the plant and check and } \\
\text { see if the identified physical items are in place and functional. The purpose is to } \\
\text { determine if the actual plant includes the designed safety items. }\end{array}$ \\
\hline 7 & $\begin{array}{l}\text { Description of the physical security means that will allow ingress/egress of personnel } \\
\text { (workers and emergency responders) during emergency situations. This is actually part } \\
\text { of emergency planning, but areas which contain large amounts of chemicals may } \\
\text { require special attention and the goal of the inspector is to determine if these special } \\
\text { needs have been taken into consideration and if realistic escape paths have been } \\
\text { planned. Depending on the specific situation, drills may be required if special measures } \\
\text { need to be taken. }\end{array}$ \\
\hline
\end{tabular}


Overall, the knowledge gained from LWR plant experience will likely be of use to the inspector. However, careful consideration should be given to the differences that exist in an HTGR fuel plant, such as the use of large amounts of explosive gases.

An open issue at the present time is the chemical form of the uranium that enters the plant. If it comes in as uranium oxide, it will be possible to avoid the hazards of handling and processing uranium hexafluoride. If not, the plant will have all the chemical issues associated with the storage, handling, and processing of uranium hexafluoride.

\subsubsection{Fire Safety}

The purpose of these inspections is to determine if the plant has satisfied its requirements for protection against fire hazards and explosions. This area is related to the Chemical Safety area and some overlap between the two is expected. Because of criticality concerns and possible environmental concerns, the use of large volumes of water may be restricted to prevent criticality issues or diked areas may be used to control the runoff of contaminated water. The inspector should be aware of these special concerns especially in the coater area where enriched uranium, explosive gases, and high temperatures exist together.

The inspector should also be aware of support apparatus such as filters. The coaters may produce a large amount of soot and very large filters may be necessary to filter out and collect this material. Finely divided carbon can burn and large amounts of it can be an explosion hazard. The inspector should be aware of the fire hazards presented by waste material.

Table 9-6 is a selection of items that may be used to form the fire safety portion of an inspection plan.

Table 9-6. Possible Fire Safety Inspection Items

\begin{tabular}{|r|l|}
\hline Item & \multicolumn{1}{|c|}{ Inspection Topic/Area } \\
\hline \hline 1 & $\begin{array}{l}\text { Description of the fire hazard analysis, the locations of fire detectors, manual and } \\
\text { automatic responses, and key hazard areas. All this information should be in the ISA; } \\
\text { the purpose of this inspection is to determine if this information is being used to monitor } \\
\text { and operate the plant and that the workers are aware of the hazards. }\end{array}$ \\
\hline 2 & $\begin{array}{l}\text { Examination of the special means used to control fire hazards such as shields, doors, } \\
\text { sprinkler systems, and interlocks. The inspector may wish to walk down the plant and } \\
\text { see if all the design safety features are in place and functional. Finally, any special } \\
\text { worker actions should be investigated to see that they are being done. }\end{array}$ \\
\hline 3 & $\begin{array}{l}\text { Examination of the equipment used to detect and report fires, maintenance of such } \\
\text { equipment, and any calibration issues. This is mainly an issue of checking records, drill } \\
\text { and test results, and determining if such equipment is in proper working order and } \\
\text { receiving the proper attention. The goal is to see if the plant is implementing the stated } \\
\text { fire safety plan. }\end{array}$ \\
\hline 4 & $\begin{array}{l}\text { Description of the special concerns related to criticality issues and the planned } \\
\text { responses. This is actually part of the emergency response plan, but the inspector should } \\
\text { determine that the issue is actually implemented at the working level and the first } \\
\text { responders understand the concerns. }\end{array}$ \\
\hline
\end{tabular}




\begin{tabular}{|c|c|}
\hline 5 & $\begin{array}{l}\text { Description of the special concerns related to environmental issues and the planned } \\
\text { responses for runoff or releases. The inspector should compare the design features for } \\
\text { this issue with the actual physical implementation. This may be more of an issue after a } \\
\text { modification than for a new plant. }\end{array}$ \\
\hline 6 & $\begin{array}{l}\text { Description of the physical security means that will allow ingress/egress of personnel } \\
\text { (workers and emergency responders) during emergency situations. Again, this is an } \\
\text { emergency response issue, but may be of particular importance in the area of the plant } \\
\text { (coater) that uses large amounts of explosive gases. The inspector should assess the } \\
\text { reasonableness of the actions required by the workers under emergency conditions. }\end{array}$ \\
\hline 7 & $\begin{array}{l}\text { Description of the adherence to the appropriate fire safety codes such as NFPA } 801 \text { and } \\
\text { others as relevant or specified in the plant documentation/approvals (see NUREG-1520 } \\
\text { listings). This issue will be design specific and the inspector will have to assess the } \\
\text { implementation relative to the actual situation. }\end{array}$ \\
\hline 8 & $\begin{array}{l}\text { Description of the training and qualification program for the fire protection staff. The } \\
\text { goal of this inspection is to determine if an adequate training program exists and is } \\
\text { being utilized, if it is up to date, and if the proper records are being kept. The ISA and } \\
\text { the appropriate fire codes will have to be reviewed to determine the overall required } \\
\text { scope. }\end{array}$ \\
\hline 9 & $\begin{array}{l}\text { Description of the training and indoctrination methods used to instruct the workers } \\
\text { about fire safety, the combustible materials used in the plant, and the proper actions in } \\
\text { the case of a fire. This will likely be a part of general employee training and emergency } \\
\text { management. The purpose of the inspection is to determine if the workers are properly } \\
\text { informed of fire safety issues and know what to do and/or the egress paths in case of a } \\
\text { fire. }\end{array}$ \\
\hline 10 & $\begin{array}{l}\text { Examination of the equipment used to extinguish and mitigate fires and the resultant } \\
\text { effects of fires, maintenance of such equipment, and any calibration issues. This is } \\
\text { mainly an issue of checking records, any material condition or maintenance records, } \\
\text { drill and test results, and determining if such equipment is in proper working order and } \\
\text { receiving the proper attention. The goal is to see if the plant is fully prepared to } \\
\text { implement the stated fire safety plan. }\end{array}$ \\
\hline
\end{tabular}

In general, the fire safety experience gained for LWR fuel plant inspections can be used as a foundation for these inspections as long as the inspector carefully considers the new issues associated with HTGR fuel fabrication. 


\subsubsection{Emergency Management}

The purpose of these inspections is to determine if the plant has the planned emergency management measures in place and operational so that the workers and public are protected in the case of a significant fault. These issues are very likely related to those involved with LWR fuel and the LWR experience can be used as a foundation to build on.

Table 9-7 is a list of items that may be used as source material to assemble an inspection protocol.

\section{Table 9-7. Possible Emergency Management Inspection Items}

\begin{tabular}{|c|c|}
\hline Item & Inspection Topic/Area \\
\hline 1 & $\begin{array}{l}\text { Description of emergency management plan and procedures to implement it. } \\
\text { Compliance with } 10 \text { CFR70.22 and } 70.64 \text { (see NUREG-1520 listings). This should all } \\
\text { be well defined with implementation procedures. The purpose of the inspection is to } \\
\text { determine if the plan and procedures are actually being followed, necessary drills being } \\
\text { conducted, and the effectiveness of the plan evaluated and modified if necessary. }\end{array}$ \\
\hline 2 & $\begin{array}{l}\text { Accident classifications and response actions. Real time assessment of the situation and } \\
\text { the areas involved. The inspector should determine if a method exists for quickly } \\
\text { collecting information about an emerging situation and evaluating the seriousness of the } \\
\text { situation. This methodology should allow the proper response to be launched and } \\
\text { recourses effectively focused. The goal is to determine if a timely and effective } \\
\text { response can be initiated to an off normal or accident condition. }\end{array}$ \\
\hline 3 & $\begin{array}{l}\text { Description of steps taken to coordinate the plan with offsite emergency responders and } \\
\text { institutions. The goal of this examination is to determine if the necessary and proper } \\
\text { steps have been taken to ensure notification and coordination with offsite responders } \\
\text { and to inform the public of any required actions. }\end{array}$ \\
\hline 4 & $\begin{array}{l}\text { Functional list of emergency management and their roles and ways to communicate to } \\
\text { the staff and public during an event. The purpose of this inspection is to determine if the } \\
\text { emergency management functions are properly staffed and if the staff understands their } \\
\text { duties and responsibilities. Also, the communication channels need to be investigated to } \\
\text { determine if they can handle the traffic and minimize confusion. }\end{array}$ \\
\hline 5 & $\begin{array}{l}\text { Description of general employee training for emergency situations. The inspector } \\
\text { should determine if a credible general training program is in place, records kept of the } \\
\text { training, and necessary drills conducted. The adequacy of this training should be } \\
\text { assessed in light of the ISA and the expected responses. }\end{array}$ \\
\hline 6 & $\begin{array}{l}\text { Description of training for specific emergency responders. The inspector should } \\
\text { determine if a credible and specific training program is in place, records kept of the } \\
\text { training, testing conducted, and necessary drills practiced. The adequacy of this training } \\
\text { should be assessed in light of the ISA and the situations the responders are expected to } \\
\text { address. }\end{array}$ \\
\hline 7 & $\begin{array}{l}\text { Examination of equipment to be used for emergency mitigation. The goal of this } \\
\text { inspection is to determine if the responders have the proper equipment for their tasks } \\
\text { and if this equipment is properly maintained. This inspection will have to be conducted } \\
\text { in light of the ISA and the specific needs of the emergency plan. }\end{array}$ \\
\hline
\end{tabular}




\begin{tabular}{|r|l|}
\hline 8 & $\begin{array}{l}\text { Procedures to be used for safe shutdown. The inspector should assess the adequacy of } \\
\text { the safe shutdown systems/methods, if they can be reasonably performed under } \\
\text { emergency conditions, and their relationship to the ISA. The inspector should also see } \\
\text { that there is staff to conduct these procedures. }\end{array}$ \\
\hline 9 & $\begin{array}{l}\text { Descriptions and results of drills and exercises. The goal of this inspection is to } \\
\text { determine if the called for drills and exercises are being conducted, that the results are } \\
\text { being documented, and that any deficiencies are being identified and corrected. }\end{array}$ \\
\hline
\end{tabular}

Overall, the experience gained from LWR fuel plant inspections can be used as basis for these inspections. The ISA can be used to focus on HTGR specific issues.

\subsubsection{Environmental Protection}

The purpose of this inspection is to determine if the environmental protection measures detailed in the license are being effectively implemented. It is not expected to be greatly different than that for a LWR fuel plant, but the large use of hydrocarbon gases may demand more attention to atmospheric emissions issues; this will have to be assessed once a design has been completed.

Table 9-8 is a list of items that can be used to form an inspection plan.

Table 9-8. Possible Environmental Protection Inspection Items

\begin{tabular}{|r|l|}
\hline Item & \multicolumn{1}{c|}{ Inspection Topic/Area } \\
\hline \hline 1 & $\begin{array}{l}\text { Description of environmental protection plan and procedures to implement it. } \\
\text { Compliance with 10 CFR20, 51, and 70 (see NUREG-1520 listings). This should all be } \\
\text { well defined with implementation procedures. The purpose of the inspection is to } \\
\text { determine if the plan and procedures are being followed, the necessary monitoring being } \\
\text { conducted, and the effectiveness of the plan evaluated and modified if necessary. }\end{array}$ \\
\hline 2 & $\begin{array}{l}\text { Description of general employee training for environmental protection. The goal of this } \\
\text { inspection is to determine if the staff understands their roles and responsibilities with } \\
\text { regard to environmental issues, including waste minimization. Also, the goal is to } \\
\text { determine if the reporting responsibilities are properly assigned and understood. }\end{array}$ \\
\hline 3 & $\begin{array}{l}\text { Examination of the means and methods for general monitoring and evaluation of results, } \\
\text { and interface with the plant ALARA and radiation protection programs. The purpose of } \\
\text { this inspection is to determine if the environmental plan is integrated with the other } \\
\text { monitoring functions and release minimization as well as compliance is taking place. } \\
\text { The goal is to understand the links between operations, radiation protection, and } \\
\text { environmental monitoring so that they can work together to quickly identify and resolve } \\
\text { any problems. }\end{array}$ \\
\hline 4 & $\begin{array}{l}\text { Description of action levels and actions to be taken. Function description of personnel } \\
\text { in charge. This inspection is to determine if formal action levels are in place for the } \\
\text { identified release items and the immediate actions to be taken. The action assignments } \\
\text { need to be clear and have the authority to implement the appropriate action. This item is } \\
\text { related to the stop work actions in the general management plan. }\end{array}$ \\
\hline
\end{tabular}




\begin{tabular}{|c|l|}
\hline 5 & $\begin{array}{l}\text { Filter and discharge testing methods and actual implementation. The goal of this } \\
\text { inspection is to determine if the testing methods are effective in meeting the needs of } \\
\text { the release plans. They must provide confidence that the discharges are within limits } \\
\text { and poorly performing filters are quickly identified. This may involve review of the } \\
\text { inspection and calibration records. One item of interest may be the coaters, as they } \\
\text { generate a large amount of soot and HCl and require extensive filtering prior to } \\
\text { discharge. }\end{array}$ \\
\hline 6 & $\begin{array}{l}\text { Examination of current permits and local requirements. This should all be well defined } \\
\text { with implementation procedures. The purpose of the inspection is to determine if the } \\
\text { permits and requirements are being followed, the necessary monitoring being } \\
\text { conducted, and the effectiveness of the plan evaluated and modified if necessary. }\end{array}$ \\
\hline 7 & $\begin{array}{l}\text { Waste minimization plans and results. The purpose this inspection is to determine if the } \\
\text { waste handling is being conducted in a manner consistent with the license, effects are } \\
\text { underway to minimize waste generation, and the staff is executing the process properly. } \\
\text { The kernel and coating areas will most likely have the greatest issues associated with } \\
\text { waste generation and their areas should be carefully reviewed. }\end{array}$ \\
\hline
\end{tabular}

\subsubsection{Decommissioning}

At the present time, the inspection of the decommissioning plans is mostly to determine if the proper record keeping is in place to satisfy future needs. The inspector may wish to examine the equipment disposal plans for something unusual, but for the near term, records are the most likely concern.

Table 9-9 lists possible inspection points.

\section{Table 9-9. Possible Decommissioning Inspection Items}

\begin{tabular}{|r|l|}
\hline Item & \multicolumn{1}{c|}{ Inspection Topic/Area } \\
\hline 1 & $\begin{array}{l}\text { Description of the record keeping requirements for future decommissioning. This } \\
\text { should all be well defined with implementation procedures. The purpose of the } \\
\text { inspection is to determine if the plan and procedures are being followed. }\end{array}$ \\
\hline 2 & $\begin{array}{l}\text { Examination of the record keeping and methods used to acquire the data for the records. } \\
\text { The goal of this review is to check and see that the proper information and data is being } \\
\text { collected. It may be necessary to review some testing and calibration records as well. It } \\
\text { is likely that this task is connected with the general record keeping. }\end{array}$ \\
\hline
\end{tabular}

\subsubsection{Management Measures}

The purpose of this inspection is to determine if sufficient management attention is being focused on the items relied on for safety (IROFS). These items need to be maintained and tested to be sure they will perform in the proper manner both during an event and in normal operation, if they are relied upon for general monitoring. This need is similar to that required for a LWR fuel plant, but specific items may be needed for an HTGR plant; this will be design specific.

Table 9-10 outlines a few inspection topics that can be used to assemble an inspection plan. 
Table 9-10. Possible Management Measures Inspection Items

\begin{tabular}{|r|l|}
\hline Item & \multicolumn{1}{c|}{ Inspection Topic/Area } \\
\hline \hline 1 & $\begin{array}{l}\text { List of IROFS components, their needed function, and the required calibrations and } \\
\text { tests. This should all be well defined. The purpose of the inspection is to determine if } \\
\text { the list is up to date and that these items have the full attention of management. } \\
\text { Management should understand how these items connect with the ISA and emergency } \\
\text { planning. }\end{array}$ \\
\hline 2 & $\begin{array}{l}\text { Records and test results showing that the components work properly and can meet the } \\
\text { requirements of 10 CFR 70.61 and other previously identified requirements (see } \\
\text { NUREG-1520 listings). This is part of the safety culture of the plant and is fundamental } \\
\text { to meeting the events identified in the ISA. }\end{array}$ \\
\hline 3 & $\begin{array}{l}\text { Configuration management and Design Basis of IROFS. This inspection is to determine } \\
\text { if the configuration of the IROFS is known at all times and is up to date with current } \\
\text { requirements. It should be part of the general configuration management plan, but its } \\
\text { importance should be noted. }\end{array}$ \\
\hline 4 & $\begin{array}{l}\text { General staff training on the importance of IROFS items. The staff should be aware of } \\
\text { and indoctrinated in the importance of IROFS, supporting programs such as } \\
\text { Configuration Management and Design Basis preservation, and what should be done in } \\
\text { the case of problems. This issue is also related to stop work authority. }\end{array}$ \\
\hline 5 & $\begin{array}{l}\text { Organizational and functional alignment that supports the effective preservation of } \\
\text { design basis and configuration control. The goal here is to determine that facility } \\
\text { modifications and major project and construction activities (following initial } \\
\text { construction) are properly administered organizationally through proper process and } \\
\text { procedural controls, qualified design organizations, effective intra-organizational } \\
\text { communications and approval processes, etc. }\end{array}$ \\
\hline
\end{tabular}




\subsection{Items Related Specifically to HTGR Fuel}

Sub-section 9.1 focused on general issues that a fuel plant would be expected to meet. This subsection is focused more specifically on HTGR fuel issues.

\subsubsection{Process Knowledge Record Keeping on a Particle Batch Basis}

As detailed in previous sections of this document, process knowledge is an important part of fuel fabrication. Thus, it is important that each batch of fuel be connected to the process and process parameters that produced it. The purpose of this set of inspections is to determine if the actual process data is connected to the relevant fuel batch and that this information is readily available to the QA/QC group, and ultimately, the customer and/or regulator.

Table 9-11 lists a selection of items for use in creating an inspection plan.

Table 9-11. Possible Process Knowledge Inspection Items

\begin{tabular}{|r|l|}
\hline Item & \multicolumn{1}{c|}{ Inspection Topic/Area } \\
\hline \hline 1 & $\begin{array}{l}\text { Description of fuel batch record keeping, retrieval, and method of implementation. This } \\
\text { should be a well defined part of the fuel QA and QC plans. The inspector should review } \\
\text { the tracking/record keeping and determine if it is complete and unambiguous. }\end{array}$ \\
\hline 2 & $\begin{array}{l}\text { Examination of process records, labeling, and retrieval. Means to protect against } \\
\text { unauthorized changes or deletions. This process should be well defined as to who enters } \\
\text { the information, the level of automation, and who validates the overall data package. } \\
\text { Because process knowledge is very difficult or impossible to recreate, unauthorized } \\
\text { changes can be an issue. The inspector should quiz management on how this issue is } \\
\text { handled and how schedule pressures are avoided. The purpose of this review is to } \\
\text { understand the strong and weak points of the process. }\end{array}$ \\
\hline 3 & $\begin{array}{l}\text { Method and inspection of secure data storage location (if on site). It is very likely that } \\
\text { data collection and storage will be automated and a large amount of information will be } \\
\text { collected. This information has to be stored, protected, and readily available for retrieval } \\
\text { in the case of a fuel problem. The goal of this inspection is to determine that the } \\
\text { information technology issues have been properly addressed. }\end{array}$ \\
\hline 4 & $\begin{array}{l}\text { Means of long term (years) record storage and availability and the procedures and } \\
\text { controls that are used to ensure proper record storage. The goal of the inspection is to } \\
\text { determine if the process records will be available for long periods of time as they could } \\
\text { be needed for the final disposal of the fuel. Additionally, adequate procedures need to } \\
\text { exist specifying record retention times, methods, controls, disposition, etc. }\end{array}$ \\
\hline 5 & $\begin{array}{l}\text { Procedures to handle equipment malfunctions and non-conforming data packages; scrap } \\
\text { or continue decision. This is actually part of the QA plan for non-conforming items. } \\
\text { Because of the importance of these issues in fuel fabrication, it is important that the } \\
\text { critical parameters be clearly defined and a keep/reject limit rigidly enforced. The } \\
\text { inspector should determine that such a process is in fact being used in the plant. }\end{array}$ \\
\hline
\end{tabular}


6 Explanation of blending operations and other intentional loss of identity operations. Batches of fuel may be blended together to make larger lots for further processing. This will result in the loss of identity for the batches. This issue should be handled in a proscribed way to guarantee that substandard material will not be mixed with good material. The inspector should check for clear procedures and methods for handling any blending operation. The appropriate interfaces to other process governing programs, such as the criticality program, should be evident in these procedures.

While batch tracking is done with LWR fuel, the specific process knowledge needs for the final product make the issue more complicated for HTGR fuel and the inspector will have to be critical in their assessment of the process. To that end, the extent of process proceduralization and adherence to those procedures governing the blending operations should be very clear and exacting.

\subsubsection{Proper Calibration and Operation of the Complex Measuring Tools}

HTGR fuel requires many complex fabrication steps that must be closely controlled as well as complex and tedious measurement tasks. The inspector must determine if the equipment is being properly operated, calibrated, and the measurements done correctly. Also, sufficient time must be allowed for the testing and analysis. This process is not unlike that for an LWR fuel plant, but may be technically more challenging and time consuming.

Table 9-12 lists a selection of items for possible inclusion in an inspection plan.

Table 9-12. Possible Calibration and Operation Inspection Items

\begin{tabular}{|r|l|}
\hline Item & \multicolumn{1}{c|}{ Inspection Topic/Area } \\
\hline \hline 1 & $\begin{array}{l}\text { List of all equipment used for QA/QC determination and the calibration and } \\
\text { maintenance requirements. This should be well defined with written procedures and } \\
\text { calibration intervals. The goal is to determine it the equipment is properly identified and } \\
\text { tracked. }\end{array}$ \\
\hline 2 & $\begin{array}{l}\text { Calibration, maintenance, and configuration control records of the QC equipment. The } \\
\text { goal of this inspection is to determine if the equipment is properly maintained, } \\
\text { calibrated, and controlled. Some results could be sensitive to preparation techniques, so } \\
\text { the methods must be consistent and controlled. Special concerns should be noted so that } \\
\text { the operator/analyst is aware of them. }\end{array}$ \\
\hline 3 & $\begin{array}{l}\text { Review of the local data storage and collection methods. This is a design issue. Some } \\
\text { information may be locally collected and evaluated prior to being released to central } \\
\text { data storage. Procedures must be in place as to data collection accept/reject conditions } \\
\text { and the prevention of unauthorized changes. Instrument parameters must be consistent. } \\
\text { The inspector should determine if the process is controlled. }\end{array}$ \\
\hline 4 & $\begin{array}{l}\text { Training methods/records of the QC personnel. This inspection is to determine if the } \\
\text { staff has the proper qualifications to conduct the work and has had the specific training } \\
\text { necessary. This review should determine that individual equipment qualifications exist } \\
\text { such that only trained and qualified operators use this equipment. }\end{array}$ \\
\hline
\end{tabular}




\begin{tabular}{|c|l|}
\hline 5 & $\begin{array}{l}\text { Procedures and formal sample collection/preparation methods. This inspection is to } \\
\text { determine if the critical tasks are being conducted under written procedures, the } \\
\text { methods for preparation and testing are consistent, and the equipment is being operated } \\
\text { within clearly defined parameters. Configuration control measures should be in place to } \\
\text { interface actual equipment operations with the training and qualification programs. The } \\
\text { goal is to make sure that equipment field changes, manufacturer technical bulletin } \\
\text { modifications, etc., are adequately accounted for in the facility sponsored training and } \\
\text { qualification programs. }\end{array}$ \\
\hline 6 & $\begin{array}{l}\text { Is adequate time available for conducting the sampling and analysis? The QC tasks for } \\
\text { HTGR fuel can be rather labor and time intensive and sufficient time should be } \\
\text { available to conduct and interpret them. Also, additional time may have to be made } \\
\text { available if retesting is needed. The workflow and decision points should reflect this } \\
\text { need. }\end{array}$ \\
\hline 7 & $\begin{array}{l}\text { Repair and maintenance of equipment. The goal of this inspection is to determine if } \\
\text { qualified personnel are performing any necessary repair and maintenance work. Some } \\
\text { of the analysis equipment is rather complex and qualified staff may be needed to service } \\
\text { it. The inspector should determine if such staff (local or off-site) is being used. }\end{array}$ \\
\hline
\end{tabular}

\subsubsection{Proper Operation of the Fabrication Line}

The inspector needs to determine if the overall fabrication line is being run in the proscribed manner and all the batches of fuels tracked correctly. A large number of relatively small batches of fuel will be processed, subjected to QC, blended together, further processed, and finally combined into lots. The inspector must determine that the small batches are being fabricated correctly, tracked correctly, subject to the proper sampling and QC, and that the end product meets all specifications and is tagged with the appropriate process data.

The actual fabrication method and batch size is a design issue and plant documentation will have to be consulted to determine the process flow and identity or loss of identity.

Table 9-13 lists some items that may be used to construct an inspection plan.

Table 9-13. Possible Operation of the Fabrication Line Inspection Items

\begin{tabular}{|r|l|}
\hline Item & \multicolumn{1}{c|}{ Inspection Topic/Area } \\
\hline \hline 1 & $\begin{array}{l}\text { Description of fabrication flow through the entire fabrication line and the steps and } \\
\text { procedures guiding the process. This should be well established and clearly defined. } \\
\text { The purpose of this inspection is to determine if the process is the same as listed in the } \\
\text { licensing documentation and if the facility is following its own plan. }\end{array}$ \\
\hline 2 & $\begin{array}{l}\text { Points at which batch identity is born, checked, and lost. See Process Knowledge } \\
\text { Record Keeping On a Particle Batch Basis (Section 9.2.1) for record keeping needs. } \\
\text { The tracking points in the fabrication process should be clearly identified and the fate of } \\
\text { the collected information determined in advance. The inspector should determine if the } \\
\text { fuel process knowledge needs are being maintained. }\end{array}$ \\
\hline
\end{tabular}




\begin{tabular}{|c|c|}
\hline 3 & $\begin{array}{l}\text { Description of the rules for acceptance or rejection of a batch, the disposition of the } \\
\text { material, and assurances that it goes to the proper end point and does not get lost or } \\
\text { mixed with other material. The rules for the evaluation of a batch of fuel should be clear } \\
\text { and unambiguous and the material should go to a well defined area. The inspector } \\
\text { should determine if sufficient controls are in place to prevent mixing of good and bad } \\
\text { material. }\end{array}$ \\
\hline 4 & $\begin{array}{l}\text { Description of material tracking methods. The purpose is to ensure that material balance } \\
\text { points exist that account for the SNM as well as the accepted and rejected batches, what } \\
\text { goes in equals what goes out, and the sum of the accepted fuel and rejected fuel equals } \\
\text { the total fuel amount. The inspector should determine if proper material tracking } \\
\text { methods are in place. Performing a mass inventory is complicated by the fact that the } \\
\text { coatings account for a significant portion of the mass and must be correctly accounted } \\
\text { for by adjusting the weight uranium per net weight of material at each fabrication step } \\
\text { (kernels, coated particles and compacts). }\end{array}$ \\
\hline 5 & $\begin{array}{l}\text { Description of tracking methods for scrap and rejected material. The inspector should } \\
\text { determine how process scrap is handled and if all the material is properly accounted for. }\end{array}$ \\
\hline 6 & $\begin{array}{l}\text { Clearly defined equipment operational parameters. The inspector should check to see } \\
\text { that calibration check points or methods are available to identify malfunctioning } \\
\text { equipment early. A clear method should be in place to identify and tag out-of-service } \\
\text { equipment. The purpose of this inspection is to determine if the process is well } \\
\text { specified, the equipment properly setup, and the operating parameters clearly defined. } \\
\text { The inspector should also note if the operators can quickly identify malfunctioning } \\
\text { equipment and remove it from service. Identification and logging of small deviations } \\
\text { from the design point may be significant. }\end{array}$ \\
\hline 7 & $\begin{array}{l}\text { Up to date local procedures and checklists. The inspector should determine if a method } \\
\text { is in place to ensure that procedures and checklists are up to date and equipment is } \\
\text { operated in accordance with the procedures. The goal of this inspection is to determine } \\
\text { if the fabrication line is being operated in accordance with the current process design. }\end{array}$ \\
\hline 8 & $\begin{array}{l}\text { Configuration control at the local level. The inspector should determine if configuration } \\
\text { control measures are being properly applied on a local level. It should be noted if the } \\
\text { operators can make undocumented adjustments to the equipment and there should be } \\
\text { assurances that the equipment is assembled in a consistent manner; this is part of the } \\
\text { formal configuration control, but minor adjustments may be done at the local level } \\
\text { without proper logging. The goal of this inspection is to determine if the actual day to } \\
\text { day configuration of the equipment is the same as the current design basis. }\end{array}$ \\
\hline 9 & $\begin{array}{l}\text { Up to date training records. The purpose of this inspection is to make sure that the } \\
\text { fabrication line is tended by workers who understand their job and the impacts on } \\
\text { quality that improper operation will have. }\end{array}$ \\
\hline 10 & $\begin{array}{l}\text { Adequate staffing for the workload. The inspector should note if there is sufficient staff } \\
\text { to conduct all the operations required and monitor the process information. The } \\
\text { inspector should note whether the staff is fit for duty and not overly fatigued or } \\
\text { distracted from being attentive to their tasks. The goal is to determine if the fabrication } \\
\text { process is receiving the proper attention. }\end{array}$ \\
\hline
\end{tabular}


11 Task assignments. The inspector should note if the fabrication line and process inspection duties are properly designed to ensure that monotony of routine and repetitive performance of tasks do not influence effectiveness and consistency of the proper performance of tasks.

The overall goal of this inspection process is to determine if the fabrication line has a well defined configuration, is operated by competent staff, is adequately staffed, and is being operated in a consistent and reproducible manner. See the previous sections of this document for details on the specific equipment and methods involved in fuel production.

\subsubsection{Data Analysis Methods}

HTGR fuel fabrication requires a rather elaborate data collection and analysis infrastructure so the inspector must determine if this infrastructure is in place and is functioning as designed. The primary goal of this inspection is to assess the infrastructure and determine if the necessary inspection methods are in place.

Table 9-14 lists some items that may be used to construct a data analysis inspection plan.

Table 9-14. Possible Items for a Data Analysis Methods Inspection

\begin{tabular}{|r|l|}
\hline Item & \multicolumn{1}{c|}{ Inspection Topic/Area } \\
\hline 1 & $\begin{array}{l}\text { List of data analysis methods and the point in the fabrication process they must be } \\
\text { started and completed. This should be well established as part of the QC plan and } \\
\text { integrated into the fuel inspection line. The goal of this inspection is to determine if the } \\
\text { analysis methods are well defined and integrated into the process. They may be part of } \\
\text { the overall software that operates the plant. See previous sections of this document for } \\
\text { descriptions of the methods. }\end{array}$ \\
\hline 2 & $\begin{array}{l}\text { The time required for data analysis and evaluation and how this is integrated into the } \\
\text { fabrication schedule. The purpose of this inspection is to determine if important process } \\
\text { decisions are made using the actual data prior to the beginning of the process. At risk } \\
\text { processing may be done, but a means for removing the material from the process line } \\
\text { should be clear. }\end{array}$ \\
\hline 3 & $\begin{array}{l}\text { The relevant configuration control and monitoring to ensure that the testing is consistent } \\
\text { over the long term. The inspector should determine if the methods are controlled and } \\
\text { how changes are documented. If this is part of the software that controls the plant, a } \\
\text { means of ensuring the stability of the software should be apparent. }\end{array}$ \\
\hline 4 & $\begin{array}{l}\text { The proper and timely interface with the process knowledge record keeping system. The } \\
\text { goal of this inspection is to determine when analytic results are being recorded by the } \\
\text { system (all analysis tries or just the final product) and if it can be subjected to } \\
\text { unauthorized changes. }\end{array}$ \\
\hline 5 & $\begin{array}{l}\text { A method of tracking to make sure the batch accept/reject decision is made with the } \\
\text { proper and timely information. The purpose of this inspection is to determine if the } \\
\text { analytic results are actually being used to make the called out decisions. }\end{array}$ \\
\hline
\end{tabular}


6 Software/hardware version control and documentation is properly maintained. The goal is to determine that appropriate configuration controls exist for software/hardware changes and modifications, version and revision control, input parameters, etc. that govern data analysis methods inspections. Consideration should be given to commercial off-the-shelf hardware and software usage and compatibility concerns with any peripheral equipment as operating system upgrades occur, etc.

A major purpose of the data analysis methods inspection is to make sure the tests are well defined, properly and consistently conducted, and used to control the fabrication process.

\subsubsection{Configuration Control of the Fabrication Apparatus}

While control of the fabrication apparatus is important for all fuel fabrication plants, the process knowledge needs for HTGR fuel place some rather stringent needs on the equipment. The configuration of the coating equipment will have to be rigidly maintained as the coating process is sensitive to small changes in the apparatus.

Table 9-15 lists some items that may be used to construct a fabrication configuration control inspection plan.

Table 9-15. Possible Items for a Fabrication Configuration Control Inspection

\begin{tabular}{|r|l|}
\hline Item & \multicolumn{1}{c|}{ Inspection Topic/Area } \\
\hline \hline 1 & $\begin{array}{l}\text { List of fabrication equipment that requires configuration control and the components } \\
\text { involved. This should be well defined and cover all important fabrication line } \\
\text { components, such as kernel production, kernel sintering, particle coating, and } \\
\text { compacting into final fuel forms. The purpose of this inspection is to determine if all the } \\
\text { proper equipment has been identified and controlled. }\end{array}$ \\
\hline 2 & $\begin{array}{l}\text { The procedure/methods used for configuration control and any special means used for } \\
\text { monitoring the adherence to design. This may be done by drawings, procedures, leak } \\
\text { testing, specific tests, detailed inspecting, etc. The purpose is to determine if the } \\
\text { equipment is being assembled and used in a consistent manner. }\end{array}$ \\
\hline 3 & $\begin{array}{l}\text { A method for controlling design aspects of the equipment. The inspector should } \\
\text { determine if the equipment design is stable and if a means is available for preventing } \\
\text { unauthorized or unnoticed changes. }\end{array}$ \\
\hline 4 & $\begin{array}{l}\text { A method for handling non-conforming aspects or parts. A specific means should be } \\
\text { available for handling non-conforming equipment and any fuel that may have been } \\
\text { produced with it. The goal of the inspection is to determine if a formal means exists for } \\
\text { handling this type of problem. }\end{array}$ \\
\hline 5 & $\begin{array}{l}\text { A method for documenting maintenance and changes to the critical equipment. This } \\
\text { should be part of the configuration control plan; it is called out separately because of the } \\
\text { critical nature of the process equipment. }\end{array}$ \\
\hline
\end{tabular}

The major goal of the equipment configuration control process is to determine if a means exists to ensure the process equipment design is stable over time and does not drift due to small undocumented changes or modifications. 


\subsubsection{Control of Raw Materials and Contamination}

The purpose of this inspection is to determine if the plant has a means to control the purity of the raw materials used in the process. Normally this is part of the general fabrication process, but HTGR fuel is particularity sensitive to transition metal impurities and care must be taken not to introduce them into the process at any stage.

Table 9-16 lists some items that may be used to construct an impurity control inspection plan.

Table 9-16. Possible Items for a Raw Materials and Contamination Inspection

\begin{tabular}{|r|l|}
\hline Item & \multicolumn{1}{c|}{ Inspection Topic/Area } \\
\hline \hline 1 & $\begin{array}{l}\text { Plan for controlling specific impurities and methods to accomplish this. This should be } \\
\text { a well defined part of the plant fabrication process. The goal of this inspection is to } \\
\text { determine if the plant is following its own plan. }\end{array}$ \\
\hline 2 & $\begin{array}{l}\text { Methods to control the introduction of impurities during the fabrication process; control } \\
\text { and measurement points. The purpose of this inspection is to determine what measures } \\
\text { are being used to control impurities and how they are being applied. In particular, the } \\
\text { inspector should check for items such as raw material inspection, furnace graphite that } \\
\text { could release impurities at high temperatures, particle handling that could result in } \\
\text { metallic contamination (sieving, tabling, riffling, etc.), and possible contamination by } \\
\text { airborne particulates. Thus, both raw material impurities and contamination introduced } \\
\text { to the process are important. }\end{array}$ \\
\hline 3 & $\begin{array}{l}\text { Methods to track and monitor the critical fabrication processes such as the heat treating } \\
\text { and particle upgrading (sieving and tabling) processes. The goal of this inspection is to } \\
\text { ensure that processes that have the potential to introduce impurities into the final } \\
\text { product are monitored. }\end{array}$ \\
\hline 4 & $\begin{array}{l}\text { A formal method to document problems and treat them as a lessons learned issue. The } \\
\text { purpose of this inspection is to determine if management is monitoring the impurity } \\
\text { issue and responds to problems in a proactive way. }\end{array}$ \\
\hline 5 & $\begin{array}{l}\text { A formal training and qualification program to support the program for controlling the } \\
\text { introduction of impurities during the fabrication process. The goal is to determine that } \\
\text { plant staff is familiar with the critical nature of impurity control and, as appropriate, } \\
\text { undergo strict position-specific qualifications or some other comparable program to } \\
\text { bolster defense from the introduction of impurities. }\end{array}$ \\
\hline 6 & $\begin{array}{l}\text { Plan for the inspection of feedstock records, storage, and handling. } \\
\text { and }\end{array}$ \\
\hline
\end{tabular}

\subsection{Inspection Planning}

A host of both general and specific items for inspection have been noted for possible use in an inspection plan. The general items focus on the overall management structure, the control of the plant, the configuration of the plant, the safety of the plant, and the emergency coordination with local authorities. The specific items focus on the particle needs of HTGR fuel, the equipment used for fabrication and analysis, and data collection, analysis and reporting. Together these items will give the inspector a reasonable picture of the plant and its approach to the fabrication process. 
Prior to beginning any inspection, a plan of action should be written and reviewed by the relevant NRC supervisor. Figure 9-1 lists items (identified by the references) to be included in the development of a plan.

\section{Inspection Planning}

Review of past inspection reports for trends and issues

Recent license performance review areas needing improvement, any fuel QA/QC issues

License requirements and integrated safety summary, any enforcement items

Coordination of personnel - technical reviewers, resident inspectors, regional inspectors, others familiar with the plant under inspection

Risk focus - dominant hazards, risks/scenarios, controls, root causes

Management response - backlog of risk significant issues, resolution of past issues, recurring issues and root causes, self assessments, safety consciousness

Figure 9-1. Inspection planning items. 
The inspection may be conducted in the usual manner (see NRC Inspection Manual):

1) Entrance

i) Introductory statements

(a) Inspection number

(b) NRC personnel

(c) Focus of inspection

ii) Primary inspection areas

(a) Plant operations

(b) Recent events and issues

(c) Open issues from the past

(d) Expectations

iii) Coordination with Licensee

(a) Schedule walk downs

(b) Schedule plant personnel discussions

(c) Documentation requests

iv) Questions and clarifications

2) Inspections

i) Identified areas

ii) Emerging areas and new concerns

iii) Documentation clarification

3) Exit

iv) Discussions and explanations

i) Introductory statement

(a) Inspection number and personnel

(b) Reiterate coordination

(c) Reiterate focus

ii) Results of walk downs

(a) Areas reviewed

(b) Issues identified

iii) Inspection focus areas

(a) Reiterate inspection focus areas

(b) Review findings area by area

(c) Discussions and clarifications with Licensee

iv) Open items

(a) Current status, item by item

(b) Specific concerns

v) Summary

(a) Review all new issues and findings

(b) Review all comments and clarifications by Licensee

vi) Final questions

vii) Close

At the completion of the inspection, a final report will be prepared and any required actions taken. 


\subsection{Reference Documents}

Table 9-17 lists a set of related documents for a review of this topic and used as a model for the construction of the tables and table entries in this section.

Table 9-17. Fuel Fabrication Inspection Protocol Documents

\begin{tabular}{|l|l|l|}
\hline \multicolumn{1}{|c|}{ Title } & \multicolumn{1}{c|}{ Reference } & \multicolumn{1}{c|}{ Description } \\
\hline $\begin{array}{l}\text { Standard Review Plan for the } \\
\text { Review of a License } \\
\text { Application for a Fuel Cycle } \\
\text { Facility }\end{array}$ & NUREG-1520 & $\begin{array}{l}\text { Describes the license review } \\
\text { process for a fuel facility }\end{array}$ \\
\hline NRC Inspection Manual & NMSS/FCSS Chapter 2604 & $\begin{array}{l}\text { Guidance for reviewing fuel } \\
\text { cycle licensee performance }\end{array}$ \\
\cline { 2 - 3 } & Appendix D 2600 & $\begin{array}{l}\text { Fuel cycle facility inspection } \\
\text { planning }\end{array}$ \\
\hline
\end{tabular}

